Maurício Vilela Guerra

\title{
UTILIZAÇÃO DE ANTENAS ADAPTATIVAS EM SISTEMAS CDMA
}

\author{
Dissertação apresentada ao Departamento de Engenharia \\ Elétrica da PUC-RJ como parte dos requisitos para \\ obtenção do título de Mestre em Engenharia Elétrica
}

Orientador : João Célio Brandão

CETUC

Pontifícia Universidade Católica do Rio de Janeiro

Rio de Janeiro, 28 de setembro de 2001 
A meu pai 


\section{Agradecimentos}

- ao orientador da Dissertação, Professor João Célio Brandão, pelo apoio e confiança.

- aos professores do grupo de processamento de sinais e sistemas de comunicação, em particular ao Professor José Ricardo Bergmann.

- à CAPES, pela ajuda financeira durante o curso

- a meu pai, pelo seu constante apoio e incentivo aos estudos.

- A minha esposa Adriana, pela força, paciência e compreensão.

- E a vocês, Leonardo e Roberta, meus filhos queridos, se um dia vierem a ler estas palavras, saibam que elas aqui estão como um agradecimento à felicidade que vocês me proporcionaram. 


\title{
RESUMO
}

Este trabalho tem como objetivo avaliar alguns aspectos da utilização de antenas adaptativas em um sistema celular digital CDMA. Uma das razões para isto é que as antenas adaptativas reduzem a interferência que no sistema CDMA influencia direta e fortemente a capacidade do sistema. Inicialmente foi feito um resumo dos princípios gerais dos arranjos de antenas de sistemas celulares digitais e de algoritmos de adaptação. Com base nestes princípios, é analisada a aplicação específica a sistemas CDMA, estabelecendo-se uma modelagem do receptor incluindo o receptor

Rake. É avaliado então através de simulação o comportamento de dois importantes métodos de filtragem espacial adaptativa para sistemas CDMA.

\begin{abstract}
This work aims to evaluate some aspects of the use of adaptive arrays in digital celular CDMA systems. One reason for that is that adaptive arrays reduce the interference which strongly affects the performance of the system. First the general principles of adaptive antennas, digital cellular systems and adaptation algorithm are sumarized. Based on that principles, the application to CDMA systems is addressed, and a receiver model is developed, including the Rake receiver. Then the behavior of two filtering techniques is evaluated through computer simulation.
\end{abstract}




\section{SUMÁRIO}

1. INTRODUÇÃO

2. ANTENAS ADAPTATIVAS $\quad 4$

$\begin{array}{ll}2.1 \text { Antenas Adaptativas e seus Fundamentos } & \mathbf{7}\end{array}$

$\begin{array}{ll}2.2 \text { Filtragem Espacial } & 13\end{array}$

3. FUNDAMENIOSDOSSISTEMASCELULARESDIGITAIS ( TDMAE CDMA) 17

$\begin{array}{ll}3.1 \text { Introdução aos sistemas celulares } & \mathbf{1 7}\end{array}$

3.2 Múltiplo acesso por divisão de tempo - TDMA $\quad \mathbf{2 0}$

3.2.1 Padrões TDMA

3.2.1.1 D-AMPS

3.3 Múltiplo Acesso por Divisão de Código - CDMA

3.3.1 Modelo Analítico $\quad \mathbf{2 4}$

$\begin{array}{ll}\text { 3.3.2 IS-95 } & \mathbf{2 7}\end{array}$

3.4 TDMA versus CDMA

3.4.1 Capacidade $\quad 29$

3.4.2 Multipercursos $\quad 31$

4. ARQUITETURA CRITÉRIOS E ALGORITMOS

4.1 Classificação dos Algoritmos de Adaptação $\quad \mathbf{3 3}$

4.2 Algoritmos com Sinal de Treinamento $\quad \mathbf{3 5}$

4.2.1 O Algoritmo LMS $\quad 37$

4.2.2 O Algoritmo RLS $\quad 38$

4.3 Algoritmos Cegos $\quad 39$

4.3.1 Algoritmos de Estimação do Ângulo de Chegada

4.3.1.1 Técnicas Convencionais

4.3.2 Métodos de Sub-Espaços $\quad \mathbf{4 6}$

4.3.2.1 O Algoritmo MUSIC $\quad \mathbf{4 6}$

4.3.2.2 O Algoritmos ESPRIT $\quad \mathbf{4 8}$

4.3.2.3 O Algoritmo WSF

4.3.2.4 Método da Máxima Verossimilhança

5. ANTENAS ADAPTATIVAS EM SISTEMAS CDMA

5.1 Modelagem básica $\quad \mathbf{5 1}$

5.1.1 Sinal transmitido

5.1.2 Canal $\quad \mathbf{5 3}$

5.1.3 Receptor $\quad \mathbf{5 4}$ 
5.2 Técnicas de formatação de feixes para sistemas CDMA 62

5.2.1 Técnicas baseadas em matrizes covariância 62

5.2.2 Técnicas baseadas em sinal de referência 66

5.3 Avaliação das técnicas apresentadas 69

6. CONCLUSÃO

REFERÊNCIAS 


\section{ÍNDICE DE FIGURAS}

Fig. 2.1 - Técnicas de implementação de antenas adaptativas 6

Fig .2.2 - Ilustração do sistema de coordenadas de uma matriz de antenas

Fig. 2.3 - Representação de uma onda plana incidente sobre uma matriz linear de 8 antenas

Fig. 2.4 - Onda plana incidindo sob um ângulo ( $\theta$, $\phi)$ em uma matriz linear uniforme 9

Fig. 2.5 - Estrutura da matriz de antenas típica para recepção de sinais de faixa larga 14

Fig. 3.1 - Sistema de comunicação móvel celular e seus componentes 18

Fig. 3.2 - Estrutura Celular

Fig. 3.3 - TDMA

Fig. 3.4 - Estrutura do frame no padrão TDMA IS-54/136 22

Fig. 3.5 - Esquema de modulação $\pi / 4-D Q P S K$

Fig. 3.6-CDMA

Fig. 3.7 - Esquema de demodulação do sinal DS - CDMA 26

Fig. 3.8 - Estrutura de transmissão do enlace de subida

Fig. 3.9 - Esquema de modulação do enlace de subida do sistema CDMA 27

Fig. 4.1 - Classificação ampla dos algoritmos de antenas adaptativas 34

Fig. 4.2 - Estrutura de uma matriz de antenas adaptativa 35

Fig.5.1 - Sistema de filtragem espacial do enlace direto capaz de formar $\mathrm{K}$ feixes 52 simultaneos

Fig. 5.2 - Receptor do usuário i em um sistema CDMA

Fig. 5.3 - Receptor Rake convencional

Fig. 5.4 - Receptor Rake de duas dimensões e 3 ramos

Fig.5.5 - Estrutura de decodificação e integração para M sinais incidentes

Fig.5.6 - Estrutura simplificada de recepção

Fig.5.7 - Estrutura de recepção orientada pela decisão

Fig.5.8 - Estrutura de recepção baseada no sinal reespalhado $\quad 68$

Fig.5.9 - Diagrama de radiação após 250 iterações $(S / N=0 \mathrm{~dB})$

Fig.5.10 - Diagrama de radiação após 1000 iterações $(S / N=0 \mathrm{~dB})$

Fig.5.11 - Gráfico da evolução do valor absoluto do erro após 250 iterações $(S / N=0 \mathrm{~dB} 71$ )

Fig.5.12 - Gráfico da evolução do valor absoluto do erro após 1000 iterações $(S / N=0$ dB 71 )

Fig.5.13 - Diagrama de radiação após 2000 iterações $(S / N=-10 \mathrm{~dB})$

Fig.5.14 - Gráfico da evolução do valor absoluto do erro após 2000 iterações $(S / N=-1073$ dB)

Fig.5.15 - Diagrama de radiação após 2000 iterações $(S / N=0 \mathrm{~dB})$

Fig.5.16 - Distribuição de ângulos de chegada igualmente espaçados entre 0 e $\pi / 2$

Fig.5.17 - Taxa de erro de bit versus número de usuários $\quad 76$

Fig.5.18 - Distribuição de ângulos de chegada igualmente espaçados entre 0 e $3 \pi / 4 \quad 77$

Fig. 5.19 - Taxa de erro de bit versus número de usuários $\quad 78$

Fig. 5.20 - Taxa de erro de bit versus número de usuários 


\section{ÍNDICE DE TABELAS}

Tabela 5.1 - Caracterização do arranjo pela sua banda efetiva 59

Tabela 5.2 - Taxa de erro de bit versus número de usuários

Tabela 5.3 - Taxa de erro de bit versus número de usuários

Tabela 5.4 - Taxa de erro de bit versus número de usuários 


\section{INTRODUÇÃO}

Os serviços de comunicações têm apresentado ultimamente em todo mundo, inclusive no Brasil, um aumento significativo no número de usuários, enquanto a faixa de frequiência alocada para estes serviços é limitada. Neste contexto, um dos objetivos essenciais para os projetos de sistemas de telefonia celular modernos é maximizar a sua capacidade de tráfego. Isto ocorre não somente em função do crescimento da quantidade de usuários, como também devido aos novos tipos de serviços que estão sendo introduzidos no mercado de telefonia, requerendo sistemas capazes de transmitir e receber vídeo, voz e dados, num ambiente integrado a altas velocidades.

Inicialmente, os sistemas analógicos de primeira geração apresentavam uma capacidade relativamente pequena, incapaz de suprir a atual demanda em muitos lugares do mundo. Posteriormente, para resolver este problema foram desenvolvidos os sistemas celulares digitais, onde a técnica de múltiplo acesso à estação rádio base é um elemento essencial para aumento de capacidade.

Atualmente, sistemas de segunda geração utilizando técnicas TDMA (Time Division Multiple Access) e CDMA (Code Division Multiple Access) competem mundialmente pelo enorme mercado de telefonia celular. Enquanto isto um grande esforço tem sido observado no desenvolvimento da chamada $3^{\mathrm{a}}$ geração que significa, em resumo, comunicação multimídia com mobilidade, serviços pessoais, incluindo acesso a Internet com taxas variando, sob demanda, de centenas de $\mathrm{Kbit} / \mathrm{s}$ a cerca de $2 \mathrm{M}$ bit / $\mathrm{s}$.

Em razão da crescente demanda do tráfego, será uma conseqüência inevitável que não somente os fabricantes desenvolvam sistemas mais eficientes, assim como as empresas operadoras dos serviços de telefonia celular procurem otimizar seus sistemas para absorver este aumento. Atualmente, uma das mais promissoras tecnologias especificamente voltadas para o aumento da capacidade de tráfego de sistemas de telefonia celular são as antenas adaptativas. Para sistemas TDMA e CDMA existem previsões de aumento na capacidade de até 3 a 5 vezes, respectivamente. 
Outras vantagens tais como uma maior área de cobertura e um maior potencial de agregar-se outros tipos de serviços ao sistema são previstos com a utilização das antenas inteligentes nas comunicações móveis celulares.

Tanto a $1^{\mathrm{a}}$ como a $2^{\mathrm{a}}$ geração de sistemas celulares, foram projetadas sob a hipótese de que apenas antenas convencionais seriam usadas. Só recentemente estes sistemas estão sendo capazes de se beneficiar das vantagens das antenas adaptativas porém de uma forma sub-ótima. A plena obtenção destes benefícios poderá se dar nos sistemas de $3^{\text {a }}$ geração que estão sendo desenvolvidos com esta premissa e sendo assim, desenvolvendo arquiteturas adequadas à implementação das antenas adaptativas.

A implementação da tecnologia de antenas adaptativas envolve 3 aspectos distintos de uma forma geral:

(i) O projeto do conjunto ou matriz de antenas.

(ii) A definição das diferentes arquiteturas de receptor/processador.

(iii) A escolha de um algoritmo mais compatível com a aplicação a ser utilizado no processo de adaptação dos coeficientes da matriz de antenas.

Dependendo da forma de implementação, uma antena adaptativa pode ser vista como um sistema de diversidade espacial. Porém em sua forma plena uma antena adaptativa correponde a uma filtragem espacial. A filtragem espacial está baseada na integração das tecnologias de rádio frequiência e software. Em função disto, podemos afirmar que uma matriz de antenas adaptativas é um produto decorrente da união entre o eletromagnetismo e o processamento digital de sinais, sendo o primeiro responsável pelo desenvolvimento dos sinais de comunicações, e o segundo por tornar os sistemas de comunicação inteligentes. 
As antenas adaptativas tem sido estudadas desde a década de 50 e sua teoria é encontrada em diversos livros [4,47,58,61]. Nos últimos anos sua aplicação a sistemas celulares tem recebido bastante atenção dos pesquisadores [70] e, em particular sua aplicação a sistemas CDMA [66,72]. Contudo, alguns aspectos relacionados a implementação das antenas adaptativas em receptores CDMA ainda merecem ser investigados. É o que se procura fazer neste trabalho. A partir de uma revisão dos principais métodos propostos na literatura, fazemos um estudo visando determinar as formas mais convenientes de implementação das antenas adaptativas em sistemas CDMA. Identificadas estas formas procuramos avaliar algumas delas e compará-las quanto a sua eficiência e complexidade.

É feito inicialmente no capítulo 2 uma revisão dos elementos básicos das antenas adaptativas composto pela sua estrutura, o processamento do sinal observado, e o processamento de adaptação. A seguir, no capitulo 3, são apresentados os fundamentos dos sistemas celulares com ênfase na interface rádio e na caracterização dos métodos de acesso TDMA e CDMA. Além disto, acrescenta-se uma pequena abordagem sobre o canal de propagação. No capitulo 4 são revistas de forma resumida as diferentes estruturas e algoritmos de adaptação dos coeficientes de uma matriz de antenas.

No capítulo 5 apresentamos de início uma modelagem do receptor CDMA incluindo o receptor Rake. Resumimos em seguida alguns trabalhos pioneiros que apontaram o potencial de melhoria das antenas adaptativas e sua utilização conjunta com o receptor Rake. Identificamos então duas abordagens importantes na implementação de antenas adaptativas em sistemas CDMA. Algoritmos específicos dentro destas duas alternativas são analisados e comparados através de simulação em computador. 


\section{ANTENAS ADAPTATIVAS}

Antenas adaptativas são antenas que modificam seu diagrama de radiação durante sua operação de acordo com um determinado critério, dependendo da aplicação. Como as antenas adaptativas são de fato conjuntos ou matrizes de antenas, os termos antenas adaptativas e matrizes de antenas adaptativas se confundem. Uma matriz de antenas caracteriza-se pelo uso de duas ou mais antenas para a transmissão ou recepção de um sinal de rádio. Para se tornar uma matriz adaptativa, os sinais provenientes de cada elemento devem ser processados em tempo real através de algoritmos adequados. Embora seja possível a aplicação da técnica tanto na transmissão como na recepção, é para este último caso que tem se voltado a maioria das aplicações.

As antenas adaptativas são bastante úteis em sistemas de radar ou comunicações sujeitos a interferências, pois elas podem mudar seu diagrama de radiação, automaticamente, em resposta às mudanças na direção do sinal, criando ganhos maiores nas direções desejadas e menores nas direções interferentes, sempre de maneira a maximizar a relação sinal-interferência. $O$ uso de antenas adaptativas torna o sinal menos sensível aos desvanecimentos, interferências co-canal e interferências devido à multipercursos de propagação.

Uma matriz de antenas pode ser vista como um sistema de diversidade espacial. Os primeiros sistemas de adaptação eram analógicos e alguns dos esquemas de adaptação são formas típicas de processamento em sistemas de diversidade, como combinação por seleção （ a escolha do sinal com maior razão sinal-ruído) ou por máxima razão (pesos proporcionais à razão sinal ruído).

Com o desenvolvimento da tecnologia de processamento digital, esta tecnologia passou também a ser usada nas antenas adaptativas. Neste caso, os sinais provenientes das antenas são previamente digitalizados antes de entrar no combinador, que passa a ser um processador digital. Em relação aos algoritmos de processamento digital, existe um vasto conjunto de possibilidades. Note-se que o problema de antenas adaptativas pode ser visto como filtragem espacial adaptativa, e 
assim algoritmos desenvolvidos em outras aplicações como por exemplo equalização, podem ser utilizados.

Dentro do contexto de antenas adaptativas, o termo " antena " tem um significado bastante amplo. Este consistirá de um grupo de elementos irradiantes, uma rede ou circuito combinador, e finalmente uma unidade de controle. Esta unidade de controle poderá ser identificada como o bloco inteligente da antena adaptativa, normalmente implementada através de um processador digital de sinais. O processador faz o controle dos parâmetros da matriz de antenas baseados nos diversos sinais de entrada, tendo como propósito principal a otimização do enlace de comunicação. Diferentes critérios de otimização podem ser utilizados de acordo com níveis de inteligência. Conforme a literatura mais recente sobre aplicações de antenas adaptativas nas comunicações celulares, podemos definir os " níveis de inteligência " a partir de 3 técnicas distintas de implementação representadas através a figura 2.1:

- Lobo Comutado ou feixes comutados: Sendo a mais simples, esta técnica contém somente uma função básica de comutação entre antenas direcionais independentes ou os feixes pré definidos da matriz de antenas. O ajuste escolhido é aquele que produz a melhor performance, normalmente em termos da potência recebida. Devido a alta diretividade comparada a uma antena convencional, um certo ganho é atingido.

- Matriz de Antenas com Regulagem de Fase Dinâmica ( phased array) : Nesta técnica, a adaptação consiste apenas no ajuste da fase dos sinais provenientes dos diversos elementos.

- Matriz de Antena Adaptativa: Esta técnica mais completa em que os sinais são modificados em amplitude e fase antes de serem combinados, de acordo com o algoritmo adequado. Naturalmente o desempenho das técnicas aumenta com o aumento da complexidade. 


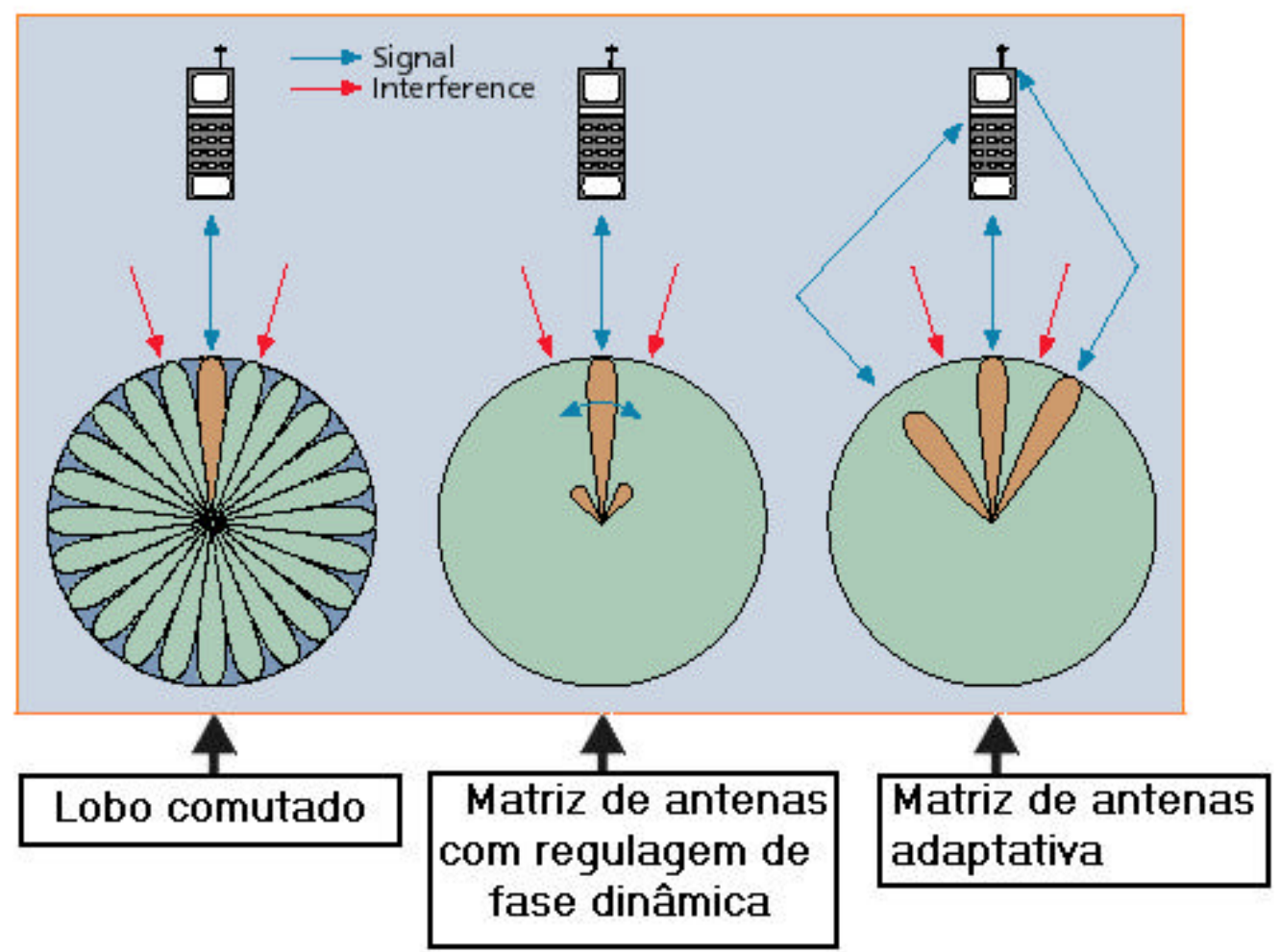

Fig .2.1 - Técnicas de implementação de antenas adaptativas 


\subsection{Antenas Adaptativas e seus Fundamentos}

Uma matriz de antenas e sua representação através de um sistema esférico de coordenadas poderá ser visto através da figura 2.2 onde $\phi$ é o azimute e $\theta$ o angulo de elevação.

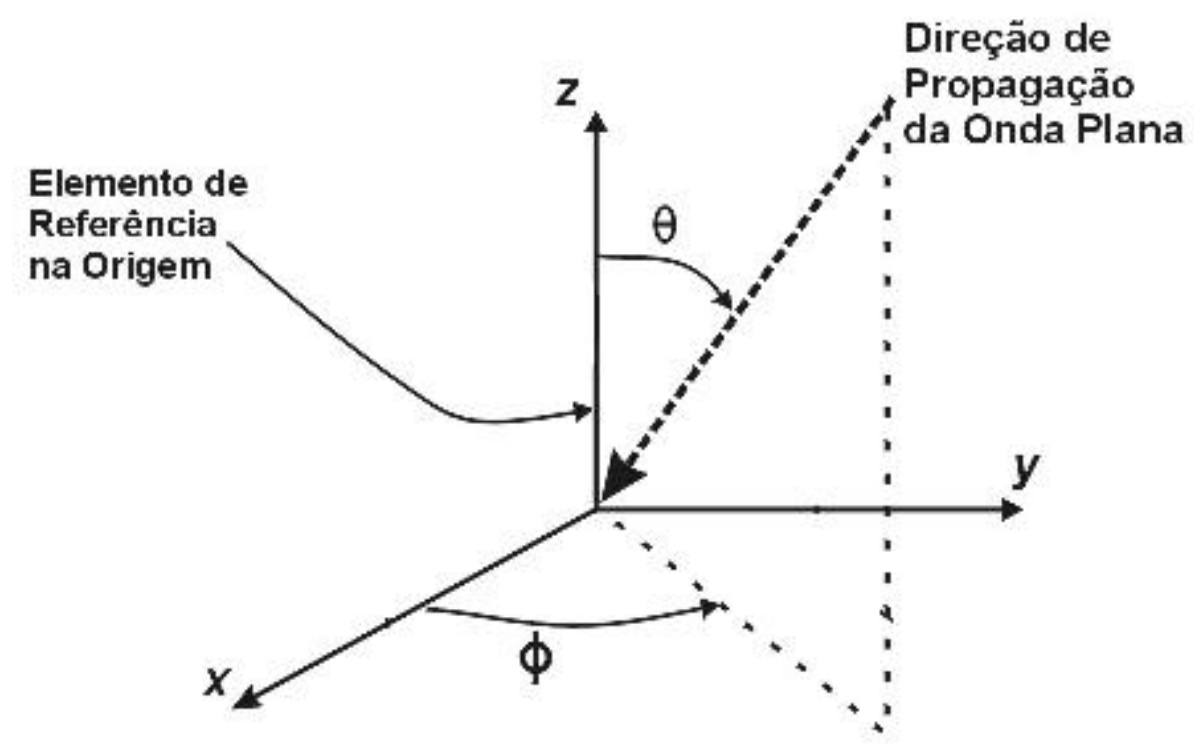

Fig. 2.2 - Ilustração do sistema de coordenadas de uma matriz de antenas

Em geral o modelo é simplificado com as seguintes hipóteses:

- Ângulo de elevação $\theta=90^{\circ}$

- Elementos dispostos regularmente ( linear/circular)

- Elementos com diagramas iguais

Na figura 2.3 é representada uma matriz de antenas linear ao longo de um eixo horizontal com dipolos verticais paralelos e igualmente espaçados entre si. 


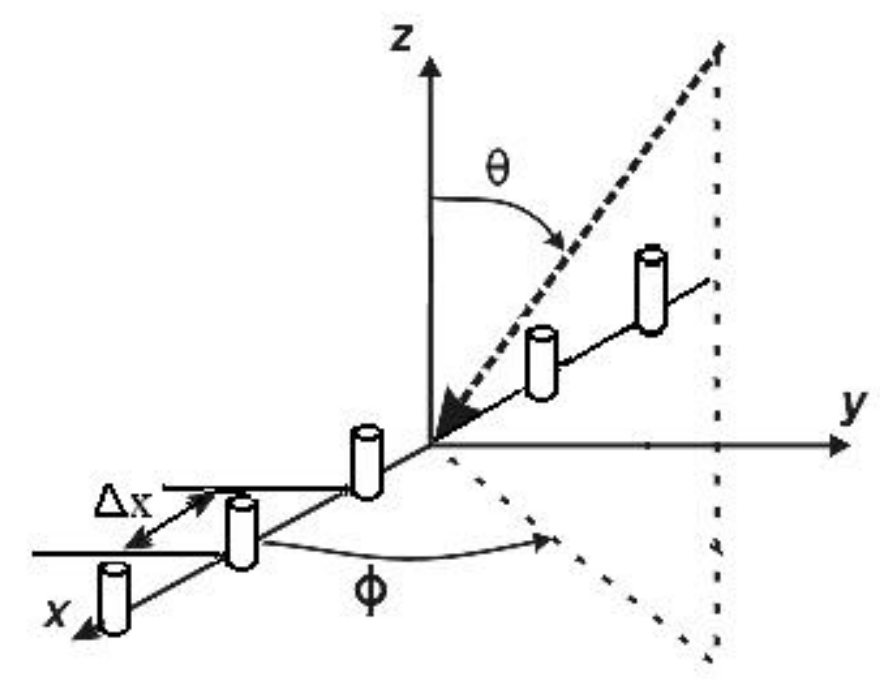

Fig .2.3 - Representação de uma onda plana incidente sobre uma matriz linear de antenas

Além disto, de forma a facilitar a análise das matrizes de antenas adaptativas, outras premissas são adotadas.

- O espaçamento entre os elementos da matriz é suficientemente pequeno de forma a não permitir variações de amplitude entre os sinais recebidos nos diferentes elementos.

- Não existe acoplamento mútuo entre os elementos da matriz de antenas.

- A largura de faixa do sinal incidente na matriz de antenas é pequena quando comparada a frequiência da portadora.

Para implementar um determinado diagrama de radiação, as saídas dos elementos são combinadas linearmente. A estrutura típica de uma matriz de antenas linear com $\mathrm{M}$ elementos igualmente espaçados de $\Delta_{\mathrm{X}}$ e combinadas linearmente pode ser vista na Fig 2.4. 


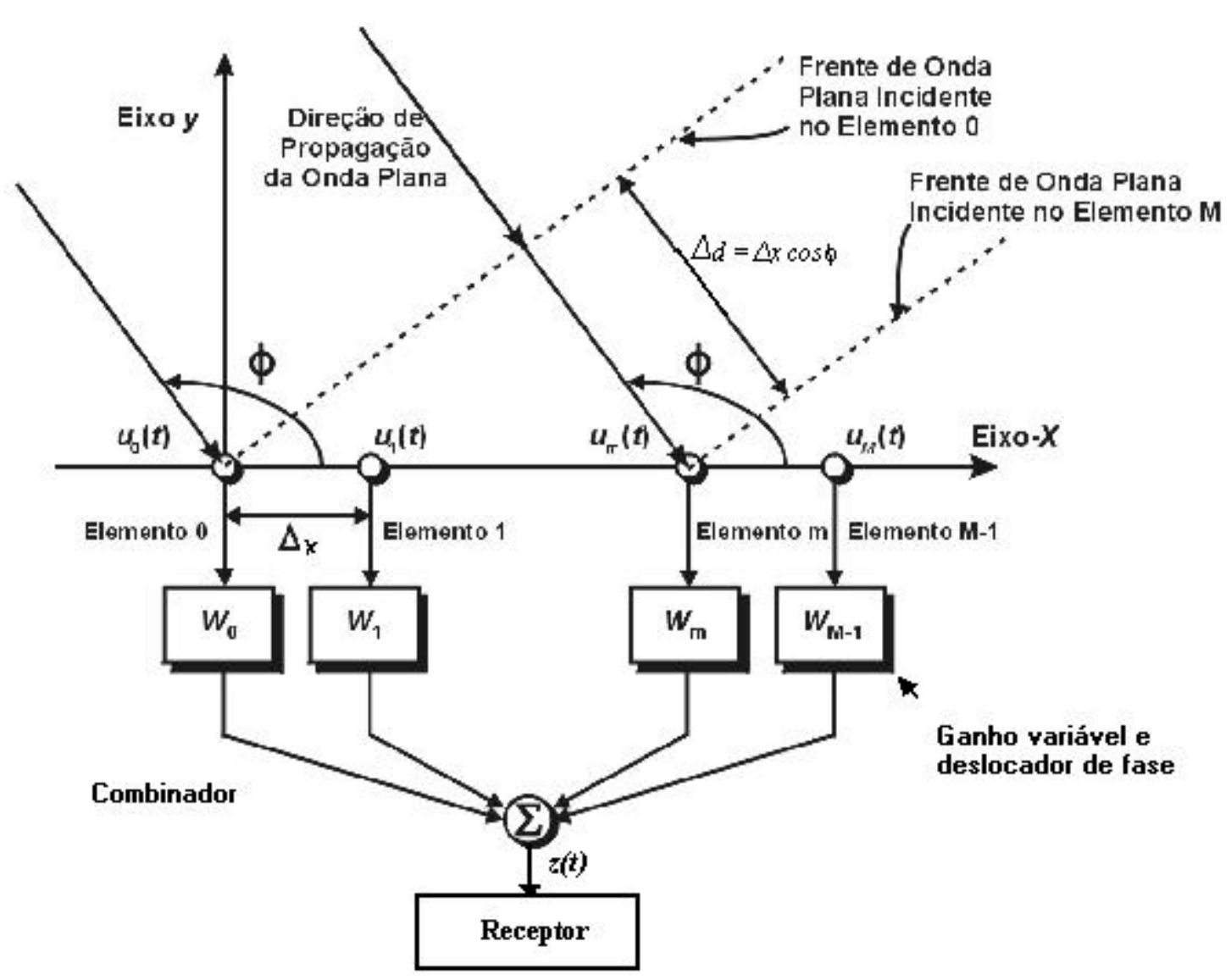

Fig .2.4 - Onda plana incidindo sob um ângulo $(\theta, \phi)$ em uma matriz de antenas linear uniforme

Note-se pela figura 2.4 que cada derivação da matriz de antenas é provido por um elemento de adaptação ou atualização $w_{m}$. Este elemento tem a finalidade de modificar a amplitude e a fase do sinal correspondente antes de somá-lo às outras saídas.

$\mathrm{Na}$ análise que se segue, os sinais serão representados por sua envoltória complexa cujo conceito e propriedades básicas são revistos no Apêndice 2.1 


\section{Modelo do arranjo linear uniforme}

Serão desenvolvidas a seguir as relações entrada-saída para um arranjo de antenas linear uniforme. Como visto no Apêndice 2.1, um atraso $\tau$ no sinal de entrada, $\mathrm{s}(\mathrm{t})$ (envoltória complexa) corresponde a introduzir uma defasagem de $2 \pi \mathrm{f}_{0} \tau$. No caso de uma onda com inclinação angular $\phi$, observa-se pela Fig. 2.4 que o espaçamento entre as frentes de onda chegando nos diversos elementos, é igual a $\Delta_{\mathrm{X}} \cdot \cos \phi$, onde $\Delta_{\mathrm{X}}$ é o espaçamento entre os elementos. Podemos então escrever a expressão do sinal em um elemento como

$u_{m}(t)=s(t) e^{-j \beta m \Delta d}=s(t) e^{-j \beta m \Delta x \cos \phi}$

onde $\beta=2 \pi \lambda$, sendo $\lambda$ o comprimento de onda do sinal incidente. Tipicamente observa-se a relação $\Delta_{\mathrm{X}} / \lambda=1 / 2$. Neste caso verifica-se através de (2.1) que a defasagem entre dois elementos vizinhos pode assumir valores entre $-\pi \mathrm{e}+\pi$.

Na saída do arranjo de antenas temos

$$
z(t)=\sum_{m=0}^{M-1} w_{m} u_{m}(t)=s(t) \sum_{m=0}^{M-1} w_{m} e^{-j \beta m \Delta x \cos \phi}=s(t) f(\phi)
$$

O termo $f(\phi)$ é a resposta da matriz de antenas (incluindo o conjunto de coeficientes) representada através da figura 2.4, ou também é o termo que determina a razão entre o sinal $z(t)$ presente na saída da matriz de antenas e o sinal $s(t)$ medido no elemento de referência, em função do ângulo de chegada $\phi$.

Ao se trabalhar com matrizes de antenas torna-se mais conveniente utilizarmos a notação vetorial. Diante disto, podemos definir o vetor de coeficientes

$$
w=\left[w_{0} \ldots w_{M-1}\right]^{H}
$$


onde, $H$ representa uma transposição Hermitiana, definida como um processo de transposição combinado com a conjugação complexa.

Os sinais provenientes de cada elemento da matriz são agrupados para formar um vetor do sinal de entrada definido por:

$\mathrm{u}(\boldsymbol{t})=\left[u_{0}(t) \ldots u_{M-1}(t)\right]^{T}$

Assim, a partir da expressão (2.2), a saída da matriz de antenas $z(t)$ poderá ser expressa através de um produto do vetor de coeficientes da matriz de antenas, $w$, com o vetor de dados $u(t)$,ou seja,

$z(t)=\boldsymbol{w}^{H} \boldsymbol{u}(t)$

A resposta da matriz de antenas poderá ser expressa da seguinte forma:

$f(\phi)=\boldsymbol{w}^{H} \boldsymbol{a}(\phi)$

onde

$a(\phi)=\left[1 \quad a_{l}(\phi) \ldots a_{M-1}(\phi)\right]^{T}$

e, no caso da matriz linear,

$a_{m}(\phi)=e^{-j \beta x_{m} \cos \phi}$

O vetor a $(\phi)$ é conhecido como vetor de direção para o ângulo $\phi$. Um conjunto de vetores de direção, cada qual calculado ou medido sobre todos os valores de $\phi$ é denominado "array manifold" e pode ser visto como um coletor da matriz de antenas. Na realidade a finalidade deste coletor é mapear um vetor de direção para cada ângulo de chegada. 
Note-se ainda que

$\mathbf{u}(t)=s(t) \mathbf{a}(\phi)$

e substituindo em (2.5) temos

$z(t)=s(t) \boldsymbol{w}^{H} \boldsymbol{a}(\phi) s(t) f(\phi)$

\section{RAZÃO SINAL-RUÍDO}

Supõe-se em geral que o sinal na saída do elemento $i$ do arranjo de antenas é corrompido por ruído aditivo gaussiano branco representado por $n_{i}(t)$. Podemos então definir o vetor $\boldsymbol{n}(t)^{T}=$ $\left[n_{l}(t), n_{2}(t) \ldots n_{M}(t)\right]$. Podemos então rescrever

$\mathbf{u}(t)=s(t) \mathbf{a}(\phi)+\mathbf{n}(t)$

observando que (2.10) agora não se aplica. Usando (2.5) podemos escrever

$$
z(t)=\mathbf{w}^{H} s(t) \mathbf{a}(\phi)+\mathbf{w}^{H} \mathbf{n}(t)
$$

e determinar a seguinte expressão para a Razão Sinal-Ruído

$$
R S R=\frac{E\left\{\left\|\mathbf{w}^{H} s(t) \mathbf{a}(\phi)\right\|^{2}\right\}}{E\left\{\left\|\mathbf{w}^{H} \mathbf{n}(t)\right\|^{2}\right\}}=\frac{\sigma_{s}^{2} \mathbf{w}^{H} \mathbf{a}(\phi) \mathbf{a}^{H}(\phi) \mathbf{w}}{\mathbf{w}^{H} \mathbf{R}_{n n} \mathbf{w}}
$$

onde $\sigma_{s}^{2}$ é a variância do sinal desejado e $\mathbf{R}_{\mathrm{nn}}$ é a matriz covariância do ruído. Note-se que

$$
\mathbf{R}_{u u}=\sigma_{s}^{2} \mathbf{a}(\phi) \mathbf{a}^{H}(\phi)+\mathbf{R}_{n n}
$$




\subsection{Filtragem Espacial}

Sistemas projetados para recepção da propagação espacial de sinais freqüentemente deparam-se com a presença de sinais interferentes. Se o sinal desejado e os sinais interferentes ocupam a mesma banda de frequiência temporal, então a filtragem linear temporal (invariante no tempo) não poderá ser utilizada para separar de forma completa o sinal desejado dos sinais interferentes. Entretanto, os sinal desejado e os interferentes são normalmente originados a partir de diferentes localizações. Esta separação espacial pode ser utilizada para separar o sinal desejado dos interferentes utilizando a filtragem espacial no receptor. Em função disto, o combinador combinará linearmente as amostras espaciais da série temporal de cada elemento para obter na saída uma série temporal escalar da mesma forma que um filtro FIR combina linearmente dados amostrados temporalmente.

Conforme será possível averiguar-se, a estrutura da Figura 2.4 leva a desempenho insatisfatório quando os sinais, principalmente o sinal interferente, apresentam faixa relativamente larga. Pode-se mostrar que uma solução é utilizar uma combinação de filtragem espacial com filtragem temporal usando a mesma estrutura de filtro transversal como representado na Figura 2.5. Esta estrutura permite um ajuste no ganho e na fase na banda de interesse. Se o espaçamento ou atraso $z^{-1}$ for suficientemente pequeno, essa estrutura se aproxima do filtro transversal ideal que permite controle completo de ganho e fase em cada freqüência na banda passante.

Com relação as antenas adaptativas, um sinal é considerado ser de banda estreita se e somente se todas as componentes de frequiência deste sinal ao incidirem sobre a matriz de antenas sofrerem um deslocamento de fase, porém mantendo sua magnitude aproximadamente constante 
como é possível observar através da configuração de matriz típica para este tipo de sinal apresentada na Figura 2.4.

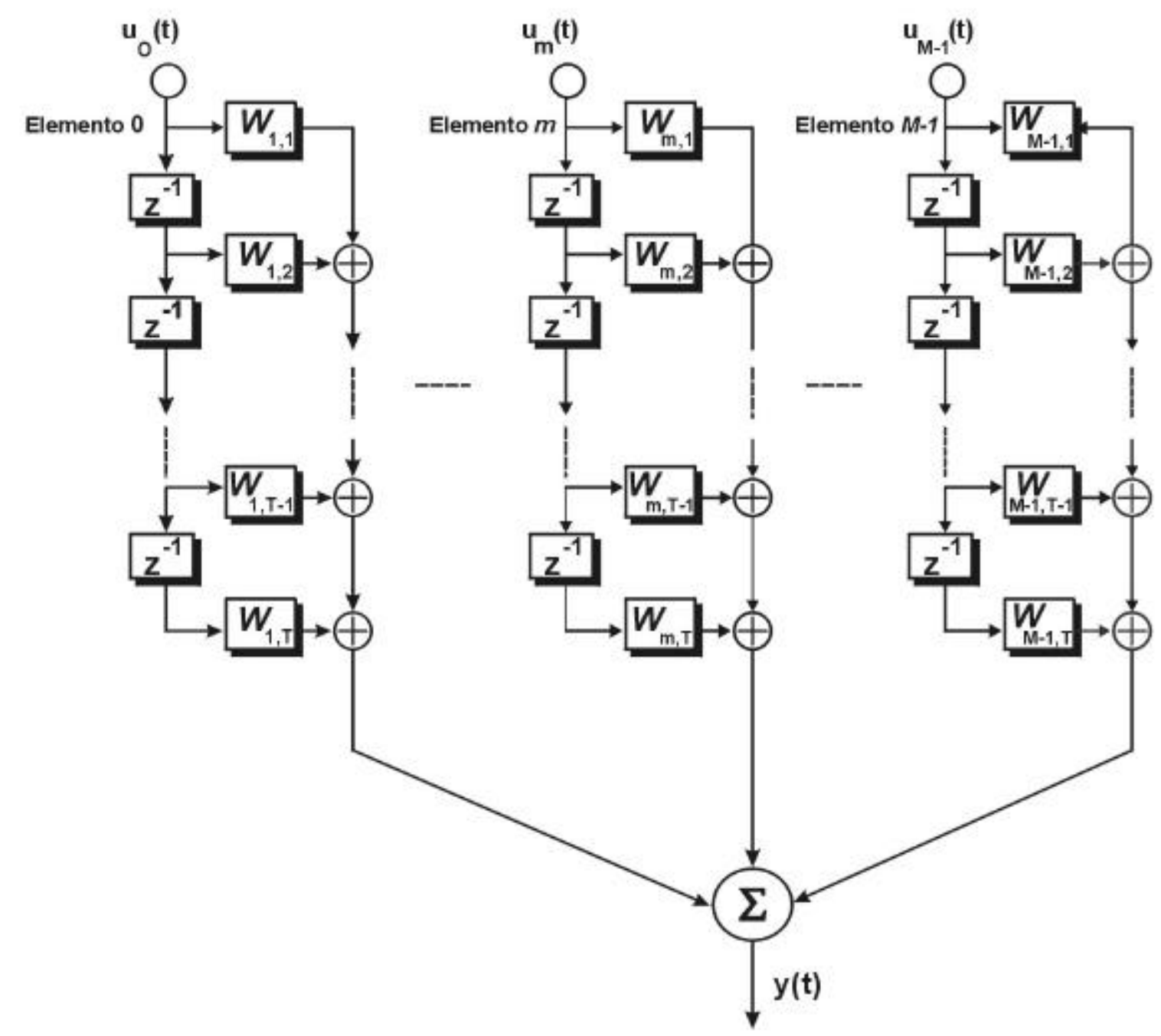

Figura 2.5 - Estrutura da matriz de antenas típica para recepção de sinais de faixa larga

Um sinal é considerado ser de banda larga quando todas as componentes de frequiência deste sinal forem não somente submetidas a um deslocamento de fase assim como também a uma variação de amplitude na medida em que o mesmo atravessa uma matriz de antenas. 


\section{APÊNDICE 2.1}

Um sinal limitado em faixa em torno de uma frequiência $f_{0}$ pode ser escrito como

$\tilde{s}(t)=v(t) \cos \left[2 \pi f_{c} t+\theta(t)\right]=\operatorname{Re}\left\lfloor v(t) e^{j \theta(t)} e^{j 2 \pi f_{0} t}\right\rfloor$

onde $v(t)$ e $\boldsymbol{\theta}(t)$ podem ser vistos como sinais moduladores em amplitude e fase. Uma vez que $f_{0}$ apenas define a região do espectro de frequiências, o produto

$s(t)=v(t) e^{j \Theta(t)}$

contém toda a informação relevante do sinal. Este produto é denominado envoltória complexa.

Em resumo, todo sinal passa-faixa pode ser decomposto em uma portadora e uma envoltória complexa (que determina a envoltória e a fase desta portadora).

Observa-se na Fig. 2.4 que o sinal em cada elemento é uma versão atrasada do sinal no primeiro elemento. Vamos considerar que este atraso $\tau$ é relativamente pequeno de forma que

$v(t-\tau) \cong v(t)$ e $\theta(t-\tau) \cong \theta(t)$. Neste caso,

$\tilde{s}(t-\tau)=\operatorname{Re}\left\lfloor v(t) e^{j \theta(t)} e^{j 2 \pi f_{0}(t-\tau)}\right\rfloor$

e assim

$s(t-\tau) \cong s(t) e^{-j 2 \pi f_{0} \tau}$ 
Nota-se portanto que o efeito do atraso é introduzir uma defasagem $-2 \pi \mathrm{f}_{0} \tau$ na envoltória complexa.

A representação complexa também deve ser estendida aos coeficientes $\left\{\mathrm{w}_{\mathrm{m}}\right\}$ da matriz de antenas. Como foi observado, a envoltória complexa determina a envoltória propriamente dita e a fase da portadora modulada que representa o sinal. Se considerarmos coeficientes reais, só teremos condição de alterar a amplitude e não a fase da portadora, o que seria uma limitação no modelo do sistema. 


\section{FUNDAMENTOS DOS SISTEMAS DIGITAIS ( TDMA E CDMA )}

Neste capítulo serão resumidas as principais características dos sistemas celulares digitais e, em particular, das tecnologias de transmissão e múltiplo acesso utilizadas nestes sistemas. $\mathrm{O}$ interesse principal é a definição de um modelo básico para o processamento do sinal no canal de comunicação e sobretudo nos receptores.

\subsection{Introdução aos Sistemas Celulares}

Os sistemas de comunicações móveis são constituídos de três componentes básicos: o terminal móvel, a estação rádio base (ERB) e a central de comutação e controle (CCC) (figura 3.1). O terminal móvel é um transceptor portátil e inteligente utilizado pelo usuário enquanto a ERB é um transceptor de maior porte que interliga os usuários e a CCC Estes terminais são munidos de um sistema computacional que processa algoritmos usados no plano de controle e plano do usuário do protocolo de múltiplo acesso deste sistema de comunicações. Os acessos, chamados de canais de tráfego, são solicitados à estação rádio base que detém o seu controle. O plano de controle é suportado por canais exclusivos entre os terminais móveis e a estação rádio base, sendo estes chamados de canais de controle. Da mesma forma que os terminais móveis, a ERB utiliza transceptores de potência limitada de maneira a atender uma região geográfica especificada denominada de célula. 


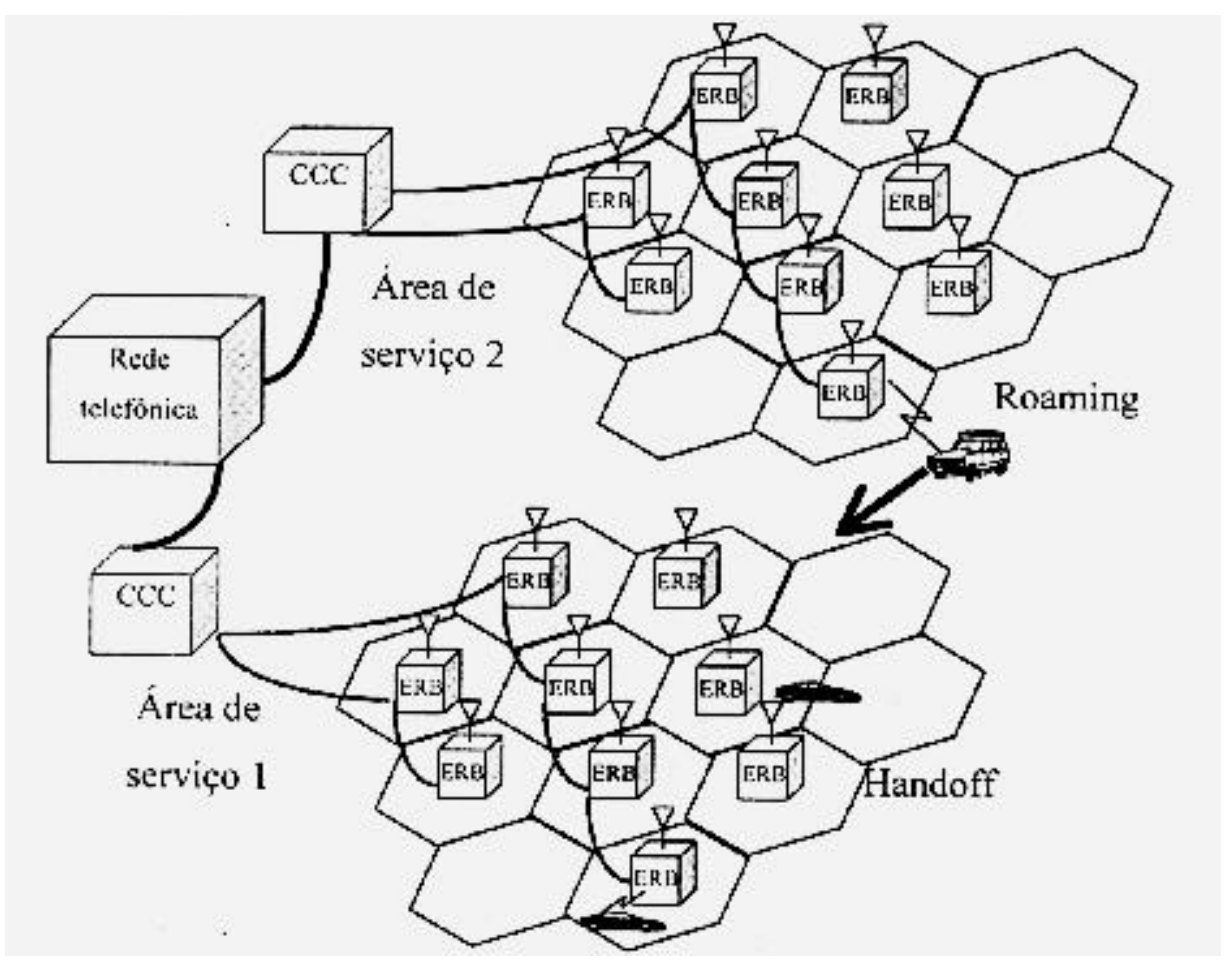

Fig. 3.1 - Sistema de comunicação móvel celular e seus componentes

A célula é resultado da subdivisão da região geográfica atendida pelo serviço. A cala célula são destinadas um grupo de canais, de tal sorte que em células adjacentes, grupos com canais diferentes são utilizados. O menor grupamento de células adjacentes cujos canais somam o total de canais disponíveis para o serviço é denominado decluster. O número de células em cada cluster é escolhido conforme as condições de interferência Quanto mais próximas as células de canais reutilizados maior é a interferência cecanal. Este número de células por cluster é denominado de fator de reuso e indica o grau de utilização do sistema maior o fator de reuso, menor é a quantidade de tráfego cursado pelo sistema para mesma quantidade de canais.

Sabemos que uma das formas de se implementar o aumento de capacidade dentro de um sistema celular é conseguido aravés da reutilização de freqüências, isto é, um mesmo grupo de canais ser utilizado por duas células distintas pertencentes a diferentes grupos ou clusters, e estando suficientemente afastadas entre si para evitar uma interferência mútua muito 
intensa. A organização das células em clusters e o reuso de frequiência estão ilustrados na Fig. 3.2 .

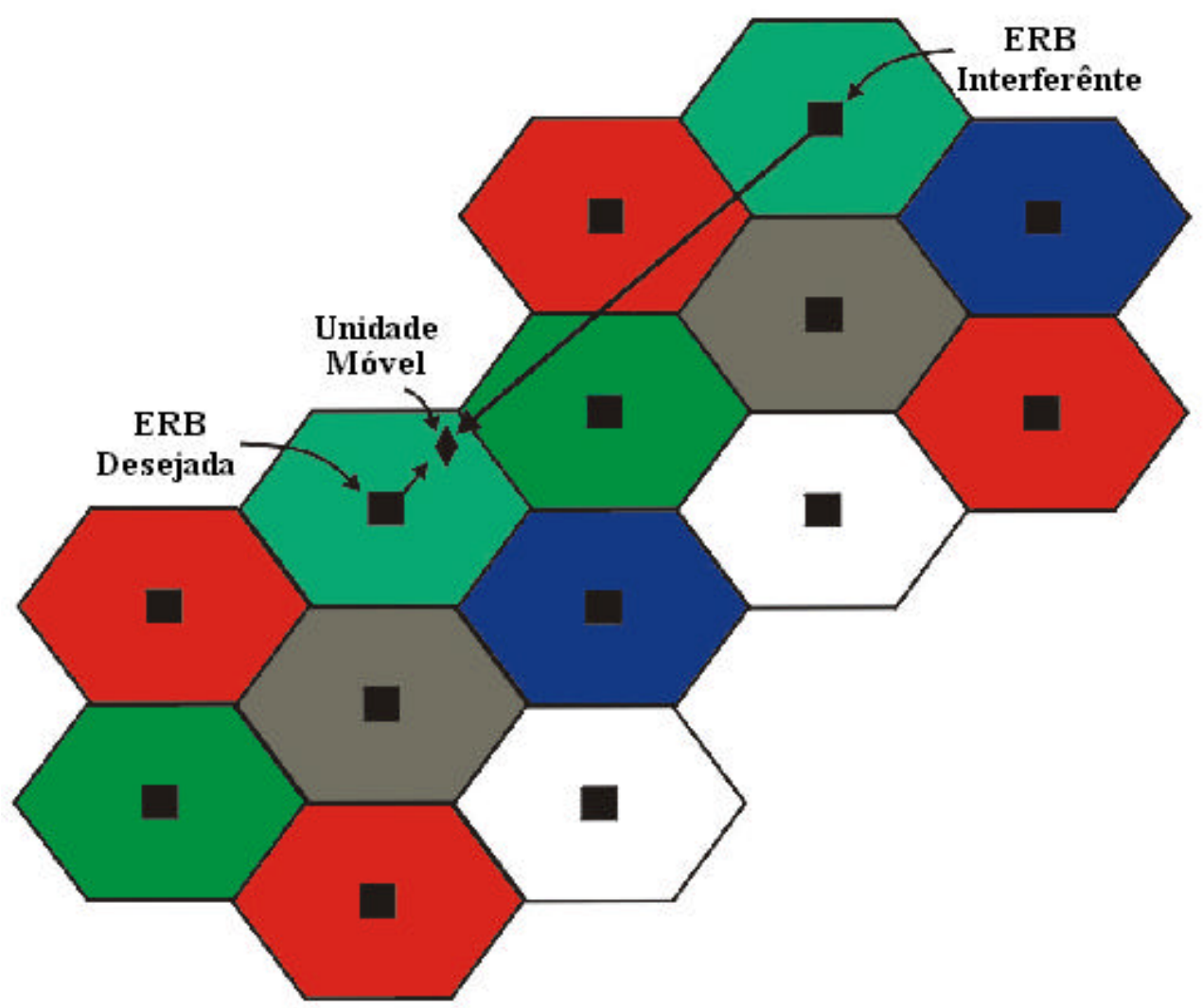

Fig. 3.2 - Estrutura celular

A central de comutação e controle (CCC) faz a interface entre diversas estações rádio base e a rede fixa. Assim, entre as funções da central estão: Controlar as estações rádio base filiadas a ela, comutar para permitir o estabelecimento de comunicação entre usuários e compatibilizar os serviços oferecidos pela rede fixa com os serviços móveis.

Dá-se o nome de interface radio ao canal de comunicações que interliga os terminais móveis e a ERB. O projeto desta interface, em particular a escolha do sistema de múltiplo acesso e da modulação, é crítico para determinação da capacidade de um sistema celular. Esta é basicamente limitada po interferência. A seguir descrevemos de forma resumida os sistemas de múltiplo acesso e modulação usados nos sistemas celulares digitais de segunda geração. 


\subsection{Múltiplo Acesso por Divisão de Tempo - TDMA}

Os sistemas celulares digitais de segunda geração usam duas formas de múltiplo acesso: divisão no tempo ou divisão em código ( TDMA ou CDMA respectivamente). Os sistemas TDMA dividem o tempo de transmissão em intervalos ou janelas de tempo e cada intervalo pode ser usado para transmissão ou recepção por um usuário diferente. Assim, cada usuário ocupa um determinado intervalo num processo que se repete ciclicamente como podemos observar através da figura 3.3. Um conjunto de $N$ intervalos de tempo formam um quadro. Sistemas TDMA transmitem dados em rajadas após armazená-los num buffer, de tal forma que a transmissão não é continua. Um canal pode ser visualizado como um determinado intervalo que se repete a cada quadro. É importante observar que no sistema TDMA, quanto maior é o fator de reuso, ou seja, maior o número de células por cluster, maior será a razão Sinal-Interferência. Entretanto, um aumento no fator de reuso implica em um menor número de canais por célula disponíveis (considerando constante o número total de canais) para atender o tráfego, acarretando uma redução na capacidade do sistema.

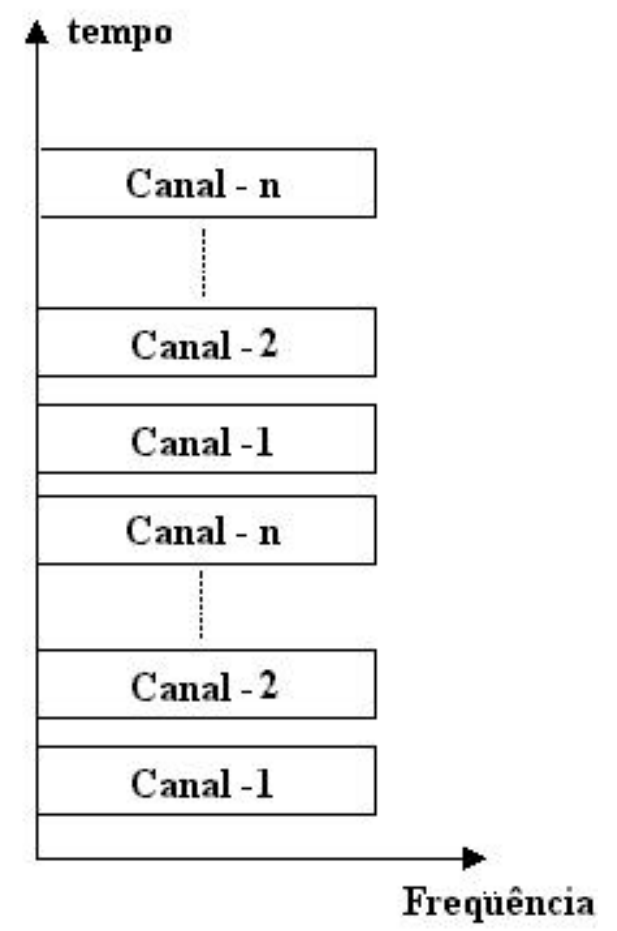

Fig. $3.3-T D M A$ 


\subsubsection{Padrões TDMA}

Três sistemas TDMA estão hoje implantados mundialmente: o sistema DAMPS que evoluiu do AMPS e que está definido na seção seguinte, o sistema GSM que foi inicialmente desenvolvido para unificar as comunicações móveis na Europa e o sistema Japonês. Abordaremos aqui como ilustração apenas o sistema D-AMPS.

\subsubsection{D-AMPS}

Historicamente, considerando o requisito de compatibilidade, a TIA (Telecommunications Industry Association) aprovou um padrão TDMA com $30 \mathrm{kHz}$, designando-o originalmente por IS-54. (Interim Standard). Posteriormente, passou a ser conhecido por D-AMPS, ou seja, AMPS digital. Este padrão utiliza um TDMA com 3 usuários por portadora. O quadro tem a duração de $40 \mathrm{~ms}$, correspondendo cada janela a 6.67 ms. O formato básico do quadro está mostrado na Fig. 3.4.

Conforme é possível observarmos através da Figura 3.4 o quadro TDMA inclui um preâmbulo que contém as informações de endereço e sincronização que tanto a estação rádio base quanto o terminal do usuário móvel utilizam para identificar um ao outro. Além disto, tempos de guarda são utilizados para permitir a sincronização dos receptores entre diferentes intervalos e quadros.

É interessante comentar que o sistema D-AMPS foi desenvolvido com a condição de apresentar certa compatibilidade com o sistema AMPS dada a infraestrutura existente deste sistema nos Estados Unidos. Assim foi estabelecida a meta de colocar 3 canais de voz digitalizada em um canal AMPS de30 KHz. Para isto foi padronizado um vocoder combinado com código corretor de erro operando a taxa de $16,2 \mathrm{Kbit} / \mathrm{s}$ e um modulador DPSK quaternário capaz de transmitir aproximadamente a 48,6 Kbit/s correspondentes aos 3 canais de voz. 


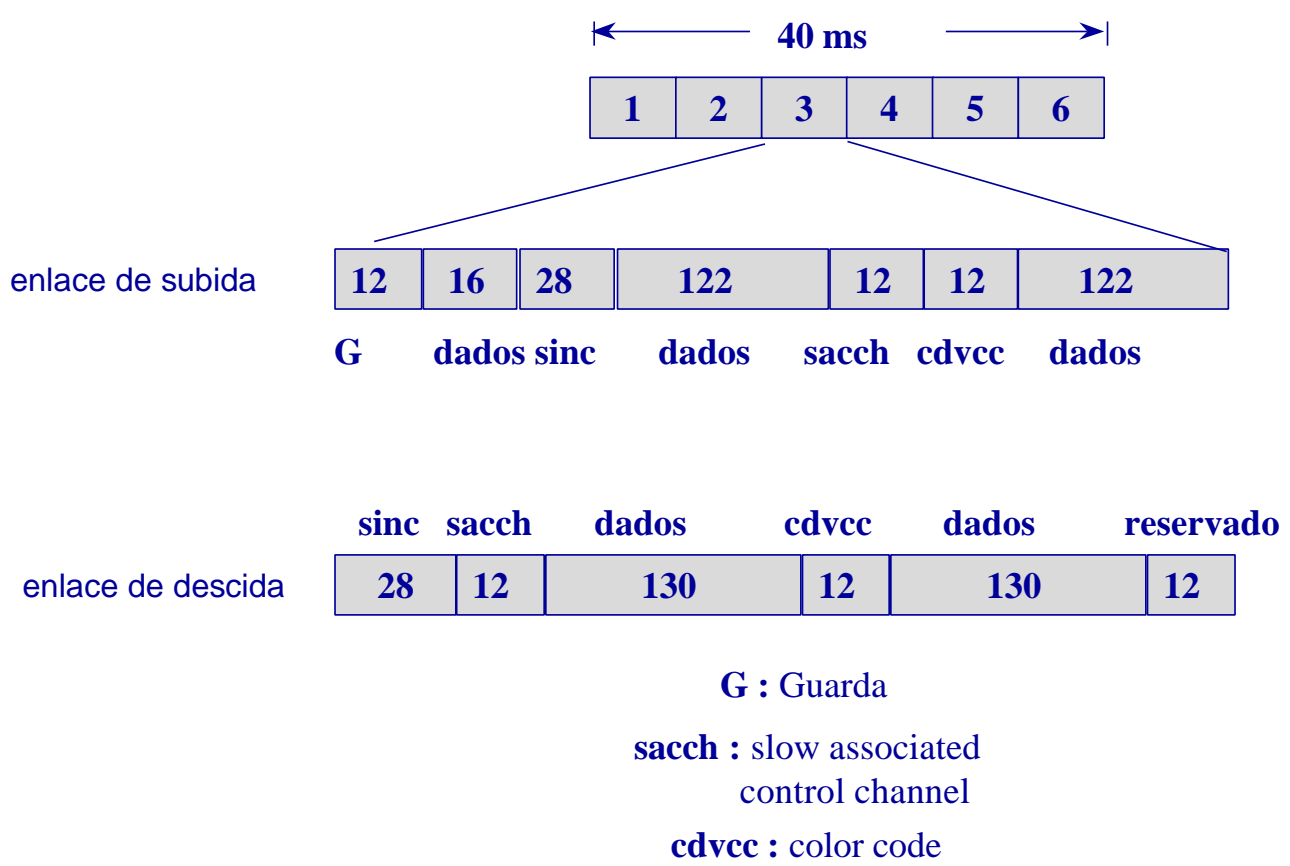

Fig. 3.4 -Estrutura do frame no padrão TDMA IS-54/136

A técnica de modulação utilizada no padrão D-AMPS é conhecida como $\pi / 4$ Shifted Differential QPSK ou simplesmente $\pi / 4-D Q P S K$. O esquema de modulação do sistema $\pi / 4-D Q P S K$ está mostrado na Fig. 3.5 onde $\theta_{\mathrm{k}}$ representa a fase da portadora em um intervalo de tempo $[k T,(k+1) T]$ e $\phi_{\mathrm{k}}$ é uma fase adicional obtida a partir dos bits de entrada

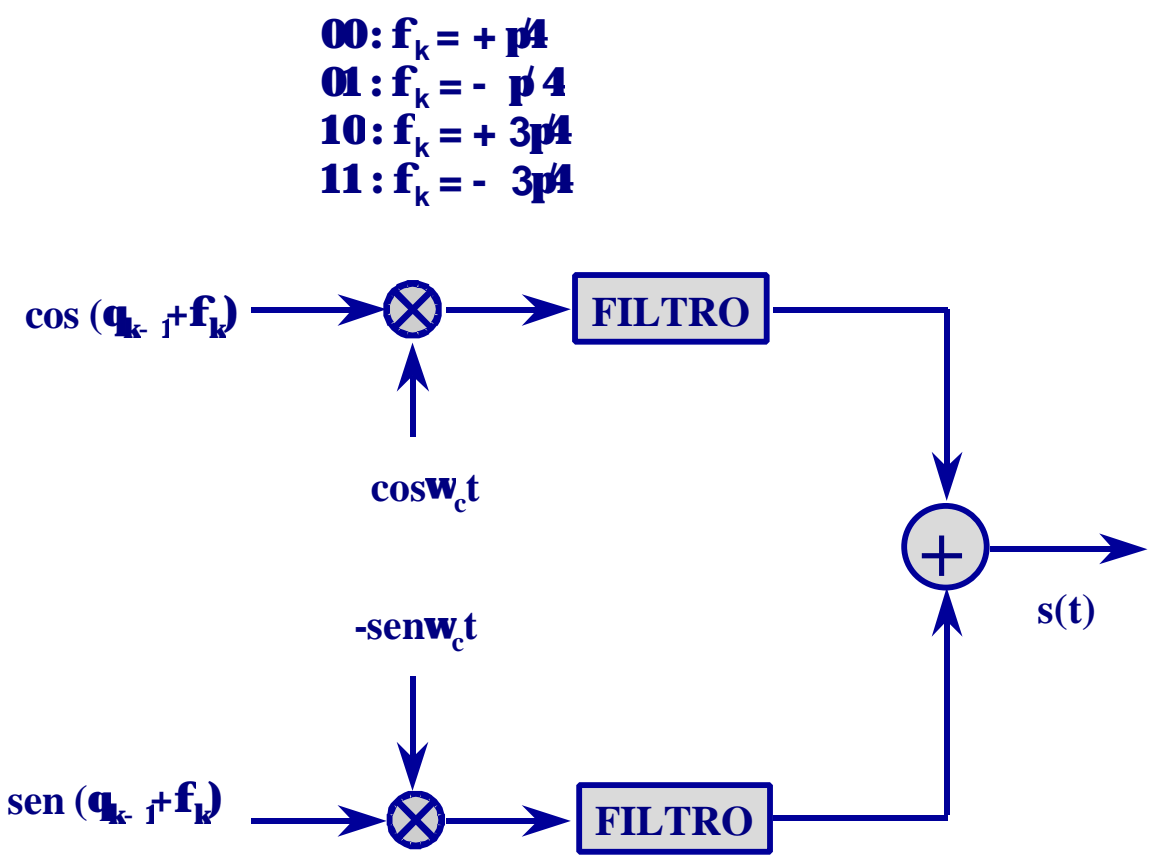

Fig. 3.5 - Esquema do modulador $\pi / 4$ - DQPSK 
Pode-se verificar pela análise do diagrama queo sinal transmitido no intervalo será expresso por

$s(t)=\cos \left(\omega_{c} t+\theta_{k-1}+\phi_{k}\right) ; \mathrm{t} \in[k T,(k+1) T] ; \phi_{\mathrm{\kappa}}= \pm \pi A, \pm 3 \pi A$

Pode-se verificar que este sistema corresponde a um sistema PSK onde se tem duas constelações representativas das fases da portadoras que se alternam a cada intervalo de símbolo ( 2 bits). Isto é, supondo $\theta_{0}=0$, obtém-se $\theta_{1}= \pm \pi A, \pm 3 \pi A, \theta_{2}=0, \pi, \pm \pi / 2, \theta_{3}=$ $\pm \pi A, \pm 3 \pi A$, etc. A implicação disto é que as variações de envoltória são reduzidas, reduzindo-se com isto a degradação provocada por amplificação não linear.

\subsection{Múltiplo Acesso por Divisão em Código - CDMA}

O CDMA é um sistema de múltiplo acesso no qual todos os usuários podem compartilhar um mesmo canal na freqüência e no tempo conforme ilustrado na figura 3.6.

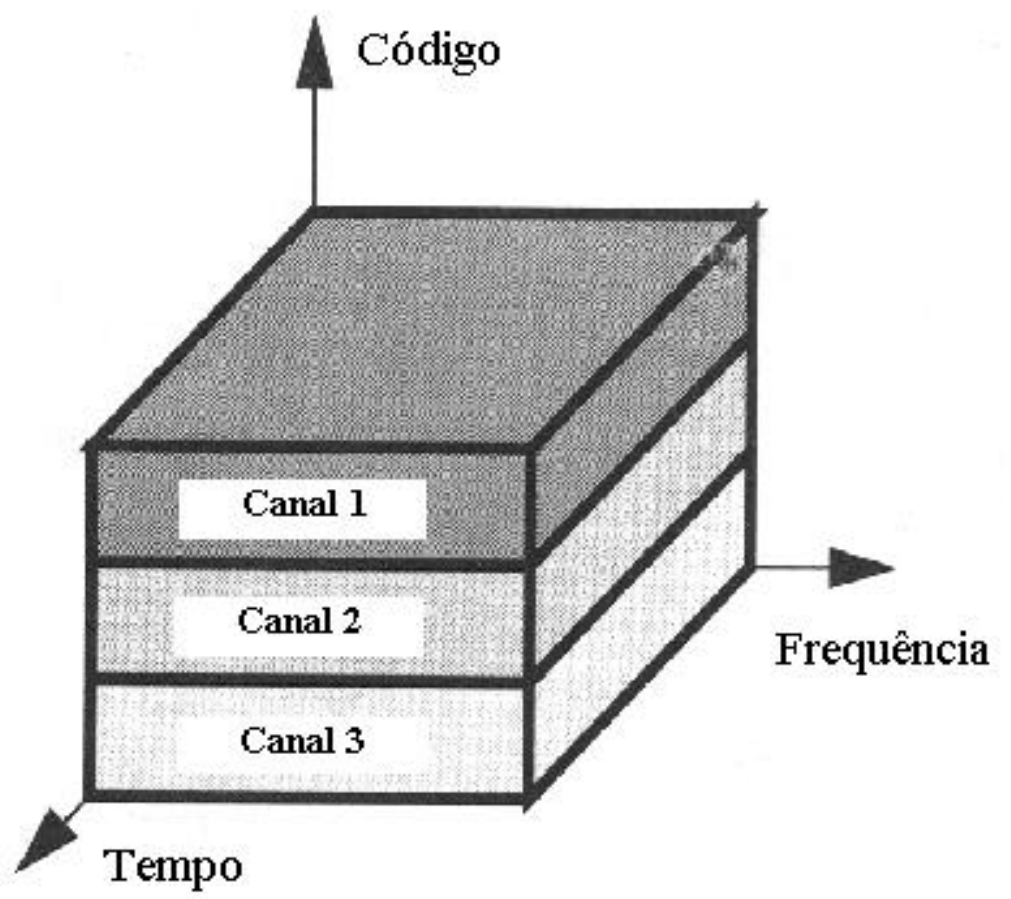

Fig. 3.6 - CDMA 
O sistema CDMA usado em sistemas de $2^{\mathrm{a}}$ geração ( IS-95 ) é baseado na técnica de Espalhamento do Espectral por Seqüência Direta, na qual a faixa do sinal é espalhada sobre uma banda muito mais larga utilizando uma sequiênciapseudoaleatória. Esta banda larga é compartilhada por todos os usuários, que se diferenciam entre si mediante códigos pseudoaleatórios ortogonais uns aos outros.

\subsubsection{Modelo Analítico}

O sinal com espalhamento espectral por seqüência direta é o resultado do produto de 3 sinais: o sinal de informação, o sinal de espalhamento e uma portadora, isto é

$$
s(t)=m(t) c(t) \cos \left(2 \pi f_{c} t\right)
$$

onde

m(t) é um trem de pulsos representando a informação codificada em bits, dado por

$$
m(t)=\sum_{j=-\infty}^{\infty} b_{j} g\left(t-j T_{b}\right)
$$

$g(t)$ é um pulso retangular unitário de duração $T_{\mathrm{b}}$;

$\left\{b_{j}\right\}$ é uma seqüência de amplitudes binárias associadas aos bits;

$$
c(t)=\sum_{j=-\infty}^{\infty} c_{j} h\left(t-j T_{c}\right)
$$

$h(t)$ é um pulso de duração $\mathrm{T}_{\mathrm{c}}<<\mathrm{T}_{\mathrm{b}}$

$\left\{c_{j}\right\}$ é uma seqüência de amplitudes binárias associadas aos pulsos denominados chpis;

$\mathrm{f}_{\mathrm{c}}$ é a freqüência da portadora.

A razão entre $T_{b}$ e $T_{c}$ define o grau de espalhamento e é denominadaganho de processamento. 
Um sistema CDMA é constituído pela soma de um conjunto de sinais com espalhamento espectral por seqüência direta. Assim, na sad́a do transmissor tem-se uma soma de sinais do tipo de (3.2) cuja forma específica é diferente nos enlaces de subida ou descida.

No enlace de descida, a soma é feita antes da modulação e esta soma modula a portadora. A expressão correspondente é

$$
s(t)=\sum_{i=1}^{m} m_{i}(t) c_{i}(t) \cos \left(2 \pi f_{c} t+\theta\right)=\left[\sum_{i=1}^{m} m_{i}(t) c_{i}(t)\right] \cos \left(2 \pi f_{c} t+\theta\right)
$$

No enlace de subida, o terminal móvel transmite o seu sinal com espalhamento espectral usando cada um sua portadora. A demodulação acontece na entrada do sistema de recepção da ERB. A expressão correspondente é

$$
s(t)=\sum_{i=1}^{m} m_{i}(t) c_{i}(t) \cos \left(2 \pi f_{c} t+\theta_{i}\right)
$$

Note-se que o sinal transmitido no enlace direto do sistema CDMA todos os sinais são somados na ERB com uma mesma potência e esta igualdade de potência se mantém no receptor do terminal móvel. Entretanto, no enlace reverso, embora cada terminal móvel possa transmitir com a mesma potência, o nível do sinal recebido na ERB depende da atenuação entre o terminal móvel e a ERB. Assim, em princípio, os sinais chegam com potências desiguais ao receptor da ERB, exigindo que seja feito um controle da potência na transmissão de forma que os terminais mais distantes transmitam com potência maior para compensar a maior atenuação.

Na recepção, o sinal desejado é primeiramente demodulado e em seguida recuperado mediante um correlacionador para cada canal, capaz de canalizar a energia que vem do sinal associado a cada código específico, agrupando seu espectro. Os espectros dos sinais restantes são vistos como ruído pelo sistema. O processo é ilustrado através da Fig. 3.7 onde são representados na entrada do canal $i$, após a demodulação, o conjunto de sinais $\left\{m_{\mathrm{i}}(t)\right\}$ espalhados pelo conjunto de seqüências de espalhamento $\left\{c_{i}(t)\right\}$.

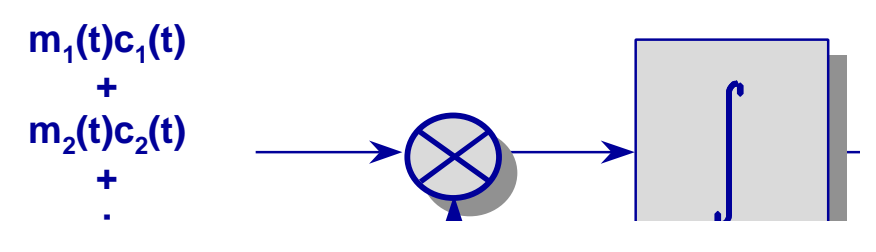


Fig. 3.7 - Esquema de demodulação do sinal DS -CDMA

Na saída do correlacionador tem-se, desprezando o ruído propriamente dito,

$$
x=s+\sum_{k \neq i} u_{k, i}=\int_{T_{b}} m_{i}(t) c_{i}^{2}(t) d t+\sum_{k \neq i} \int_{T_{b}} m_{k}(t) c_{k}(t) c_{i}(t) d t
$$

Podemos observar que $c_{i}^{2}(t)=1$ e assim, o primeiro termo $s$ corresponde à integração do pulso utilizado na transmissão do bit e fornece a informação desejada. O segundo termo corresponde à soma das interferências $\left\{u_{k, \mathrm{i}}\right\}$ dos outros sinais. Idealmente

$u_{k, i}=\int_{T_{b}} m_{k}(t) c_{k}(t) c_{i}(t) d t=0$

e assim a interferência seria nula. No entanto, devido a diversos aspectos de implementação, tem-se que tipicamente a interferência é uma variável aleatória cujo valor médio quadrâitco é bem menor do que o valor médio quadrático correspondente à mensagem. Pode-se mostrar que, quando as seqüências de espalhamento podem ser modeladas como seqüências de amplitudes aleatórias e equiprováveis e estatisticamente independentes entre si, a azão entre os valores médios quadráticos das amostras do sinal e do ruído é igual ao ganho de processamento. Este mesmo resultado também se aplica a códigos gerados através de seqüências de comprimento máximo.

\subsubsection{IS-95}


O sistema CDMA utilizado no padrão IS-95 é implementado em uma faixa de 1,25 MHz. O espalhamento é feito em diversas etapas, incluindo uma mistura de códigos de espalhamento (código de Walsh e seqüência de comprimento máximo) e código corretor de erro (código convolucional). A estrutura de transmissão do enlace de subida está mostrada na Fig. 3.8

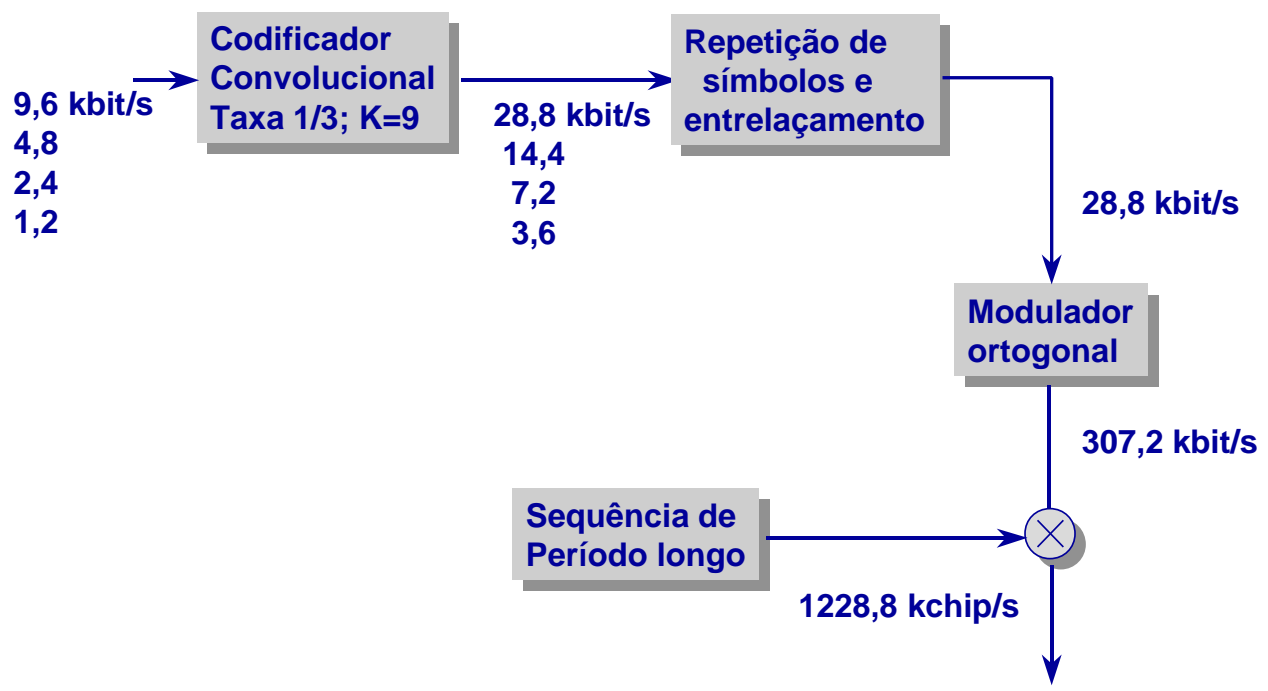

Fig. 3.8 - Estrutura de transmissão do enlace de subida

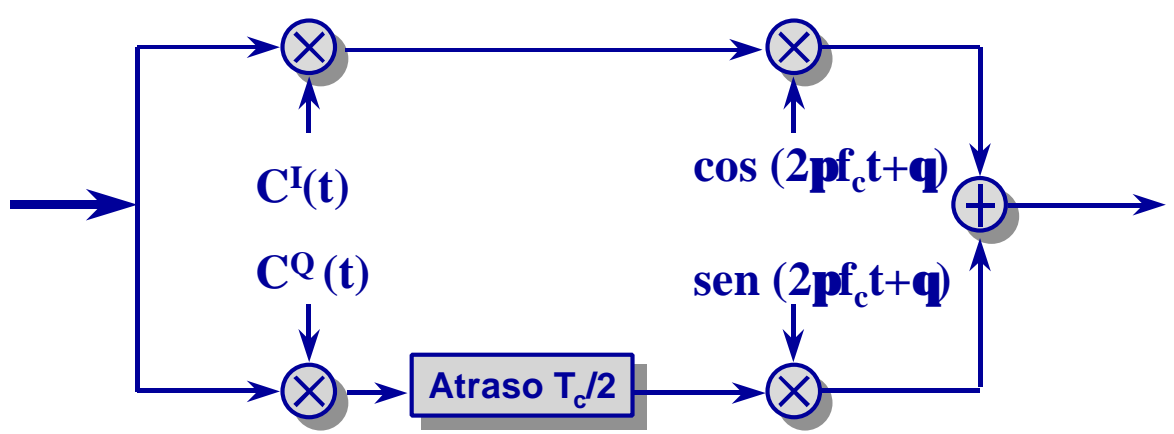

Fig. 3.9 -Esquema de modulação do enlace de subida do sistema CDMA IS-95

O sinal de voz digitalizado no terminal móve a taxas variáveis entre 1,2 Kbit/s e 9,6 $\mathrm{Kbit} / \mathrm{s}$ passa inicialmente por um código convolucional de taxa $1 / 3$ resultando portanto um 
sinal de taxa 3 vezes maior. Após um processo de entrelaçamento e repetição de símbolos destinados a redução de energia transmitida, o sinal entra em um modulador ortogonal. Este associa a cada grupo de 6 bits uma seqüência de Walsh de 64 bits resultando, além da modulação em si, um espalhamento do sinal por um fator 64/6. Este sinal é então espalhado por uma seqüência de comprimento máximo de taxa $1228 \mathrm{Kchip} / \mathrm{s}$, gerada por um shiftregister de tamanho 42 o que eqüivale a uma periodicidade de $2^{42}-1$. Esta sequiência é denominada seqüência de período longo. Finalmente o sinal resultante entra em um modulador PSK quaternário que na realidade eqüivale a um modulador PSK binário com diversidade de fase. Ou seja, o mesmo sinal modula as duas portadoras em quadratura do sistema PSK. Note-se porém que antes desta modulação novos espalhamentos, desta vez por sequiências de período curto $\left(2^{15}-1\right)$, são efetuados.

Pode-se observar pela descrição acima que a expressão do sinal transmitido no sistema CDMA IS-95 corresponde a dois termos análogos a (3.5) um com portadora em coseno e outro com portadora em seno.

No receptor, deve-se gerar uma réplica local da sequiência de chips sincronizada com a seqüência usada na transmissão. As portadoras também devem ser demoduladas de forma coerente ou não coerente. No enlace de subida do sistema I-95 é usada a demodulação não coerente. Neste caso, são utilizadas no receptor duas portadoras em quadratura na mesma frequiência das portadoras transmitidas, porém sem sincronismo de fase. Após a demodulação é realizado todo o processamento inverso ao realizado no transmissor.

\subsection{TDMA versus CDMA}


Serão discutidas a seguir algumas características dos sistemas digitais TDMA e CDMA que diferenciam bastante os dois sistemas e que são importantes neste trabalho.

\subsubsection{Capacidade}

Em um sistema TDMA um conjunto de canais - janelas de tempo/portadoras - é dividido entre as células de um cluster e estes mesmos canais são reutilizados em clusters adjacentes. Assim, uma vez definido o número de canais disponíveisv, o número de canais por célula será dado por $N / J$ onde $J$ é o número de células por cluster também conhecido como fator de reuso. Assim, quanto menor o fator de reuso maior será a capacidade de uma célula. Mas um fator de reuso pequeno significa que células utilizando os mesmos canais estarão a uma distância relativamente curta, o que poderá acarretar interferência além do limite aceitável. Assim, o fator de reuso é determinado em função de um compromisso entre capacidade e interferência, sendo afetado também por outros parâmetros de desempenho como potência do sinal transmitido, nível de ruído do receptor. Deve-se ressaltar que, uma vez estabelecido o fator de reuso, a capacidade fica bem determinada e não depende mais de eventuais variações destes parâmetros de desempenho.

Como ilustração vamos tomar uma faixa de referência igual a $1.25 \mathrm{MHz}$, o que eqüivale a 125 canais D-AMPS. Com um fator de reuso 7 teremos uma capacidade de aproximadamente 18 canais por célula.

Em um sistema CDMA, o fator de reuso é 1, ou seja, todos os canais disponíveis são inteiramente reutilizados em todas as células. Porém, o conceito de canal é bem distinto neste caso e está basicamente associado a um código. Na realidade o que é reutilizado é uma mesma faixa de freqüência. O número de canais disponíveis depende de forma dinâmica desta faixa e dos parâmetros de desempenho mencionados anteriormente . Este cálculo parte do objetivo de desempenho (taxa de erro) determinado para o sistema, o que pode ser associado a um determinado valor da razão $E_{b} / N_{0}$ (Energia por bit sobre Densidade Espectral de Potência de Ruído). A densidade espectral de potência de ruído corresponde à potência do ruído por unidade de faixa e pode ser calculada dividindese a potência do ruído total - incluindo o ruído 
propriamente dito e a interferência dos outros sinais - pela faixa da portadora CDMA. Em princípio, supondo M sinais de mesma potência na célula, temos

$$
N_{0}=\frac{(M-1) P_{s}+P_{n}}{W}
$$

Notando que a energia por bit é a razão entre a potência do sinal e a taxa de bits, podemos expressar $E_{b} / N_{0}$ como

$$
\frac{E_{b}}{N_{0}}=\frac{\frac{P_{s}}{R}}{\frac{(M-1) P_{s}+P_{n}}{W}}
$$

Em geral, a potência de ruído pode ser desprezada em presença da potência dos sinais interferentes. Além disto, aproximando M1 por M chega-se a

$$
M \cong \frac{(W / R)}{\left(E_{b} / N_{0}\right)}
$$

Tomando-se valores típicos do sistema CDMA IS-95, isto é, faixa de 1,25 MHz, W/R $=\mathrm{G}_{\mathrm{p}}=128$ e $E_{b} / N_{0}=5(7 \mathrm{~dB})$, obtemos aproximadamente 27 canais por célula. Na realidade este número é significativamente aumentado através das técnicas de ativação por voz e de setorização, podendo chegar, idealmente, a mais de 100. Por outro lado, a capacidade é reduzida pela interferência de sinais das células adjacentes. Incluindese estes elementos em (3.15 ) tem-se a seguinte expressão geral para a capacidade no sistema CDMA:

$$
M \cong \frac{(W / R)}{E_{b} / N_{0}} F \cdot G_{s}\left(\frac{1}{v}\right) F_{c p}
$$

onde $F<1$ é um fator que leva em conta a interferência de outras células, $G_{s}>1$ é o ganho de setorização, $v<1$ é o fator de melhoria devido ao uso de taxa variável em função da atividade de voz e $F_{c p}<1$ é um fator associado ao controle de potência imperfeito.

É importante ressaltar que, embora no sistema TDMA o número típico de canais por célula não seja tão inferior, os sinais que utilizam estes canais não interferem entre si pelo 
menos de forma significativa - enquanto todos os sinais da célula de um sistema CDMA ocupam a mesma faixa e têm aproximadamente a mesma potência no receptor. Este aspecto é de grande importância ao se analisar a utilização de antenas adaptativas nestes sistemas. A eficiência dos algoritmos de adaptação e formação de feixe das antenas adaptativas depende do número de sinais presentes e muitos deles são inviáveis em sistemas CDMA devido ao grande número de sinais interferentes. No sistema TDMA, os sinais interferentes são em geral provenientes de sinais utilizando o mesmo canal em uma célula distante.

\subsubsection{Multipercursos}

O canal de propagação em um sistema de comunicação celular é bastante complexo. Ele é geralmente caracterizado por múltiplos percursos de propagação do sinal- ou simplesmente multipercurso - do transmissor até o receptor. Sendo s(t) o sinal transmitido, o sinal recebido terá a seguinte expressão:

$r(t)=\sum_{i=0}^{L-1} a_{i}(t) s\left(t-\tau_{i}\right)$

onde L é o número de componentes de multipercurso, $a_{i}(t)$ é a atenuação e $\tau_{i}$ é o atraso relativo de cada componente. Assim, o canal pode ser caracterizado por uma resposta a impulso

$h(\tau, t)=\sum_{i=0}^{L-1} a_{i}(t) \delta\left(\tau-\tau_{i}\right) \quad$ e $\quad r(t)=\int_{-\infty}^{+\infty} h(t, \tau) s(t-\tau) d \tau$

O comportamento em presença de multipercursos é bem diferenciado nos sistemas TDMA e CDMA. Como se viu, o multipercurso gera várias réplicas do sinal transmitido com diferentes valores de atraso em relação a um sinal de referência. Considerando as durações típicas dos pulsos transmitidos no sistema TDMA e CDMA (aproximadamente 40 $\mu$ s no DAMPS e $1 \mu$ s no IS-95) e os valores típicos de atrasos verifica-se que no D-AMPS o atraso corresponde a uma fração do pulso e no IS-95 a um certo número de pulsos. Assim, no 
TDMA a interferência devida a multipercursos é altamente correlacionada ao sinal e é uma forma de interferência entre símbolos que pode ser reduzida através de um equalizador.

No sistema CDMA, além dos atrasos corresponderem a vários pulsos, as versões atrasadas sofrem expressiva redução devido ao processo de espalhamento e as propriedades dos códigos utilizados. Considere-se na entrada do correlacionador da Fig.3.6 um sinal espalhado $m(t) c(t)$ e sua versão atrasada $m(t-\tau) c(t-\tau)$. A saída correspondente a este sinal será

$u=\int_{T_{b}} m(t-\tau) c(t-\tau) c(t) d t$

Os códigos utilizados no IS-95 gerados a partir de seqüências de comprimento máximo são códigos quase ortogonais com a propriedade típica dos códigos cíclicos. Isto é, qualquer deslocamento no tempo de uma seqüência código leva a outra seqüência código. $\mathrm{O}$ que significa que qualquer deslocamento no tempo leva a uma seqüência ortogonal. Com isto o resultado de ( 3.15 ) apresenta o mesmo comportamento da interferência de outro usuário, ou seja, sua potência original é bastante reduzida. Isto explica a capacidade do sistema CDMA de reduzir o efeito dos multipercursos. 


\section{ARQUITETURAS, CRITÉRIOS E ALGORITMOS}

Nos capítulos anteriores foram apresentados os fundamentos das antenas adaptativas e do ambientes celular.

Com relação às antenas adaptativas foi desenvolvido o modelo da estrutura e a resposta do sistema que depende da combinação dos coeficientes $\{w\}$ como representado na figura 2.4. A determinação destes coeficientes é crucial para a operação eficiente do sistema de antenas adaptativas e como o ambiente é extremamente variável deve ser feita de forma adaptativa.

A seguir procuraremos desenvolver arquiteturas completas do sistema de antenas adaptativas incluindo o processamento para cálculo dos coeficientes. Estas estão ligadas ao critério de otimização adotado e ao tipo de sistema celular a que se aplicam.

\subsection{Classificação dos Algoritmos de Adaptação}

Conforme mencionado anteriormente, muitos dos algoritmos de antenas adaptativas atualmente utilizados derivaram dos algoritmos de equalização os quais foram posteriormente adaptados para se adequarem à nova tecnologia de processamento espacial.

Uma classificação ampla e geral dos algoritmos de antenas adaptativas que efetivamente servirão como base das aplicações e arquiteturas a serem apresentadas posteriormente neste capítulo é proposta em [ 73 ] e está representada na figura 4.1. Como se observa nesta figura, os algoritmos podem ser classificados em duas grandes categorias: algoritmos com sinal de treinamento e algoritmos cegos. Os primeiros procuram minimizar o erro médio quadrático entre o sinal desejado e o sinal recebido, sendo a referência fornecida pelo transmissor ou receptor (sistemas orientados pela decisão). Os algoritmos cegos utilizam propriedades intrínsecas aos sinais transmitidos para determinar sua operação. 


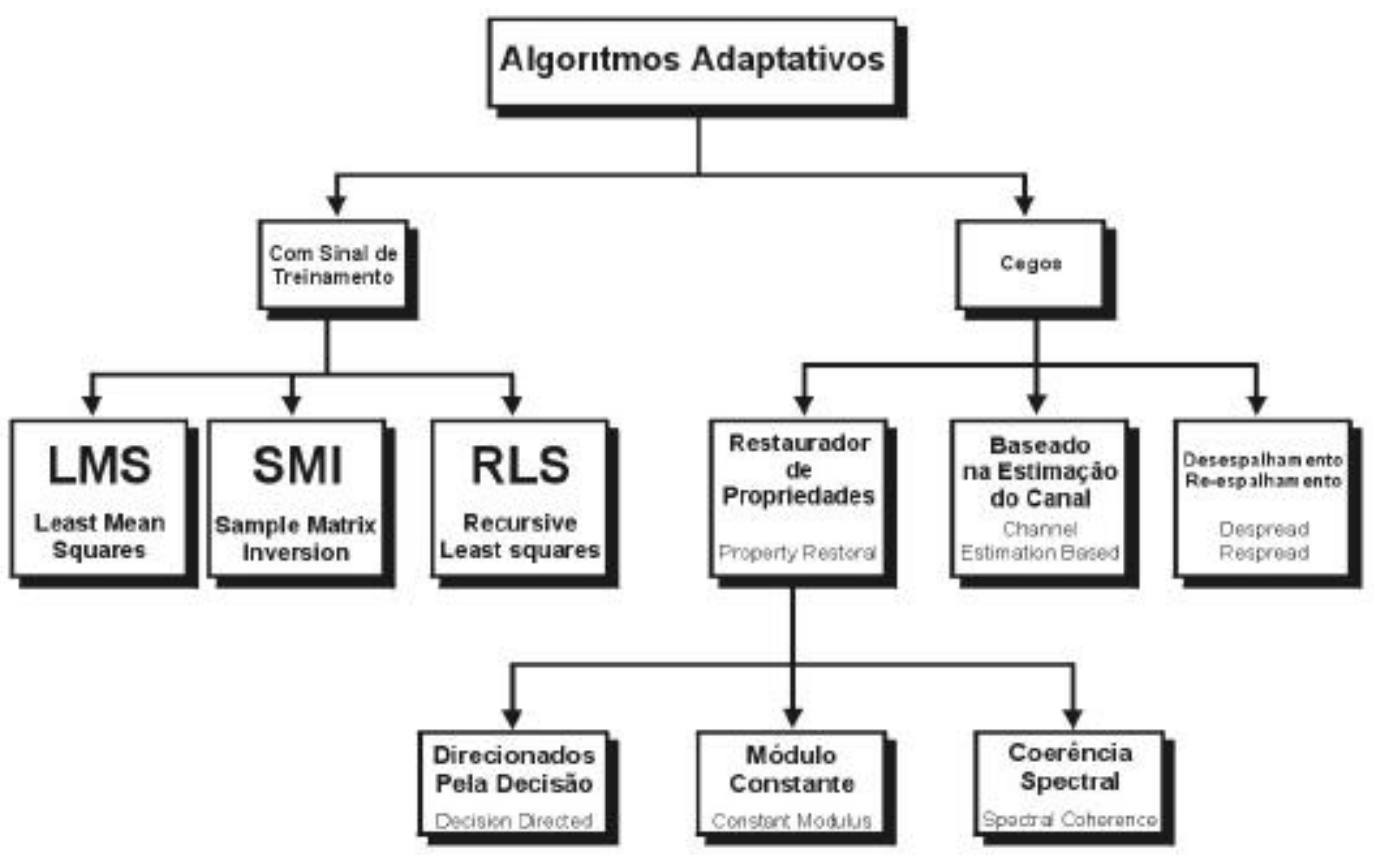

Fig. 4.1 - Classificação ampla dos algoritmos de antenas adaptativas 


\subsection{Algoritmos com Sinal de Treinamento}

A arquitetura básica para implementação dos algoritmos com sinal de treinamento está mostrada na figura 4.2 onde se observa a estrutura da matriz de antenas seguida do combinador. $\mathrm{O}$ critério de otimização básico destes algoritmos é a minimização do erro médio quadrático entre amostras do sinal colhidas na saída do demodulador e amostras do sinal de referência $\boldsymbol{d}_{i}$. Com base neste erro são ajustados os coeficientes $\left\{\mathrm{w}_{\mathrm{k}}\right\}$.

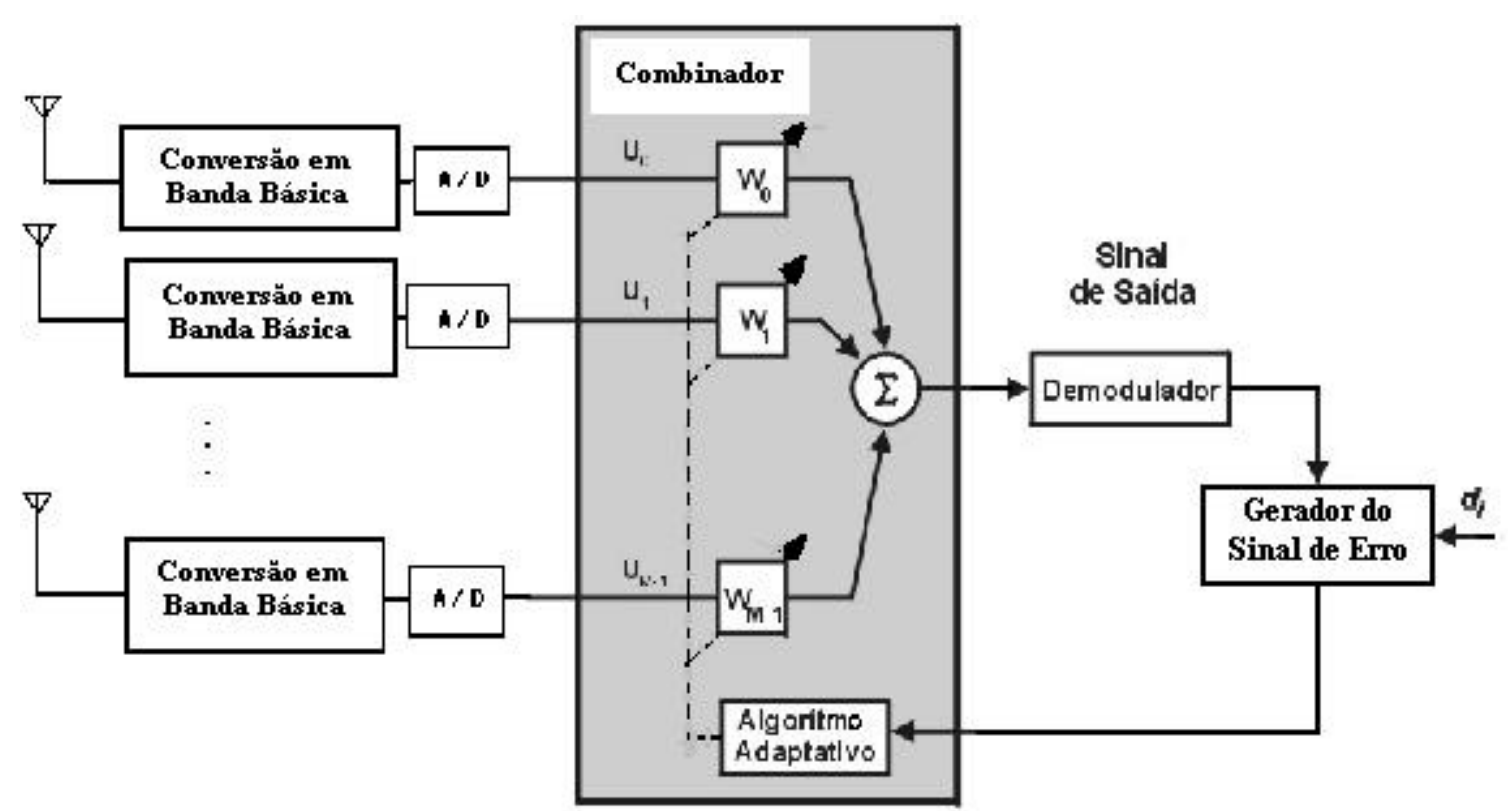

Fig. 4.2 - Estrutura de uma matriz de antenas adaptativa

Embora classificados na Fig. 4.1 como algoritmos cegos, os algoritmos direcionados pela decisão podem também ser vistos como algoritmos com sequiência de treinamento. A diferença é que o sinal de treinamento fornecido é obtido a partir da deteção. Uma vez que o sinal desejado é gerado localmente sem a exigência de um conhecimento prévio do dado transmitido, as sequiências de treinamento não serão então necessárias. Entretanto, quando ocorrerem erros no demodulador, a 
estimativa reconstruída do sinal desejado não será tão precisa fazendo com que os algoritmos adaptativos que se utilizem desta estimativa produzam ajustes incorretos nos coeficientes, degradando posteriormente a qualidade do sinal demodulado.

Uma associação que traz melhoria para tal problema é conseguida através de uma combinação entre as sequiências de treinamento e a técnica de direcionamento pela decisão. Neste caso, as seqüências de treinamento são utilizadas numa fase inicial do processo de adaptação permitindo assim que se forme um vetor de coeficientes que venha a reduzir o impacto causado pela interferência e pelo ruído. Após a fase de adaptação inicial, a técnica de direcionamento pela decisão é utilizada no rasteio de variações ocorridas no canal de rádio.

Diversos algoritmos iterativos podem ser estabelecidos para implementar o critério de minimização do erro médio quadrático de acordo com a estrutura e as definições aqui definidas. Os principais serão formulados a seguir em função de um vetor de coeficientes $\mathbf{w}(n)=\left[\begin{array}{c}w_{0}(n) \\ w_{1}(n) \\ : \\ w_{M-1}(n)\end{array}\right]$

de um vetor de dados

$$
\mathbf{u}(n)=\left[\begin{array}{c}
u_{0}(n) \\
u_{1}(n) \\
: \\
u_{M-1}(n)
\end{array}\right]
$$

e do erro $e(n)$ entre a referência $d(n)$ e o sinal processado pela matriz de antenas, onde $n$ representa a ordem da iteração.

Na descrição a seguir são apresentadas formulações para um filtro transversal. Deve-se relembrar que as mesmas se aplicam à matriz de antenas bastando observar que as derivações de um filtro transversal correspondem às saídas de cada elemento da antena. 


\subsubsection{O Algoritmo LMS}

O algoritmo Least-Mean Square, criado por Widrow e Hoff ( 1960 ), é um algoritmo simples também conhecido como algoritmo do gradiente estocástico. Ele pode ser visto como a forma recursiva de obter os valores dos coeficientes de um filtro transversal que minimizam o erro médio quadrático entre o valor do sinal desejado e seu valor na saída do filtro. A média neste caso é uma média estatística e o modelo supõe o conhecimento da matriz auto-correlação dos dados $\mathbf{R}_{\mathrm{u}}=$ $\mathbf{E}\left(\mathbf{u u}^{\mathbf{T}}\right)$ e do vetor correlação entre o erro e os dados $\mathbf{R}_{\mathbf{d u}}=\mathrm{E}(\mathbf{u d})$ Pode-se mostrar que a solução geral para o problema é obtida a partir da condição (erro ortogonal aos dados)

$\nabla \boldsymbol{\varepsilon}=2 E(\mathbf{u} e)=2 E\left[\mathbf{u}\left(\mathbf{u}^{T} \mathbf{w}-d\right)\right]=2\left[\mathbf{R}_{\mathbf{u}} \mathbf{w}-\mathbf{R}_{\mathbf{u d}}\right]=0$

A solução ótima para os coeficientes é dada então por

$$
\mathbf{W}_{\mathbf{o}}=\mathbf{R}_{\mathbf{u}}^{-1} \mathbf{R}_{\mathbf{u d}}
$$

A equação ( 4.4 ) sugere a utilização do algoritmo steepest descent que consiste na busca do mínimo de uma função através do gradiente. De acordo com ( 4.3 ), para implementação do algoritmo LMS é necessário determinar E(ue). Na prática, porém, utiliza-se o chamado algoritmo do gradiente estocástico onde o valor esperado é substituído por uma estimativa da correlação entre erros e dados na seguinte forma:

$$
\mathbf{w}(\mathbf{n}+\mathbf{1})=\mathbf{w}(\mathbf{n})+\mu e(n) \mathbf{u}(\mathbf{n})
$$

onde $\mu$ é uma constante de adaptação cujo valor influencia a convergência do algoritmo. 
Uma característica significativa do filtro do algoritmo LMS é a sua simplicidade que fazem dele um algoritmo padrão. Ele pode ser resumido da seguinte forma: (a) computação da saída do filtro espacial que é função do conjunto de coeficientes (b) geração do sinal de erro através da comparação da saída produzida pelo filtro com a resposta desejada (c) cálculo dos sinais de realimentação que são função do erro e dos sinais nos diversas ramos do combinador.

\subsubsection{O Algoritmo RLS}

O algoritmo RLS (Recursive Least Square) é, tal como o LMS, um algoritmo para obtenção de coeficientes ótimos de um filtro transversal que minimizam o erro médio quadrático entre o valor do sinal desejado e seu valor na saída do filtro. Porém, neste caso a média é uma média temporal definida sobre as amostras prévias do erro $e(n)$ e não uma média estatística definida sobre o espaço amostra da variável aleatória. Ou seja, o critério é a minimização de

$\varepsilon(n)=\sum_{i=1}^{n} \lambda^{-n-i}|e(i)|^{2}$

onde $\lambda$ é um fator de amortecimento.

A formulação básica do problema tem semelhança com a formulação anterior. Pode-se mostrar [ 4 ] que a solução ótima para os coeficientes é dada por

$$
\begin{gathered}
\mathbf{w}_{\mathbf{o}}(n)=\boldsymbol{\Phi}^{-1}(n) \mathbf{z}(n) \\
\text { onde } \\
\mathbf{\Phi}(n)=\sum_{i=1}^{n} \lambda^{n-i} \mathbf{u}(i) \mathbf{u}^{H}(i) \\
\mathrm{e} \\
\mathbf{z}(n)=\sum_{i=1}^{n} \lambda^{n-i} \mathbf{u}(i) d^{*}(i)
\end{gathered}
$$


O exame da expressão mostra que a implementação desta solução exige a inversão da matriz $\boldsymbol{\Phi}(\mathrm{n})$ que é representada a seguir através da matriz $\mathbf{P ( n )}$. O algoritmo RLS consiste em uma forma recursiva de calcular esta matriz inversa. $\mathrm{O}$ algoritmo pode ser resumido através das seguintes equações

$$
\begin{aligned}
& \mathbf{w}(n)=\mathbf{w}(n-1)+\mathbf{k}(n) \xi^{*}(n) \\
& \mathbf{k}(n)=\frac{\lambda^{-1} \mathbf{P}(n-1) \mathbf{u}(n)}{1+\lambda^{-1} \mathbf{u}^{H}(n) \mathbf{P}(n-1) \mathbf{u}(n)} \\
& \xi(n)=d(n)-\mathbf{w}^{H}(n-1) \mathbf{u}(n)
\end{aligned}
$$

Como mostrado em [ 4 ] o algoritmo RLS em todas as suas formas tem ampla equivalência com o filtro de Kalman. De uma forma ou de outra estes algoritmos se caracterizam por grande rapidez de convergência e grande complexidade computacional quando comparado ao algoritmo LMS. Além disto, uma outra característica importante é a instabilidade numérica. Estas duas limitações do algoritmo RLS motivaram o desenvolvimento de outras categorias do algoritmo como o "Squared-Root RLS Algorithm" e o "Fast RLS Algorithm." [ 4 ].

\subsection{Algoritmos Cegos}

Levando-se em conta que o sinal de referência nem sempre estará disponível de forma exata, o que consequentemente redundará em sua obtenção de forma imperfeita através de algum tipo de estimação, surge então, como alternativa para contornar a dificuldade de obtenção deste sinal, uma classe bastante ampla de métodos de filtragem adaptativa conhecida como filtragem cega, ou o algoritmo cego. Sua origem tem sido creditada a Godard [ 1 ] no contexto de equalização de sinais para transmissão digital. O problema básico na equalização cega é determinar os parâmetros do filtro adaptativo sem o sinal de referência. Entretanto, algum tipo de informação sobre este sinal será necessária. Com relação ao trabalho de Godard e outros, esta informação está relacionada a propriedades do sinal digital. De acordo com a modulação digital empregada, o sinal digital apresenta certas propriedades que independem dos bits transmitidos. Em um sinal PSK-4, por 
exemplo, o momento de quarta ordem, independe da fase transmitida. Uma outra propriedade observada por algumas modulações é o módulo constante do sinal transmitido, como no caso dos sinais com modulação de fase e frequiência. A utilização desta restrição tem sido usada em diversos trabalhos com propostas de algoritmo para aplicação à comunicação celular [ 2 ] [ 3 ].

Na classificação geral dos algoritmos aplicados à antenas adaptativas apresentado na figura 4.1, o conceito de algoritmos cego é estendido, incluindo além dos restauradores de propriedades que se enquadram no conceito básico descrito no parágrafo anterior - os algoritmos baseados na estimação do canal e os de desespalhamento-re-espalhamento (despread - respread).

Os algoritmos restauradores de propriedades podem ser subdivididos em algoritmos de módulo constante e algoritmos de restauração de auto coerência espectral ( Spectral selfCoherence Restoral - SCORE ). Podem também ser considerados também na categoria de restauradores de propriedades os direcionados pela decisão (decision directed - DD) cuja formulação, contudo é a mesma usada nos algoritmos com seqüência de treinamento.

Os algoritmos de módulo constante [ 13 ] [ 14 ], são aplicáveis à sinais de módulo constante e tentarão manter constante a magnitude do sinal na saída da matriz de antenas preservando ao mesmo tempo a fase dos sinais incidentes em sua entrada. A única desvantagem na utilização de um algoritmo de módulo constante deve-se ao fato deste ser deficiente na utilização da propriedade de seletividade do sinal, isto é, o algoritmo sempre tenderá a capturar o sinal de maior potência, não conseguindo distinguir um sinal de módulo constante de outro.

Os algoritmos de restauração da auto-coerência espectral utilizam as propriedades de cicloestacionariedade encontradas na maioria dos sinais digitais e analógicos. Exemplos de aplicações desta classe de algoritmo podem ser encontradas em [ 18 ] e [ 19 ]. A ciclo-estacionariedade é definida como uma periodicidade intrínseca que se expressa nas médias do processo. Ou seja, um processo é ciclo-estacionário se sua média e sua autocorrelação são periódicas. Neste caso ocorre uma redundância espectral ou seja, correlação entre componentes de freqüência .

Uma característica fundamental da técnica de restauração da auto coerência espectral ( SCORE ) que explora as propriedades de ciclo-estacionariedade encontradas nos sinais aplicados 
em comunicações, é o fato desta também ser utilizada no desenvolvimento de uma outra importante classe de algoritmos baseada na estimação de parâmetros de múltiplas frentes de ondas que chegam a uma matriz de antenas, e que será visto posteriormente na próxima seção nos algoritmos de alta resolução.

Ainda dentro da classe dos algoritmos cegos, os algoritmo baseados na estimação do canal $[22,23,24,25]$ utilizam o conhecimento de certas propriedades especiais dos códigos dos sinais espalhados (spread spectrum signals) a fim de obter-se estimativas dos parâmetros do canal. Neste tipo de técnica primeiro estima-se os parâmetros do canal utilizando-se em seguida estas estimativas para a formação dos feixes na direções dos sinais desejados. Estas técnicas são aplicáveis somente em sinais CDMA.

Finalmente, consideraremos a classe de algoritmos cegos caracterizados pelo seu tipo de funcionamento, onde o sinal é desespalhado utilizando para tal uma versão do código gerada localmente, sendo em seguida re-espalhado novamente. Também conhecida como a técnica de desespalhamento e re-espalhamento (despread-respread techniques) para os sinais CDMA, estes algoritmos fazem parte de um conjunto de técnicas de modulação e demodulação (demod-remod techniques) existentes, e bastante difundida para a rejeição de interferência de FM.

Teoricamente, a técnica de desespalhamento e re-espalhamento parte do princípio da decodificação (desespalhamento) do sinal presente na saída do iésimo usuário, realizando em seguida o processo de decisão binária. Desta forma, o código PN do i-ésimo usuário $C_{i}$ reespalhará ( ou codificará) os dados novamente, o que produzirá um erro a ser obtido entre estes dados re-espalhados e os dados presentes na saída na matriz de antenas. Cabe aqui ressaltar que o processo de minimização poderá tanto utilizar o critério de mínimos quadrados ( least-square approach ) assim como o 'steepest descent'. A premissa onde se apoia o processo adaptativo de desespalhamento e re-espalhamento leva em conta que o desespalhamento por necessitar de sincronização já estará presente antes que o processo de filtragem espacial tenha ocorrido. 


\subsubsection{Algoritmos de Estimação do Ângulo de Chegada}

Historicamente, as primeiras formas de antenas adaptativas foram desenvolvidas a partir de critérios de otimização definidos diretamente sobre o diagrama das antenas e que resultam em alguma forma de estimação do ângulo de chegada dos sinais. Hoje existe uma grande variedade de técnicas que permite o ajuste dos coeficientes da matriz de antenas a partir da estimação do ângulo de chegada de sinais. Estas técnicas são resumidas a seguir.

\subsubsection{Técnicas Convencionais}

Denominamos técnicas convencionais um conjunto de técnicas utilizadas antes dos métodos baseados nas propriedades dos sub-espaços. Basicamente incluímos aqui as técnicas de atraso e soma, de direcionamento de nulos e de otimização de razão sinal-ruído.

\section{Método Atraso-Soma}

No método atraso-soma, procura-se maximizar a potência do sinal desejado na saída do combinador. Esta será maximizada quando o vetor de coeficientes “ $w$ ” for tal que este venha alinhar as fases das componentes do sinal desejado incidente nos elementos da antena, fazendo com que estas se somem construtivamente. Observando a definição do vetor de coeficientes em (4.1) verifica-se que os valores dos coeficientes são dados pelo vetor de direção na direção do sinal desejado, isto é

$$
\mathbf{w}=\mathbf{a}(\phi)
$$

\section{Método do direcionamento de nulos}

No capítulo 2 obtivemos a seguinte expressão geral para o sinal na saída do combinador do arranjo de antenas 
$z(t)=s(t) \boldsymbol{w}^{H} \boldsymbol{a}(\phi)=s(t) f(\phi)$

em função dos vetores de coeficientes $\mathbf{W}$ e do "array manifold" $\mathbf{a}(\phi)$. Esta expressão pode ser usada para definir valores desejados para $\mathrm{f}(\phi)$ em determinadas direções. Obtém-se assim um sistema de equações com M incógnitas - os coeficientes do arranjo de antenas. Em particular podese determinar um conjunto de coeficientes que correspondam a colocação de nulos de radiação em até M direções.

\section{Otimização da razão sinal-ruído}

Enquanto nos métodos anteriores os coeficientes são obtidos para atender a uma condição sobre o sinal desejado, nas técnicas a seguir, é feita uma otimização da razão sinal-ruído. Na realidade esta otimização pode ser obtida através de duas formulações diferentes que levam aos mesmos valores para os coeficientes e consequentemente para a razão sinal-ruído.

Maximização da Razão Sinal-ruído na direção do sinal desejado

Usando-se multiplicadores de Lagrange, pode-se calcular o vetor de coeficientes $\mathbf{w}$ que maximiza a expressão da razão sinal-ruído dada por (2.13). Obtém-se a seguinte expressão

$$
\mathbf{w}=\frac{\mathbf{R}_{n n}^{-1} \mathbf{a}(\phi)}{\mathbf{a}^{H}(\phi) \mathbf{R}_{n n}^{-1} \mathbf{a}(\phi)}
$$

A razão sinal-ruído correspondente será dada por

$$
R S R=\sigma_{s}^{2} \mathbf{a}^{H}(\phi) \mathbf{R}_{n n}^{-1} \mathbf{a}(\phi)
$$

Minimização da variância do ruído condicionada a um valor determinado na direção do sinal desejado 
Este método é também conhecido como o método da variância mínima de Capon 26 ]. Os coeficientes ótimos w são a solução do seguinte problema de minimização

$$
\min _{w} E\left[|y(k)|^{2}\right]=\min _{w} w^{H} R_{u u} w \quad \text { onde } \quad w^{H} a\left(\phi_{0}\right)=1
$$

O vetor de coeficientes obtido através da solução da expressão (4.17) é freqüentemente chamado de coeficientes do combinador de resposta de variância mínima sem distorção, uma vez que para uma determinada direção de interesse, este minimizará a variância ( potência média) do sinal de saída, permitindo enquanto isto passar sem distorção （ ganho unitário e deslocamento de fase nulo ) o sinal que chega sob esta mesma direção.

Utilizando-se o método dos multiplicadores de Lagrange [ 4 ] torna-se possível resolvermos o problema de otimização forçada representado pela expressão (4.17) que é automaticamente convertido num problema similar porém sem restrições. Tal fato permitirá a aplicação do critério dos mínimos quadrados ( least-square techniques ) para a determinação de uma solução ótima para $w$. O vetor de coeficientes ótimos que determinará a solução da expressão (4.17) será definido por:

$$
w=\frac{\boldsymbol{R}_{u u^{-1}} a(\phi)}{a^{H}(\phi) R_{u u}^{-1} a(\phi)}
$$

Pode-se mostrar em [ 70 ] e [ 71 ] que as duas formulações sintetizadas em (4.17) e (4.18) levam aos mesmos valores dos coeficientes e consequentemente da razão sinal-ruído na direção do sinal desejado. E no caso particular de um único sinal em presença de ruído observa-se que a solução otimizada corresponde também a técnica atraso-soma. Porém, em presença de sinais interferentes os dois últimos métodos são bem mais eficientes do que o método atraso-soma. Resultados de simulações em [ 66 ] mostram que, para uma matriz de antenas linear de 6 elementos com espaçamentos entre si equivalentes a metade do comprimento de onda incidente, o método de 
Capon será capaz de distinguir dois sinais distintos incidindo sob ângulos de $90^{\circ}$ e $100^{\circ}$, respectivamente. Tal fato já não ocorrerá para o método do atraso e soma, que ao contrário falhará na tentativa de identificar (ou diferenciar) estes sinais.

Portanto apesar do método de Capon fornecer uma resolução superior à obtida pelo método do atraso e soma, o primeiro também apresentará algumas desvantagens em relação ao segundo, como por exemplo, vir a falhar no caso de outros sinais que são correlacionados com o sinal de interesse estarem presentes. Isto ocorrerá porque o método de Capon inadvertidamente utilizará esta correlação para reduzir a potência na saída do processador sem a colocação de nulos na direções dos sinais interferentes. Em outras palavras, as componentes correlacionadas poderiam ser combinadas destrutivamente durante o processo de minimização da potência de saída. Além disto, o método de Capon exigirá a realização do processo de inversão de matriz, o que poderá tornar extremamente onerosa sua aplicação em matrizes de antenas com muitos elementos ${ }^{1}$.

\footnotetext{
${ }^{1}$ A inversão de matrizes torna-se extremamente lenta a medida que o número de elementos da matriz de antenas aumenta. Tal fato exigiria soluções tais como " matrix inversion lemma, o que redundaria num inevitável aumento da carga computacional inviabilizando assim sua aplicação.
}

\subsubsection{Métodos de Sub-Espaços}


Apesar dos métodos clássicos apresentados anteriormente serem eficientes e bem difundidos, estes apresentam de uma forma geral limitações básicas em relação a sua resolução. A maior parte destas limitações surgem em função destes não explorarem a estrutura do espaço vetorial definido pelos sinais de entrada e seu processamento na matriz de antenas.

\subsubsection{O Algoritmo MUSIC}

O algoritmo denominado MUSIC ( Music Signal Classification) proposto por Schmidt em 1979 é resumido a seguir. Considerando D sinais na entrada da matriz de antenas pode-se escrever

$$
\mathbf{u}(t)=\sum_{l=0}^{D-1} \mathbf{a}\left(\phi_{l}\right) \mathbf{s}_{l}(t)+\mathbf{n}(t)=\mathbf{A s}(t)+\mathbf{n}(t)
$$

onde, $\quad \mathbf{s}^{\mathrm{T}}(t)=\left[s_{0}(t), s_{1}(t) \ldots \mathrm{s}_{M-l}(t)\right]$ é o vetor dos sinais incidentes, $\mathbf{n}(t)=\left[n_{0}(t), n_{l}(t), \ldots n_{M-}\right.$ ${ }_{l}(t)$ ] é o vetor de ruídos, e $\mathbf{a}\left(\phi_{\mathrm{j}}\right)$ é o vetor de direcionamento da matriz de antenas correspondendo ao angulo de chegada do $j$-ésimo sinal. Supondo que $\mathbf{s}(t)$ tem média nula, a matriz covariância $\mathbf{R}_{\mathbf{u}}$ é dada por:

$$
\mathbf{R}_{u}=E\left[\mathbf{u}(t) \mathbf{u}^{H}(t)\right]=\mathbf{A} \mathbf{R}_{s} \mathbf{A}^{H}+\mathbf{K}_{n}
$$

onde $\mathbf{R}_{s}=E\left\lfloor\mathbf{s}(t) \mathbf{s}^{H}(t)\right\rfloor, \mathbf{K}_{n}=\sigma_{n}^{2} \mathbf{I}$ e $\mathbf{I}$ é a matriz identidade $\boldsymbol{\sigma}_{n}^{2}$ é a variância das componentes do ruído e o índice $\mathrm{H}$ representa a matriz transposta conjugada.

Pode-se verificar que a matriz covariância espacial $\mathbf{R}_{\mathbf{u}}$ é uma matriz Hermitiana de ordem $M$. Assim os seus autovalores são reais e seus autovetores distintos. Prova-se [1] que se $D \leq M$ é o posto de $R_{s}$ então os autovalores $\lambda_{1}, \lambda_{2}, \cdots, \lambda_{M}$ de $\boldsymbol{R}_{\boldsymbol{u}}$ podem ser ordenados da seguinte forma: 


$$
\lambda_{0} \geq \lambda_{1} \geq \cdots \geq \lambda_{D-1}>\lambda_{D}=\lambda_{D+1}=\cdots=\lambda_{M-1}=\sigma_{n}^{2}
$$

Pode-se mostrar que os autovetores associados aos $M-D$ menores autovalores são ortogonais aos $D$ vetores de direcionamento que compõem a matriz $A$, ou seja

$$
\left\{a\left(\phi_{0}\right), \ldots, a\left(\phi_{D-1}\right)\right\} \Perp\left\{\lambda_{D}, \ldots, \lambda_{M-1}\right\}
$$

Esta é a característica essencial do algoritmo MUSIC. Isto significa que é possível estimar os vetores de direcionamento associados com os sinais recebidos encontrando-se aqueles vetores de direcionamento que estejam mais ortogonais em relação aos autovetores associados com os autovalores de $\mathbf{R}_{u}$ que são aproximadamente iguais à $\sigma_{\mathrm{n}}{ }^{2}$. Em resumo, os vetores de direcionamento correspondentes ao angulo de chegada estão no mesmo plano do sub-espaço do sinal, e portanto são ortogonais ao sub-espaço do ruído. Com isso, fazendo uma procura através de todos os possíveis vetores de direcionamento da matriz de antenas a fim de encontrar aqueles que sejam perpendiculares ao plano onde estão contidos os autovetores não principais ( sub-espaço do ruído), seremos capazes de determinar os ângulos de chegada $\phi_{i}$.

Para efetuar a procura do sub-espaço do ruído, formamos uma matriz contendo os autovetores do ruído definida por:

$$
\mathbf{V}_{n}=\left[\lambda_{D}, \ldots, \lambda_{M-1}\right]
$$

Uma vez que os vetores de direcionamento correspondentes as componentes do sinal são ortogonais aos autovetores do sub-espaço do ruído vamos ter que:

$$
\mathbf{a}^{H}(\phi) \mathbf{V}_{n} \mathbf{V}_{n}^{H} \mathbf{a}(\phi)=0
$$


Com isso, os ângulos de chegada de múltiplos sinais incidentes podem ser estimados através da localização dos picos de um espectro espacial do algoritmo MUSIC definidos pelas expressões:

$$
\boldsymbol{P}_{\operatorname{MUSIC}}(\phi)=\frac{1}{\boldsymbol{a}^{H}(\phi) V_{n} V_{n}^{H} a(\phi)}
$$

\subsubsection{O Algoritmo ESPRIT}

Este método também faz parte da classe de métodos de Sub-espaços pertencente a mesma categoria do método MUSIC apresentado na seção anterior. Definido como técnicas de estimação de parâmetros de sinais via invariância rotacional, (Estimation of Signal Parameters via Rotational Invariance Techniques), o algoritmo ESPRIT permite reduzir substancialmente a carga computacional e os níveis de armazenamento exigidos pelo algoritmo MUSIC, além de não necessitar executar uma constante procura através de todos os possíveis vetores de direcionamento de forma a torná-lo capaz de estimar o ângulo de chegada. Note-se que, de forma contrária ao algoritmo MUSIC, o algoritmo ESPRIT não exigirá que os vetores coletores da matriz de antenas (array manifold vectors) sejam conhecidos de forma precisa, diminuindo portanto os requisitos da calibragem da matriz.

O método ESPRIT usa uma técnica em que o arranjo de antenas é particionado em dois arranjos de antenas idênticos, de forma que seus elementos devem formar pares casados, com a seguinte propriedade: os elementos do segundo arranjo devem estar à mesma distância do elemento do primeiro e na mesma direção relativa.

O primeiro passo do método é a estimação dos autovalores e dos autovetores das matrizes autocorrelação correspondentes às amostras colhidas por cada um dos arranjos. Em 
seguida, com os autovetores associados aos maiores autovalores, são definidas novas matrizes cujos autovalores são usados para estimar os ângulos de chegada [71].

Outras variações do algoritmo ESPRIT incluem o beam-space ESPRIT [ 29 ], beamspace ESPRIT para uma matriz de antenas retangular [ 30 ], resolution-enhanced ESPRIT [31], virtual interpolated array ESPRIT [ 32 ], multiple invariance ESPRIT [ 33 ], higher order ESPRIT [ 34 ], e finalmente o procrustes rotation-based ESPRIT [ 35 ].

\subsubsection{O Algoritmo WSF}

O método WSF ( Weighted Subspace Fitting) que também é considerado ser uma unificação dos algoritmos MUSIC, ESPRIT e do método da máxima verossimilhança, pode ser basicamente definido através da expressão a seguir [71].

$\underset{\hat{\boldsymbol{\theta}}}{=} \max _{\underline{\boldsymbol{\theta}}}^{-1} \operatorname{traço}\left(\underline{P}_{A} \underline{\hat{U}}_{s} \underline{B}_{\hat{U}}^{H}\right) \quad \underline{B}=\underline{\boldsymbol{\Lambda}}^{2} \underline{\boldsymbol{\Lambda}}_{s}^{-1} ; \underline{\boldsymbol{\Lambda}}_{s}=\operatorname{diag}\left(\hat{\boldsymbol{\lambda}}_{1}, \ldots \hat{\lambda}_{D}\right) ; \underline{\boldsymbol{\Lambda}}=\underline{\boldsymbol{\Lambda}}_{s}-\hat{\boldsymbol{\sigma}}_{w}^{2} \underline{I}$

\subsubsection{Método da Máxima Verossimilhança}

O método da máxima verossimilhança foi um dos primeiros métodos a ser investigado dentro das técnicas existentes de estimação do angulo de chegada. Devido ao método ter uma carga computacional intensa, este era menos popular do que as técnicas de subespaço parcialmente ótimas. Entretanto, em termos de desempenho, o método de máxima verossimilhança é superior aos métodos baseados no subespaço, especialmente quando relação sinal ruído é baixa ou quando o número de amostras do sinal é pequeno. Além disto, de modo diferente aos métodos baseados no subespaço, o método da máxima verosimilhança apresentará também uma boa performance na presença de sinais correlacionados. 
Com relação as suas principais características, o método da máxima verossimilhança estima o angulo de chegada de um determinado conjunto de amostras de uma matriz de antenas fazendo a maximização de uma função logarítmica de verossimilhança (log-likelihood function).

A função $\log$ de verossimilhança é uma função densidade de probabilidade dos dados amostrados tendo sido fornecido os ângulos de chegada, e também é vista como uma função das variáveis desejadas ( neste caso os ângulos de chegada ). O método busca por aquelas direções (ou ângulos de chegada) as quais venham a maximizar o logaritmo desta função ( a função log de verossimilhança). O critério de máxima verossimilhança sugere que ondas planas provenientes destas direções provavelmente causarão a ocorrência das amostras fornecidas [36].

A maximização da função log de verossimilhança é um problema de otimização não linear. $\mathrm{Na}$ ausência de uma solução fechada, soluções através de métodos interativos serão necessários, podendo estes serem encontrados na literatura.

O método da máxima verossimilhança tem uma performance superior comparada a outros métodos, especificamente quando a relação sinal ruído é pequena, o número de amostras é pequeno, ou as fontes são correlacionadas [37], e por isso é de interesse prático. Para uma única fonte, as estimativas obtidas através deste método são assintóticamente despolarizadas [38], isto é, os valores esperados das estimativas são iguais aos seus valores verdadeiros. Neste sentido, este método poderá ser utilizado como um padrão para se comparar a performance de outros métodos. O método normalmente assume que o número de fontes $M$ são conhecidas [ 37 ].

Quando existe uma disponibilidade de um grande número de amostras, outros métodos computáveis e mais eficientes poderão ser utilizados com uma performance quase gual e deste método [ 39 ]. Análises do método para estimar as direções das fontes quando existe um movimento relativo entre a matriz de antenas e a fonte um movimento indicam seu potencial para as comunicações móveis [ 40 ], [ 41 ]. 


\section{ANTENAS ADAPTATIVAS EM SISTEMAS CDMA}

Após apresentarmos os fundamentos das antenas adaptativas e das interfaces rádio dos sistemas celulares, onde é empregada esta tecnologia, serão abordadas neste capítulo aplicações específicas a sistemas CDMA. Estas aplicações são, obviamente, influenciadas pelas características do sistema CDMA. Sabe-se, por exemplo, que sistemas de formação de feixe a partir de estimação de ângulo de chegada têm seu emprego limitado pelo número relativamente grande de sinais presentes em uma célula de um sistema CDMA. Por outro lado, processadores típicos do sistema CDMA, como o receptor Rake, podem ser devidamente combinados com os algoritmos de adaptação, no sentido de se obter um desempenho melhor. Os tópicos mencionados acima serão abordados ao longo deste capítulo

\subsection{Modelagem básica}

Devido às limitações de tamanho e processamento do receptor móvel, as antenas adaptativas são soluções para serem implementadas tipicamente nas Estações Radio Bases. Neste caso, é possível se usar uma antena adaptativa de transmissão ou de recepção.

A arquitetura típica de um sistema de antenas adaptativas na transmissão está representado na figura (5.1) onde poderemos verificar que cada sinal transmitido terá seu próprio vetor de coeficientes $w_{k}$. 


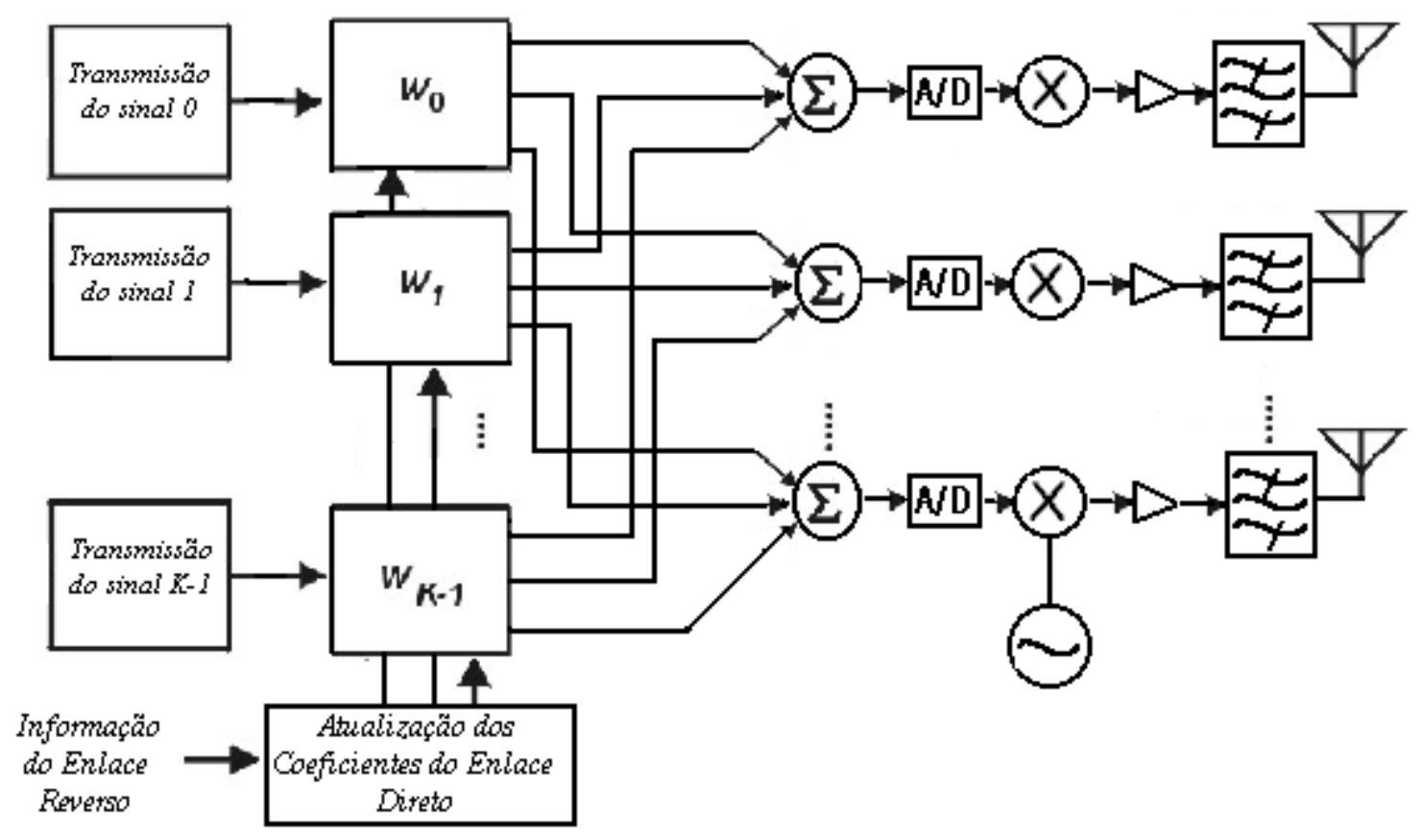

Fig.5.1 - Sistema de filtragem espacial do enlace direto capaz de formar $K$ feixes simultâneos

Em princípio, a implementação de uma antena adaptativa transmissora é mais difícil pela maior dificuldade de usar a informação sobre o canal. $\mathrm{Na}$ antena receptora esta informação pode ser estimada pois está presente no sinal recebido. Já uma antena transmissora deverá usar a informação repassada pelo receptor do enlace de descida. Abordaremos neste trabalho apenas a implementação de antenas receptoras

\subsubsection{Sinal transmitido no enlace reverso}

De acordo com o modelo e a nomenclatura introduzidos no Capítulo 3, considerando um conjunto de m sinais em uma célula e modulação PSK binária, podemos expressar a versão em banda básica do sinal transmitido pelo usuário $i$ no enlace de subida de um sistema CDMA da seguinte forma

$s_{i}(t)=m_{i}(t) c_{i}(t) e^{j \theta_{i}}$ 
onde $\theta_{i}$ é a fase da portadora do sinal transmitido pelo usuário $i$ e $\mathrm{m}_{\mathrm{i}}(t)$ é um trem de pulsos modulados por uma seqüência de amplitudes $\left\{b_{i, j}\right\}$ associadas aos bits do $i$-ésimo usuário , isto é,

$m_{i}(t)=\sum_{j=-\infty}^{\infty} b_{i, j} g\left(t-j T_{b}\right) ;$

sendo $g(t)$ um pulso retangular unitário de duração $T_{b} ; c_{i}(t)$ é o sinal de espalhamento, constituído por um trem de pulsos modulados por uma seqüência de amplitudes $\left\{c_{i, j}\right\}$ associadas ao código do usuário $i$, ou seja,

$c_{i}(t)=\sum_{j=-\infty}^{\infty} c_{i, j} p\left(t-j T_{c}\right)$

sendo $p(t)$ um pulso retangular unitário de duração $T_{\mathrm{c}}<<T_{b}$;

\subsubsection{Canal}

O canal de propagação em um sistema de comunicação celular é bastante complexo, caracterizado por multipercursos devidos a espalhamento, reflexão e difração sofridos pelo sinal. Estes efeitos resultam em um canal variante no tempo representado por uma resposta impulsional (equivalente complexa)

$h(\tau, t)=\sum_{l=0}^{L-1} \alpha_{l}(t) \delta\left(\tau-\tau_{l}\right)$

onde $\alpha_{l}(\cdot), \tau_{l}$ representam, respectivamente, a amplitude complexa e o retardo médio de percurso. A amplitude complexa da $l$-ésima componente pode de ser expressa como:

$\alpha_{l}(t)=\rho_{l} e^{j\left(2 \pi f_{l} t+\psi_{l}\right)}$

onde, $\rho_{l}$ representa o ganho de percurso, $f_{l}$ é a variação de freqüência devido ao efeito Doppler e $\Psi_{l}$ é um deslocamento de fase fixo. 
A expressão geral do sinal recebido, correspondente ao usuário $i$ será dada então por

$r_{i}(t)=\int_{-\infty}^{\infty} s_{i}(t-\tau) h_{i}(\tau, t) d \tau=\sum_{l=0}^{L-1} \alpha_{l, i}(t) s_{i}\left(t-\tau_{l, i}\right)$

Geralmente, todas os parâmetros da resposta impulsional do canal podem variar com o tempo, com o posicionamento do usuário, e finalmente com a velocidade do usuário. À medida que o usuário desloca-se dentro de uma área pequena e próxima (equivalente à alguns comprimentos de onda), assume-se que o número total de componentes de multipercursos, $L$, é fixo, e, para cada uma destas componentes, o ganho de percurso $\rho_{l}$, a variação de freqüência devida ao efeito Doppler $f_{l}$, a fase deslocada $\Psi_{l}$, e o retardo médio de percurso $\tau_{l}$, serão também considerados aproximadamente constantes.

Em canais onde as diferenças entre os retardos médios das componentes de multipercursos são muito pequenas comparadas com o intervalo de símbolo do sinal $s(t)$, também conhecidos como canais de faixa estreita, faz-se a aproximação $\tau_{l}=\tau_{0}$. Com isto, o sinal que chega ao receptor pode ser escrito como

$$
r(t)=s\left(t-\tau_{0}\right) \sum_{l=0}^{L-1} \alpha_{l}(t)
$$

e neste caso o desvanecimento é plano. Caso contrário, tem-se o desvanecimento seletivo.

\subsubsection{Receptor}

A forma básica do receptor do usuário $i$ de um sistema CDMA está mostrada na Fig. 5.2 onde a entrada é a envoltória complexa do sinal recebido ${ }^{2}$ adicionada de ruído, $\tau$ é o atraso estimado pelo receptor e $t_{0}$ é o ajuste do intervalo de integração.

\footnotetext{
${ }^{2}$ Para levar em conta a demodulação coerente, a fase da portadora, estimada pelo receptor coerente, deverá ser subtraída da fase da envoltória complexa do sinal modulado. A envoltória $\mathrm{r}(\mathrm{t})$ já inclui esta operação
} 


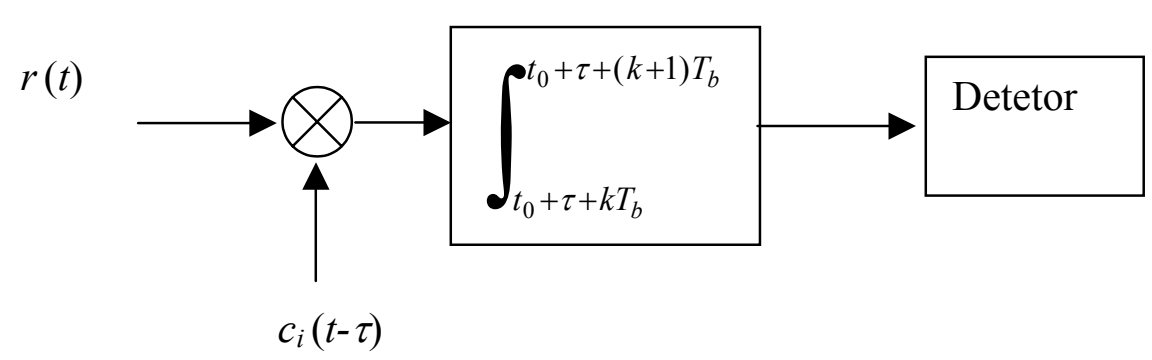

Fig. 5.2 - Receptor do usuário i em um sistema CDMA

Obviamente, para operação adequada deste esquema, diversos processamentos específicos devem ser realizados, em especial os processamentos de sincronismo da seqüência código e da portadora. Demoduladores não coerentes evitam o sincronismo de portadora às custas de degradação moderada no desempenho

Como será visto mais a frente, o receptor do enlace de subida do sistema IS-95 difere destes esquemas em dois aspectos principais: a demodulação é não coerente e a modulação é uma modulação PSK quaternária que pode ser vista como duas modulações PSK binárias em quadratura transmitindo a mesma informação com códigos diferentes. Em última análise o processo é uma forma de transmissão em diversidade.

\section{Receptor Rake}

Na Fig.5.3 está mostrado um esquema mais elaborado, incluindo um receptor Rake com 3 ramos $^{3}$. Como explicado no capítulo 3, os atrasos $\left\{\tau_{l}\right\}$ devem ser obtidos através de um processamento específico.

\footnotetext{
${ }^{3} \mathrm{Na}$ figura omite-se, por simplicidade, o índice $k$ nas integrais, correspondentes a sucessivas deteções de bits
} 


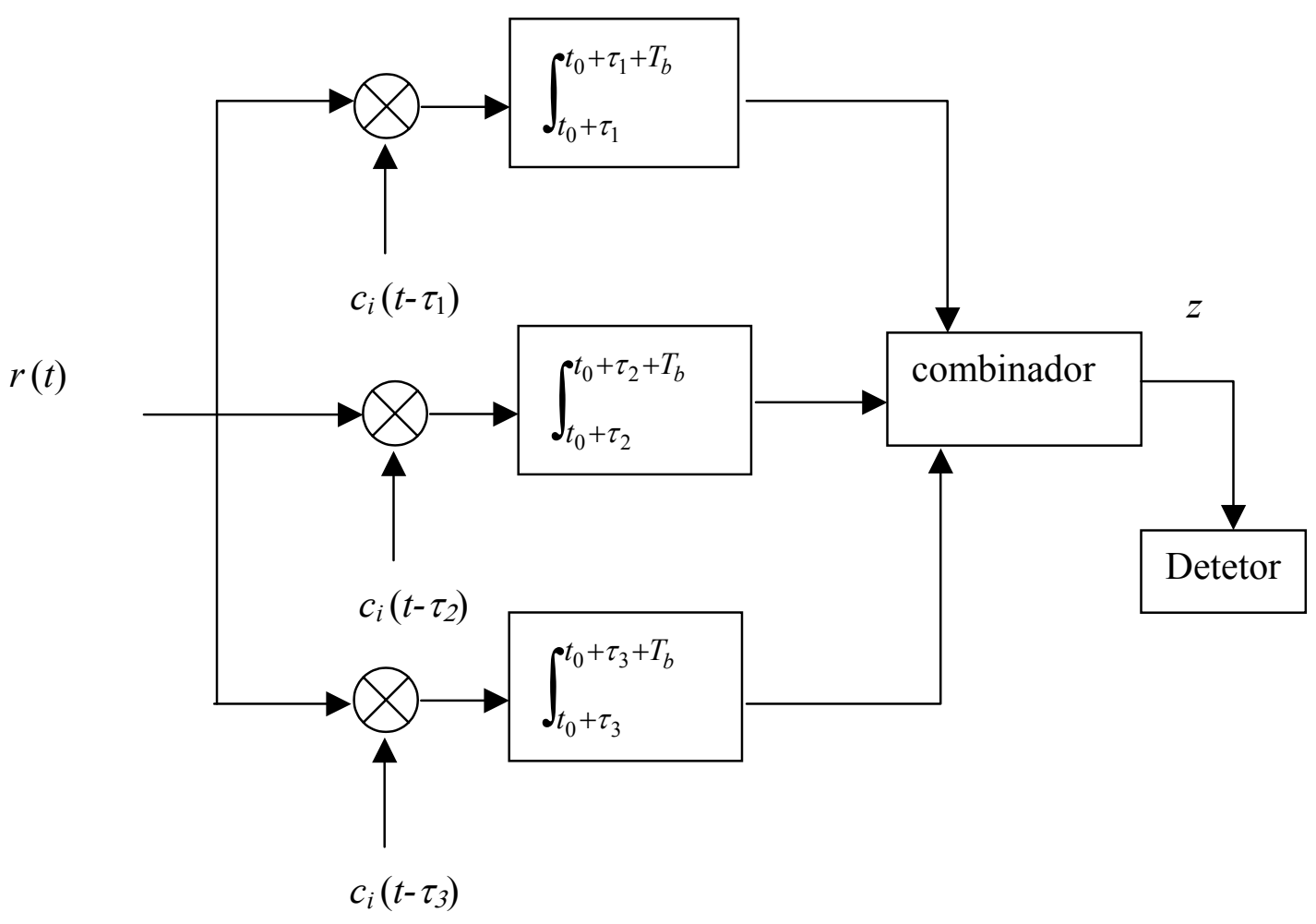

Fig. 5.3 - Receptor RAKE convencional

\section{Combinação ótima}

A combinação representada na Fig. 5.3 é, em geral, uma combinação linear. Com base na Fig. 5.3 podemos escrever a seguinte expressão geral para a variável de decisão z na saída do combinador

$z=\sum_{n=1}^{N} \lambda_{n} \int_{t_{0}+\tau_{n}}^{t_{0}+\tau_{n}+T_{b}} r(t) c_{i}\left(t-\tau_{n}\right) d t$

Na análise a seguir são feitas as seguintes hipóteses: (i) os atrasos estimados pelo receptor Rake $\left\{\tau_{n}\right\}$ são iguais aos atrasos das componentes de multipercurso do sinal do usuário desejado; (ii) os códigos dos usuários são códigos cíclicos perfeitamente ortogonais dentro do intervalo de bit, ou seja, 
$\int_{t_{0}}^{t_{0}+T_{b}} c_{i}(t) c_{j}(t) d t=\left\{\begin{array}{l}T_{b} ; i=j \\ 0 ; i \neq j\end{array}\right.$

$c_{i}(t)=c_{j}\left(t-k_{j} T_{c}\right)$

(iii) a variação de amplitude introduzida no canal é aproximadamente constante dentro de um intervalo de bit.

Com estas propriedades, ao considerarmos um sinal $\mathrm{r}(\mathrm{t})$ com vários percursos, de acordo com (5.9) podemos eliminar os seguintes produtos cruzados que seriam gerados nos integradores, ou seja,

$\int_{t_{0}+\tau_{n}}^{t_{0}+\tau_{n}+T_{b}} \alpha_{l, i} m\left(t-\tau_{l, i}\right) c_{i}\left(t-\tau_{l, i}\right) c_{i}\left(t-\tau_{n}\right) d t=0 ; \quad \tau_{l, i} \neq \tau_{n}$

Resulta então

$z=\sum_{n=1}^{N} \lambda_{n} \int_{t_{0}+\tau_{n}}^{t_{0}+\tau_{n}+T_{b}} \alpha_{n} m\left(t-\tau_{n}\right) c_{i}^{2}\left(t-\tau_{n}\right) d t=\sum_{n=1}^{N} \lambda_{n} \alpha_{n} T_{b} b_{0}$

onde os valores de $\alpha_{n}$ e $\tau_{n}$ coincidem com os principais valores de $\alpha_{l, i}$ e $\tau_{l, i}$ e $b_{0}= \pm 1$ é a amplitude detectada.

Para um ruído branco de variância $\sigma^{2}$ na entrada do receptor Rake, obtemos na saída de cada integrador um ruído de variância

$\sigma_{0}^{2}=\sigma^{2} \boldsymbol{G}$

onde $G=\frac{T_{b}}{T_{c}}$ 
Sabe-se que a combinação ótima para sinais descorrelacionados em presença de ruído de mesma potência em todos os ramos é uma combinação linear cujos coeficientes são os complexos conjugados das amplitudes complexas dos sinais. No modelo que acabamos de descrever isto significa fazer $\lambda_{\mathrm{i}}=\alpha_{\mathrm{i}}{ }^{*}$. Neste caso a razão sinal-ruído na saída do combinador é igual a soma dos valores da razão sinal-ruído em cada ramo. A razão sinal-ruído na saída do combinador será dada então por

$$
\boldsymbol{R S} \boldsymbol{R}=\frac{\boldsymbol{z}^{2}}{\sigma_{0}^{2}}=\frac{\boldsymbol{G} \sum_{\boldsymbol{n}=1}^{N}\left|\alpha_{\boldsymbol{n}}\right|^{2}}{\sigma^{2}}
$$

Com base no modelo descrito acima, apresentamos a seguir uma análise das técnicas específicas de antenas adaptativas aplicadas ao enlace de subida de sistemas CDMA.

\section{Antenas adaptativas}

Diversos trabalhos avaliam o potencial de melhoria das antenas adaptativas [22,23,24,64,65]. Alguns destes trabalhos partem de hipóteses ideais para chegar a algumas conclusões de caráter geral que vale a pena mencionar aqui. Em [23] é estabelecida a seguinte conclusão de caráter geral, para um ambiente sem multipercurso. "quando o número de usuários é menor do que o número de elementos da matriz, será possível observar um aumento substancial na relação sinal-interferência do sistema; a medida em que o número de usuários aumenta, a melhoria observada na SINR convergirá para um fator $M$ correspondente a um aumento de ordem $M$ na capacidade do sistema.

Em [24] a técnica que considera os enlaces direto e reverso de um sistema CDMA é analisada e avaliada em ambiente multicelular. Com relação a modelagem de canal, esta leva em conta a presença do desvanecimento de Rayleigh e um sombreamento com distribuição log-normal, além da atenuação com a distância, fator de atividade vocal e 
interferência. Considera-se ainda controle de potência ideal de tal forma que os sinais interferentes de usuários da mesma célula chegam ao receptor com mesma potência. ${ }^{4}$

No que se refere aos coeficientes da antena, neste caso é utilizada a técnica atraso soma, ou seja, o vetor de coeficientes é o vetor de direção na direção desejada. A simplicidade relativa da expressão dos coeficientes permite obter uma expressão para a probabilidade de bloqueio do enlace desejado, definida como a probabilidade da taxa de erro de bits exceder um certo limiar $P_{0}$ necessário para obter-se um desempenho adequado (uma relação sinal-ruído de $7 \mathrm{~dB}$ o que eqüivale a uma taxa de erro de bits de $10^{-3}$ ). Porém, a técnica de formatação do feixe acaba tendo importância relativa ainda menor pois, para facilitar a avaliação numérica, a antena adaptativa é caracterizada pela largura efetiva do feixe principal, e os resultados de desempenho são colocados em função desta largura de feixe. Com isto não é analisado o problema da obtenção dos vetores de direção.

O principal resultado em [24] pode ser sintetizado no seguinte exemplo do relacionamento aproximado entre banda efetiva do diagrama de radiação (apontado para a direção desejada) e o número de usuários correspondente a uma probabilidade de queda de enlace de $10^{-3}$. Em última análise, porém, este resultado corresponde à melhoria conseguida com setorização.

\begin{tabular}{ll}
\hline Banda & usuários \\
\hline Omnidirecional & 25 \\
$120^{0}$ & 70 \\
$60^{\underline{0}}$ & 140 \\
$30^{\underline{0}}$ & 270 \\
\hline
\end{tabular}

Tabela 5.1 - Caracterização do arranjo pela sua banda efetiva

\footnotetext{
${ }^{4}$ Os autores observam que através de simulação verifica-se que o controle de potência imperfeito, considerando-se o emprego de antenas adaptativas, não afetará o desempenho do sistema face a sua robustez.
} 


\section{Antenas adaptativas e receptor Rake}

O mesmo princípio de combinar os percursos distintos do mesmo sinal no tempo, pode ser aplicado a percursos distintos no espaço, ou seja versões do sinal com diferentes ângulos de chegada. Estes percursos distintos no espaço podem, em princípio ser separados e combinados através de uma antena adaptativa.

Em função disto em [22] se propõe a utilização conjunta de uma matriz de antenas e um receptor Rake, o que pode ser visto como um receptor Rake de duas dimensões (domínios espacial e temporal), que possa estar simultaneamente casado com o sinal desejado e ao mesmo tempo rejeitando eficientemente os sinais interferentes. A estrutura está mostrada na Fig. 5.4.

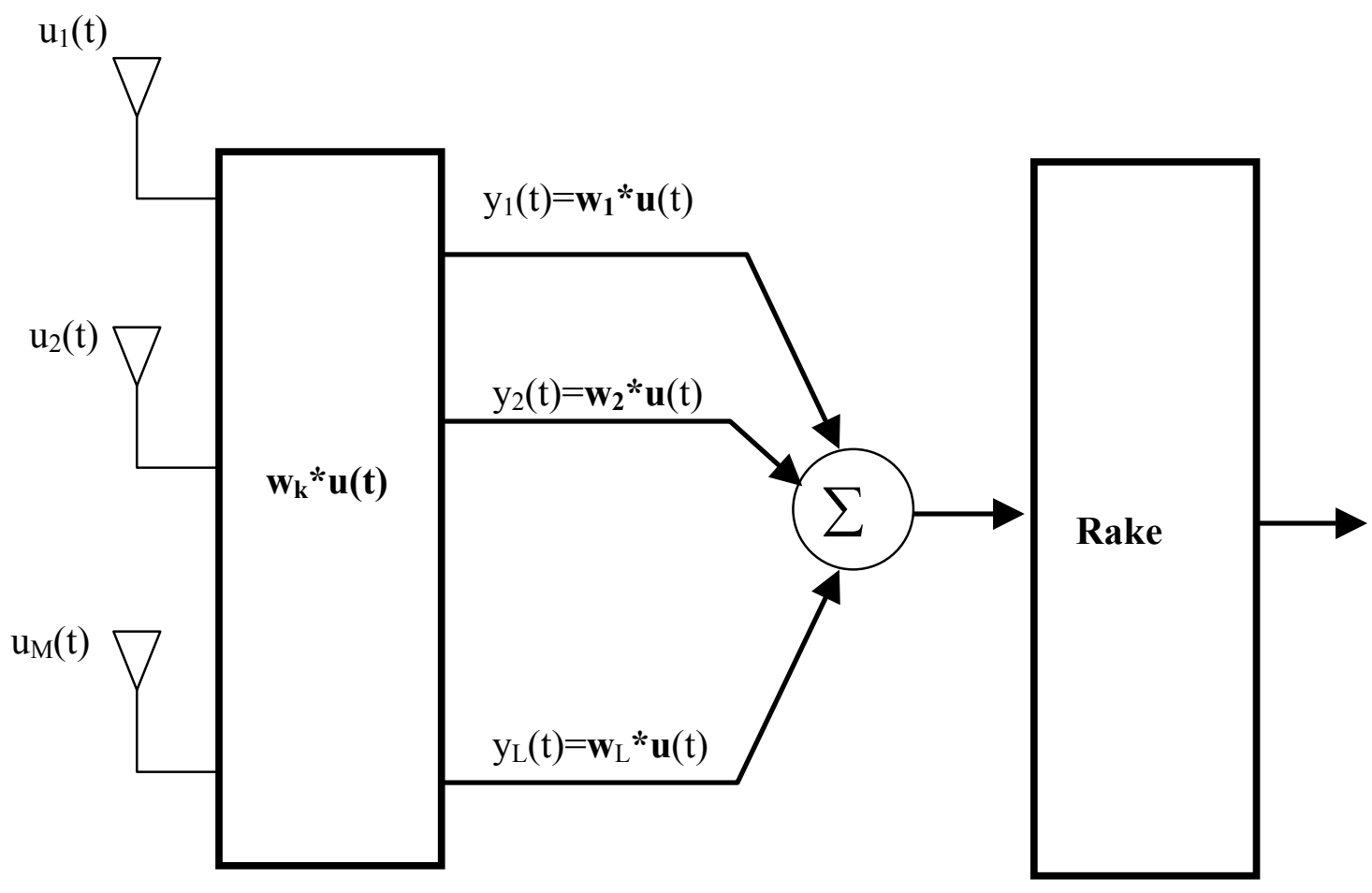

Fig. 5.4 - Receptor RAKE de duas dimensões e 3 ramos 
Parte-se do princípio de que é possível determinar $\mathrm{L}$ feixes através de $\mathrm{L}$ combinações de coeficientes $\left\{\mathbf{w}_{\mathbf{i}}, \mathrm{i}=1,2, \ldots \mathrm{L}\right\}$, um para cada percurso. Desta forma, observando (2.11) podemos expressar o sinal em um percurso $i$ na entrada do receptor Rake como

$$
y_{i}(t)=\mathbf{w}^{H}{ }_{i}(t) \mathbf{a}_{i}\left(\phi_{l, i}\right) \alpha_{i}(t) m\left(t-\tau_{i}\right) s\left(t-\tau_{i}\right)+\mathbf{w}_{i} \mathbf{n}_{i}(t)
$$

A potência do sinal em cada percurso, antes dada por $\left|\alpha_{i}\right|^{2}$, agora será dada por $\left|\mathbf{w}_{\mathbf{i}}{ }^{*} \mathbf{a}_{\mathrm{i}} \alpha_{\mathrm{i}}\right|^{2}$. Por sua vez, a variância do ruído, em vez de $\sigma^{2}$ será dada por $\left\|\mathbf{w}_{i}\right\|^{2} \sigma^{2}$. Aplicando (5.12) a este caso obtemos

$$
\boldsymbol{R S R}=\frac{\boldsymbol{z}^{2}}{\sigma_{n}^{2}}=\frac{\boldsymbol{G} \sum_{i=1}^{\boldsymbol{L}}\left|\mathbf{w}_{\boldsymbol{i}}^{*} \mathbf{a}_{i} \alpha_{i}\right|^{2}}{\sigma^{2}\left\|\mathbf{w}_{\boldsymbol{i}}\right\|^{2}}
$$

Para uma formatador do tipo atraso-soma, $\mathbf{w}_{\mathrm{i}}=\mathbf{a}_{\mathrm{i}}$, e (5.16) fica reduzida a

$$
\boldsymbol{R S R}=\frac{\boldsymbol{G} \sum_{i=1}^{\boldsymbol{L}}\left\|\mathbf{a}_{i}\right\|^{2}\left|\alpha_{i}\right|^{2}}{\sigma^{2}}
$$

Notando ainda que para elementos omnidirecionais $\left\|\mathbf{a}_{i}\right\|^{2}=\mathrm{M}$, observa-se uma melhoria na razão sinal-ruído de $\mathrm{M}$ vezes. Embora seja dado bastante destaque ao conceito de um Receptor Rake bidimensional e a formulação analítica do problema a aplicação considerada no final é bastante simplista. Ou seja, os autores consideram o usuário de interesse com L percursos resolvíveis no tempo, cada um com um ângulo de chegada distinto de tal forma que não haja interferência de um percurso no outro, e com isto, a razão sinal-ruído possa ser multiplicada pelo número de elementos da antena. 


\subsection{Técnicas de formatação de feixe para sistemas CDMA}

No capítulo 4 foram apresentadas, de forma resumida, as principais técnicas de formatação de feixe em antenas adaptativas. Neste capítulo serão discutidas aplicações destas técnicas para o caso específico de sistemas CDMA.

No material bibliográfico pesquisado, foram identificadas duas linhas básicas para a implementação de antenas adaptativas em sistemas CDMA: uma que se baseia nas matrizes covariância espaciais e a outra no ajuste a partir de referência temporal. Mas, além disto, ambas as técnicas exploram também as propriedades do sistema CDMA para torná-las eficazes.

\subsubsection{Técnicas baseadas em matrizes covariância}

As técnicas baseadas em matrizes covariância espaciais foram revistas no capítulo 4 , incluindo as técnicas baseadas nas propriedades dos subespaços. Um aspecto essencial destas técnicas é que elas dependem da estimação da direção de chegada do sinal desejado e - no caso dos métodos baseados em subespaço - dos sinais interferentes.

Sabe-se que as técnicas de subespaços são bastante eficientes, desde que o número de sinais presentes seja menor ou igual ao número de elementos da antena. Como este não é o caso típico em sistemas CDMA, em princípio são descartadas.

A técnica discutida a seguir proposta e analisada em [69] é resumida a seguir.

Considerando um canal com multipercursos e $\mathrm{N}$ usuários, de acordo com os modelos desenvolvidos neste capítulo para o sinal e no capítulo 2 para o processamento na matriz de antenas, temos a seguinte expressão geral para o sinal coletado pelos elementos da matriz de antenas 
$\mathbf{u}(t)=\sum_{i=0}^{N} \sum_{l=0}^{L-1} x_{l, i}(t) \mathbf{a}\left(\phi_{l, i}\right)+\mathbf{n}(t)$

onde

$x_{l, i}(t)=\alpha_{l, i} e^{j \theta_{l, i}} m_{i}\left(t-\tau_{l, i}\right) c_{i}\left(t-\tau_{l, i}\right)$

$\boldsymbol{a}\left(\phi_{l, i}\right)$ é o vetor de direção para o $l$-ésimo percurso do usuário $i$; $\mathbf{n}(\mathrm{t})$ é um vetor cujas componentes são os ruídos observados nos diversos coletores.

A matriz covariância $\mathbf{R}_{\mathbf{u}}$ é definida por

$\mathbf{R}_{\mathbf{u}}=E\left[\mathbf{u}(t) \mathbf{u}(t)^{\mathrm{H}}\right]$

A técnica utiliza também uma matriz covariância denominada de pósprocessamento. Ou seja considera-se um vetor $\mathbf{z}$ cuja componente $z_{m}$ é a resposta do receptor do usuário $i$ para o sinal do elemento $m$ da antena. Isto implica na estrutura de recepção mostrada na Fig.5.5 onde $t_{k}$ é o instante em que se observa a saída do integrador 
$\mathrm{u}_{1}(\mathrm{t})$

$$
\int_{t_{0}+\tau+k T_{b}}^{t_{0}+\tau+(k+1) T_{b}} \quad \mathrm{z}_{1}(k)
$$

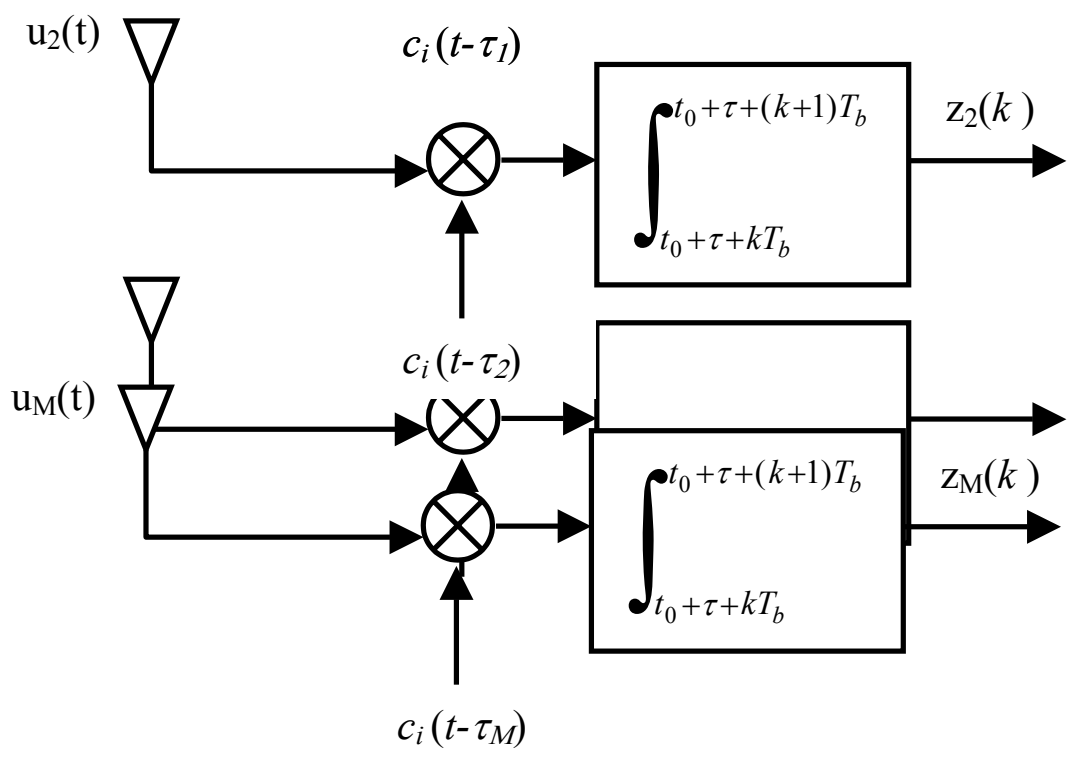

Fig. 5.5 - Estrutura de decodificação e integração para M sinais incidentes

A matriz de pós-processamento será dada por

$\mathbf{R}_{\mathbf{z z}}=E\left[\mathbf{z}\left(t_{k}\right) \mathbf{z}\left(t_{k}\right)^{\mathrm{H}}\right]$

Mostra-se em [ 69 ] que com $\mathbf{R}_{\mathbf{u u}}$ e $\mathbf{R}_{\mathbf{z z}}$ é possível obter a matriz covariância do sinal interferente mais ruído, $\mathbf{R}_{\mathbf{x} \mathbf{x}}$ através da expressão

$$
\mathbf{R}_{x x}=\frac{G}{G-1}\left(\mathbf{R}_{\mathbf{u} u}-\frac{1}{G} \mathbf{R}_{\mathrm{zz}}\right)
$$

onde $G$ é o ganho de processamento. Obtendo-se a matriz $\mathbf{R}_{\mathbf{x x}}$ pode-se aplicar a expressão (4.15) para obter os coeficientes que maximizam a razão sinal-ruído. Nota-se entretanto, 
observando (4.15) que é necessário conhecer o vetor de direção correspondente ao ângulo de chegada do usuário desejado. Pode-se mostrar [69] que este corresponde ao autovetor correspondente ao maior autovalor do problema generalizado de autovalores

$\mathbf{R}_{\mathbf{z z}} \mathbf{a}=\eta \mathbf{R}_{\mathbf{u u}} \mathbf{a}$

Mostra-se também em [69] que o vetor de coeficientes ótimos w pode ser identificado como o autovetor correspondente ao maior autovalor do problema generalizado de autovalores dado pela equação

$\mathbf{R}_{\mathbf{z z}} \mathbf{W}=\eta \mathbf{R}_{\mathbf{x x}} \mathbf{W}$

Baseado nestes resultados, tem-se então o seguinte método

1. Estimam-se as matrizes covariância $\mathbf{R}_{\mathbf{z z}} \mathbf{e} \mathbf{R}_{\mathbf{u u}}$ a partir de $\mathbf{z}(k)$ amostras e de $\mathbf{u}(t)$;

2. Obtém-se a matriz $\mathbf{R}_{\mathbf{x x}}$ aplicando-se (5.22)

3. Resolve-se a equação de autovalores dada por (5.23) para obter o vetor de direção do sinal desejado

4. Aplica-se (4.15) para obter os coeficientes do arranjo de antenas.

Alternativamente, os passos 3 e 4 podem ser substituídos por

3. Resolve-se a equação de autovalores dada por (5.24) para obter os coeficientes do arranjo de antenas. 


\subsubsection{Técnicas baseadas em sinal de referência}

As técnicas baseadas em sinal de referência foram revistas de forma resumida no Capítulo 4. Além da variedade de algoritmos, sua aplicação a sistemas CDMA leva a várias possibilidades de arquiteturas [68]. Para analisar este problema consideramos o diagrama da Fig. 5.6 que é uma forma equivalente do receptor do usuário $i$ mostrado na Fig. 5.3 onde $p\left(t_{0}-t\right)$ é um filtro casado ao pulso de chip $p(t)$ usado na transmissão e, $\left\{c_{k, i}\right\}$ são as amplitudes do código do usuário $i$. Note-se que a integração da Fig. 5.6 é feita através do filtro casado (que integra a forma de onda de 1 chip) e do somador.

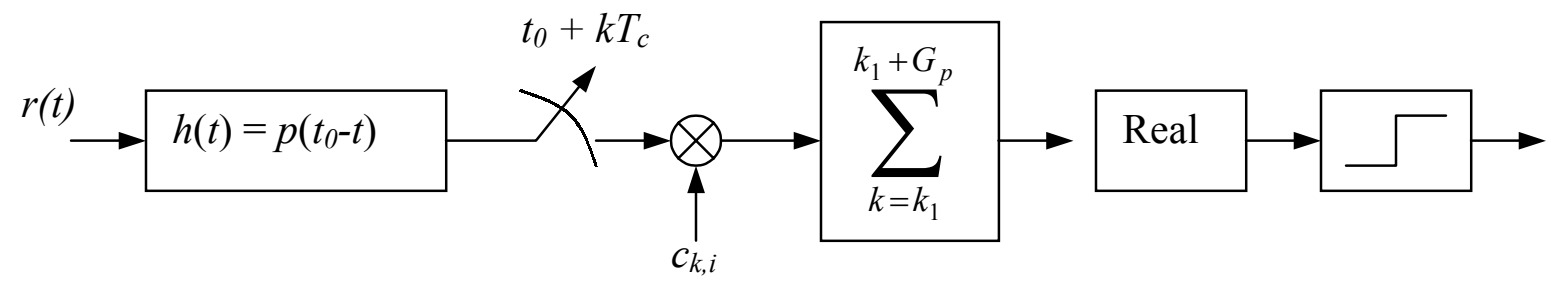

Fig. 5.6-Estrutura simplificada de recepção

\section{Algoritmo orientado pela deteção de chip}

Uma forma simples de algoritmo nesta categoria é um algoritmo LMS orientado pela deteção de chips como ilustrado na Fig. 5.7. As amplitudes dos chips na saída de cada elemento da antena são detectados e esta deteção é utilizada como referência. Chamando de $v_{m}(k)$ a $k$-ésima amostra colhida no elemento $m$ tem-se o seguinte algoritmo

$$
\mathbf{w}(k+1)=\mathbf{w}(k)-\mu v(k) e^{*}(k)
$$




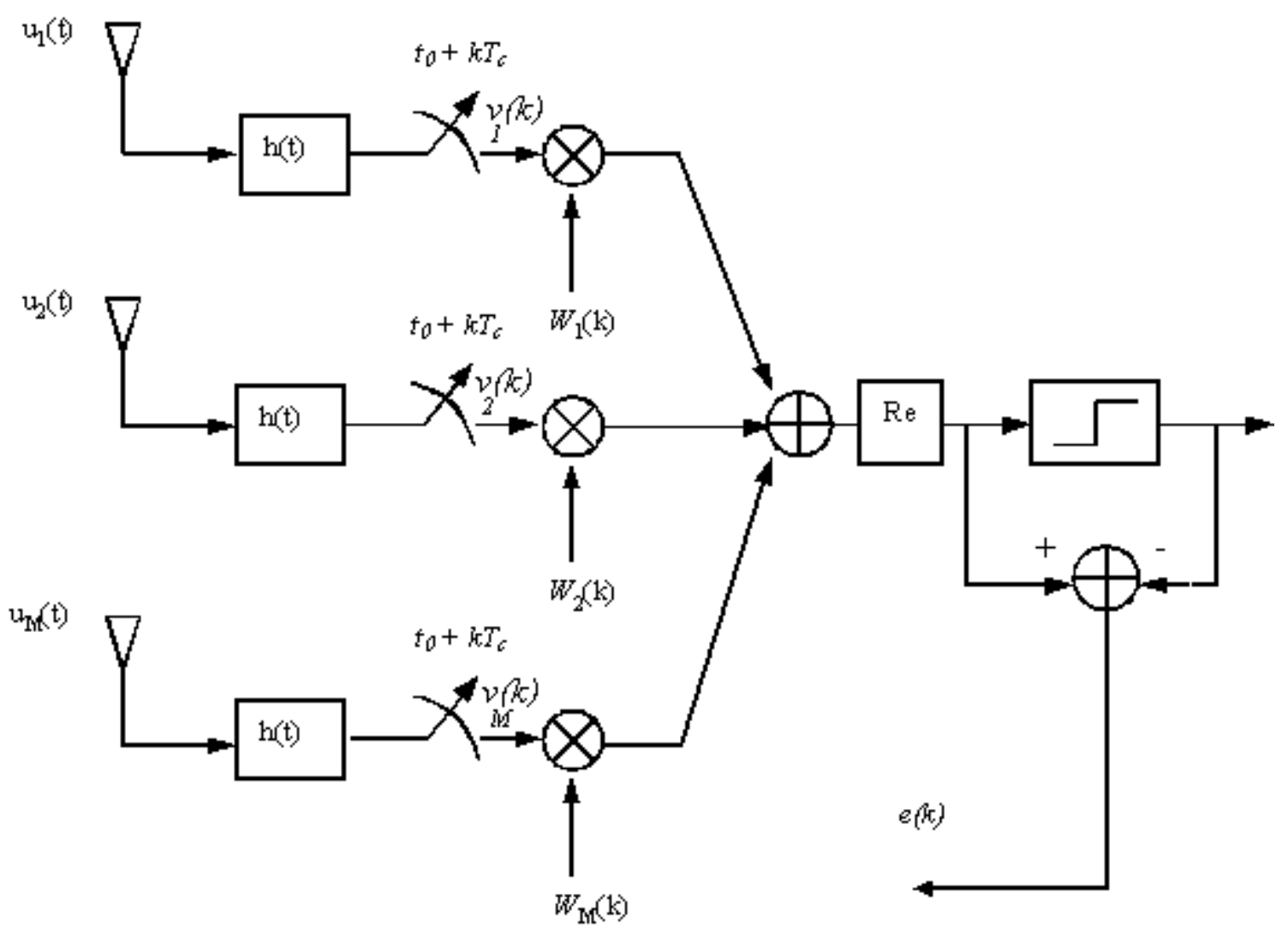

Fig. 5.7 - Estrutura de recepção orientada pela decisão

Sinal de referência obtido por reespalhamento

Como mostrado em [68] a utilização de sinal de referência obtido a partir de reespalhamento é muito mais eficiente. O esquema está mostrado na Fig. 5.8. 


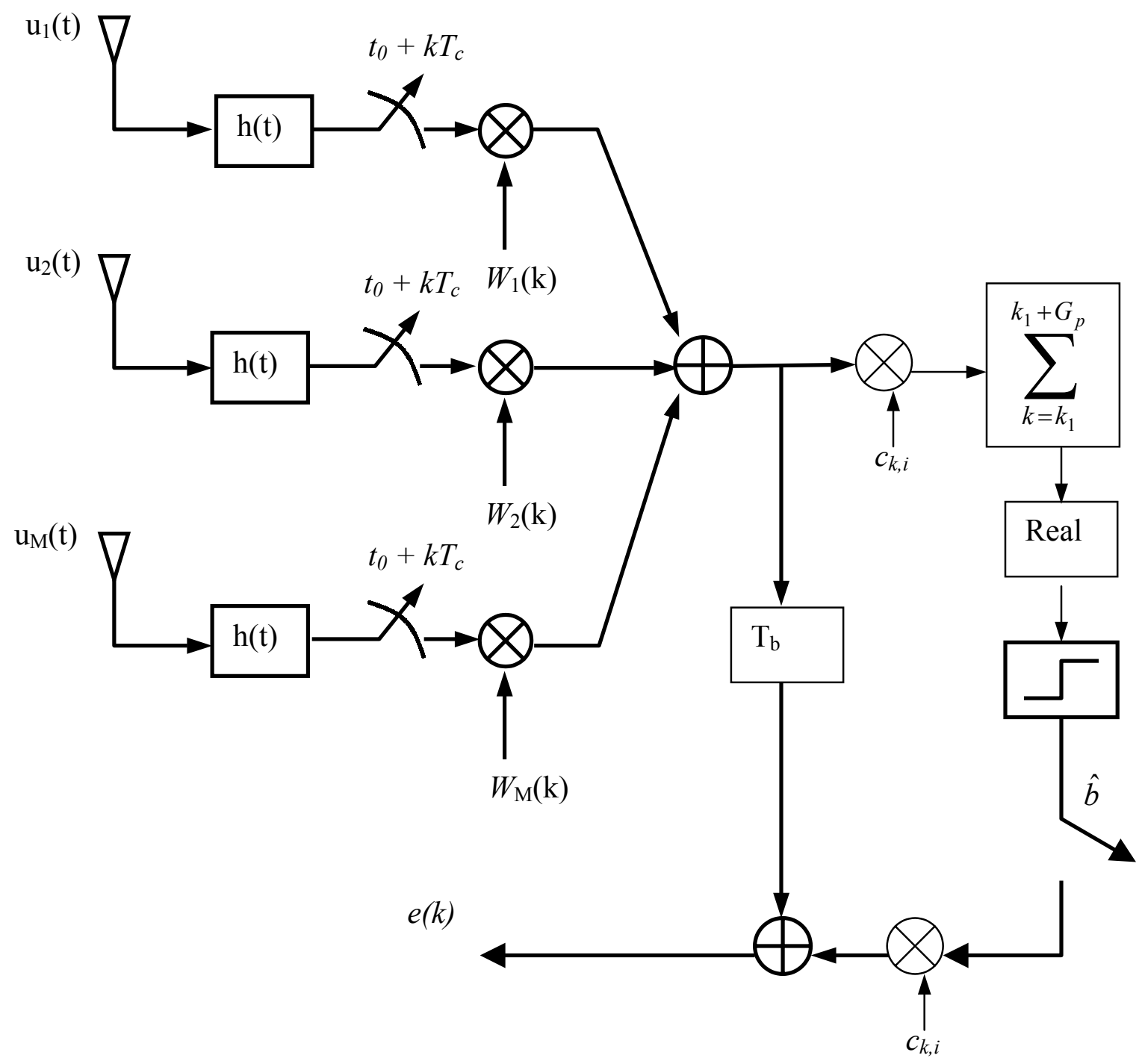

Fig. 5.8 - Estrutura de recepção baseada no sinal reespalhado

Como se observa na figura, a amplitude $\hat{b}$ correspondente ao bit detetado, é multiplicada pelo código do usuário desejado e subtraído do sinal combinado pelas antenas atrasado de $T_{b}$. Se o bit for detetado corretamente, o sinal reespalhado será uma referência perfeita. O algoritmo terá a mesma forma do anterior. 


\subsection{Avaliação das técnicas apresentadas}

Os métodos descritos nas seções anteriores foram avaliados e comparados através de simulação em computador, usando o software Matlab.

\section{Método 1}

Denominamos método 1 aquele baseado na matriz covariância. Como estabelecemos na seção 5.2.1 o método 1 estima a matriz covariância a partir de um determinado número de amostras do sinal na saída da matriz de antenas. Uma escolha natural é fazer a estimativa a cada intervalo de bit. Isto foi adotado na simulação. As estimativas feitas são armazenadas e uma nova estimativa é obtida pela média ponderada entre a estimativa anterior e a nova estimativa. Arbitramos um peso 0.9 para a estimativa atual e 0.1 para a anterior. Quanto à matriz de pós-processamento, ela é obtida incialmente com uma única amostra e progressivamente atualizada usando o procedimento que acabamos de descrever. Com relação ao canal este considera somente a presença de sinais interferentes e ruído aditivo Gaussiano branco. Outros efeitos inerentes ao meio de propagação tais como multipercursos e espalhamento angular não são considerados.

\section{Método 2}

O método 2 é o que utiliza o sinal de referência obtido pelo sinal reespalhado. Para escolha da constante $\mu$ do algoritmo em (5.25) fizemos alguns testes e verificamos que uma bom compromisso entre tempo de convergência e erro absoluto é $\mu=0.001$.

Para uma avaliação preliminar, consideramos inicialmente um conjunto de apenas 4 usuários, todos com a mesma potência no receptor e com os seguintes ângulos de chegada: $135^{0}, 22.5^{0}, 90^{\circ}$ e $67,5^{\circ}$ considerando-se o primeiro ângulo o do sinal desejado. Para espalhamento utilizamos uma seqüência de comprimento máximo de período $2^{7}-1$ e ganho de espalhamento 128. De acordo com o modelo descrito neste capítulo a modulação é PSK 
binária e a demodulação é coerente. Além da interferência dos outros usuários, adiciona-se, em cada ramo da antena, um ruído de potência $0 \mathrm{~dB}$ em relação a potência de cada sinal.

Nas Figuras 5.9 e 5.10 mostram-se os diagramas de radiação obtidos com os dois métodos após 250 e após a 1000 iterações.

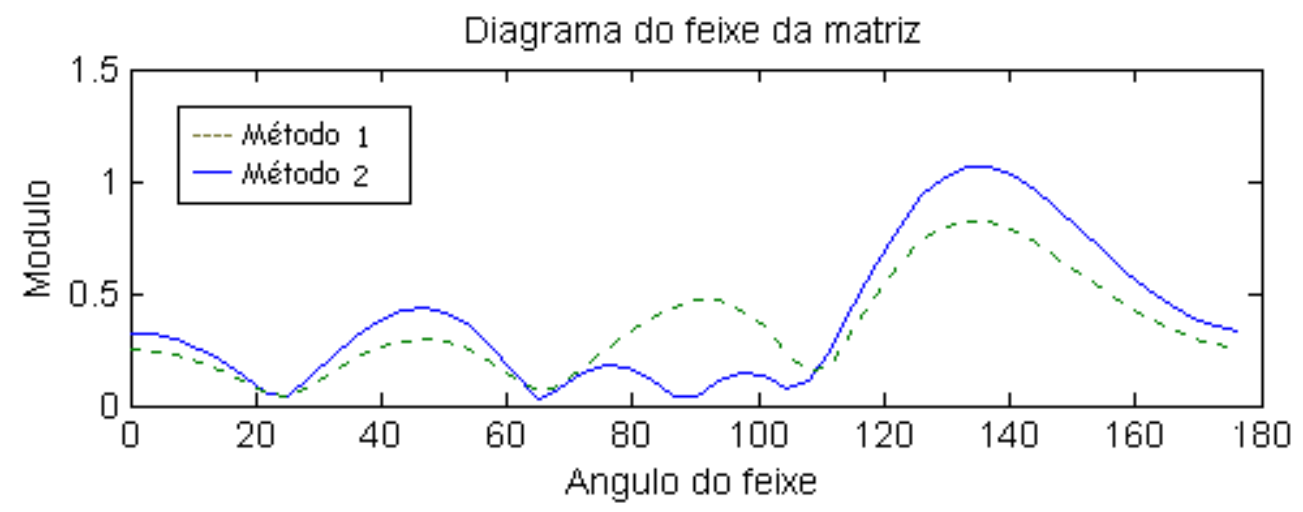

Fig. 5.9 - Diagrama de radiação após 250 iterações $(S / N=0 \mathrm{~dB})$

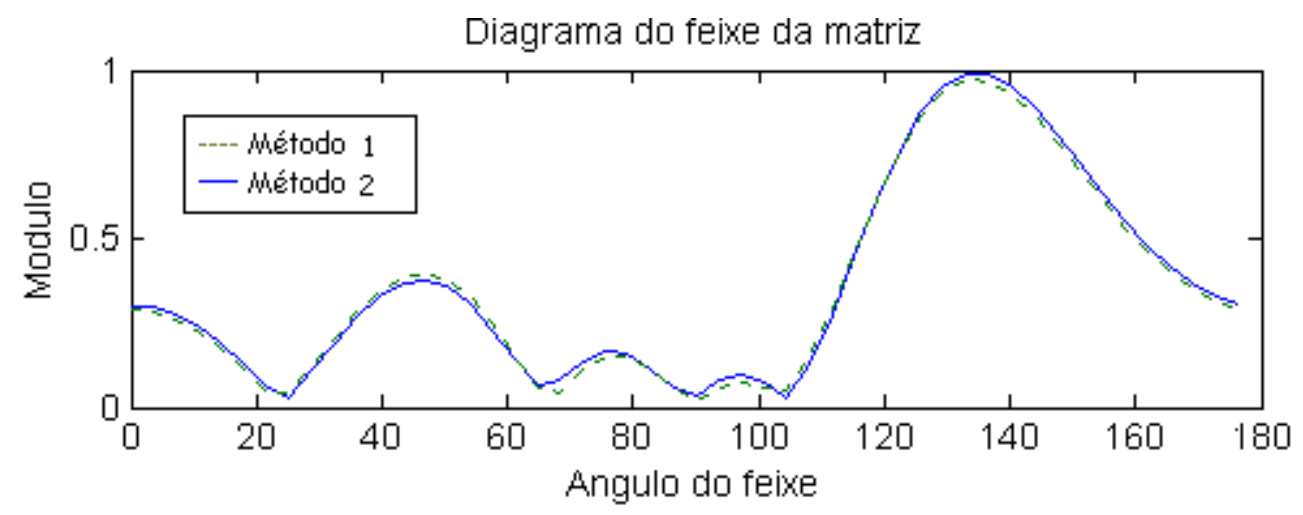

Fig. 5.10 - Diagrama de radiação após 1000 iterações $(S / N=0 \mathrm{~dB})$

Mostra-se também, no caso do método 2, a evolução do valor absoluto do erro definido como diferença entre o sinal amostrado e a sua estimativa. 


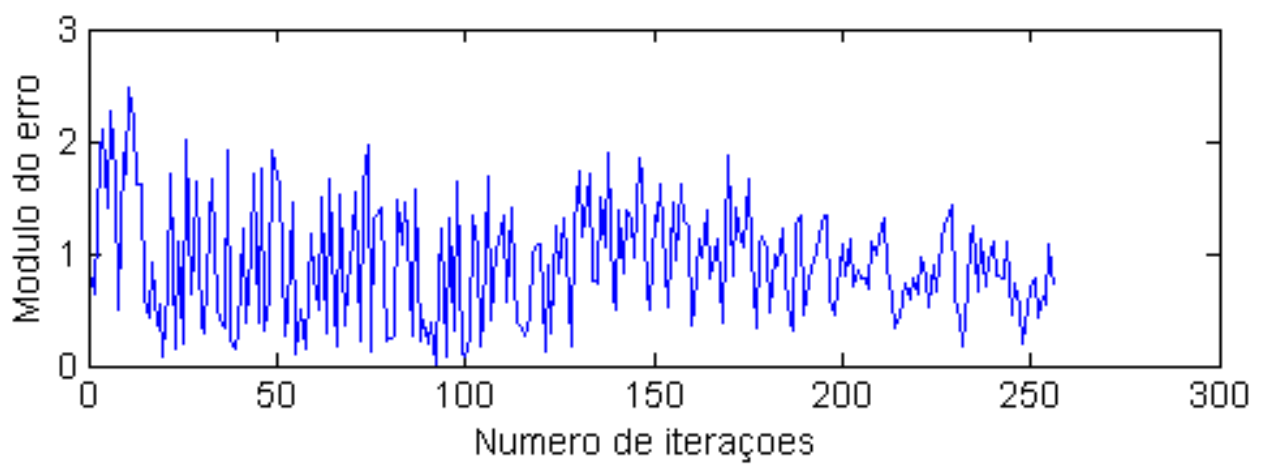

Fig. 5.11 - Gráfico da evolução do valor absoluto do erro após 250 iterações $(S / N=0 \mathrm{~dB})$

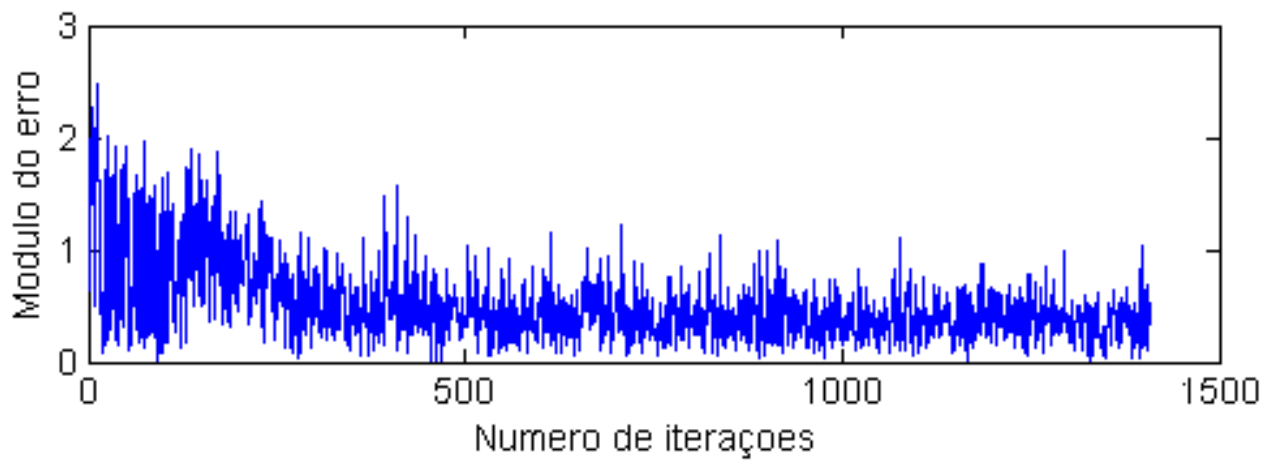

Fig. 5.12 - Gráfico da evolução do valor absoluto do erro após 1000 iterações $(S / N=0 \mathrm{~dB})$

Observamos através dos testes de validação do software realizados que para 128 amostras e um nível de potência de ruído de $-10 \mathrm{~dB}$ o método 1 apresenta-se mais eficiente do que o método 2, que mantém nulos mais acentuados sobre os sinais interferentes. Por outro lado, enquanto o método 1 converge imediatamente o método 2 só a partir do $2^{\circ}$ bit começa a apresentar bom resultado. Note-se também que, para este mesmo número de amostras reduzido, os resultados encontrados através das validações confirmam que o desempenho dos métodos não diferem muito quando a potência de ruído é substancialmente reduzida $(-60 \mathrm{dBs})$. 
Quando elevamos o número de iterações apesar dos métodos ainda manterem uma razoável aproximação com relação ao apontamento do feixe e na colocação de nulos de radiação sobre os sinais interferentes não se observa um desempenho superior do método em malha fechada em relação ao método 1. Observe que para um nível de ruído baixo de - 60 dBs e levando-se em conta o mesmo número de iterações as respostas obtidas pelos métodos continuam sendo iguais apesar da colocação de nulos mais profundos obtida pelo método em malha aberta.

Conforme é possível verificar através das figuras 5.9 e 5.10 aumentando-se o número de amostras e o ruído para um nível de potência relativamente alto (0dBs) observamos que os diagramas de radiação em ambos os métodos tornam-se cada vez mais semelhantes tanto no que diz respeito a colocação de nulos quanto no apontamento do feixe principal na direção do alvo. Os resultados obtidos de forma geral indicam que os métodos oferecem um grau de vulnerabilidade a ruído ainda bastante reduzido.

Com relação a evolução do valor absoluto do erro do método 2 apresentado pelas figuras 5.11 e 5.12 podemos confirmar a existência de um bom compromisso entre tempo de convergência e erro absoluto ao definirmos $\mu=0.001$. Como era de se esperar a medida em que a constante de adaptação do algoritmo LMS é reduzida no método 2 a taxa de convergência do erro (tempo de convergência) também é proporcionalmente diminuída, entretanto, podemos observar também uma redução nas variações presentes nos gráficos de convergência de erro.

Para verificar a influência do ruído fizemos simulações com razão sinal-ruído de - 10 dB. Observa-se nas figuras 5.13 e 5.14 que o efeito do ruído não resulta em um diagrama de radiação muito diferente daquele obtido na figura 5.10, entretanto, observa-se através do gráfico da evolução do erro absoluto que o método 2 converge mais rapidamente tornando-o neste caso mais eficiente. 


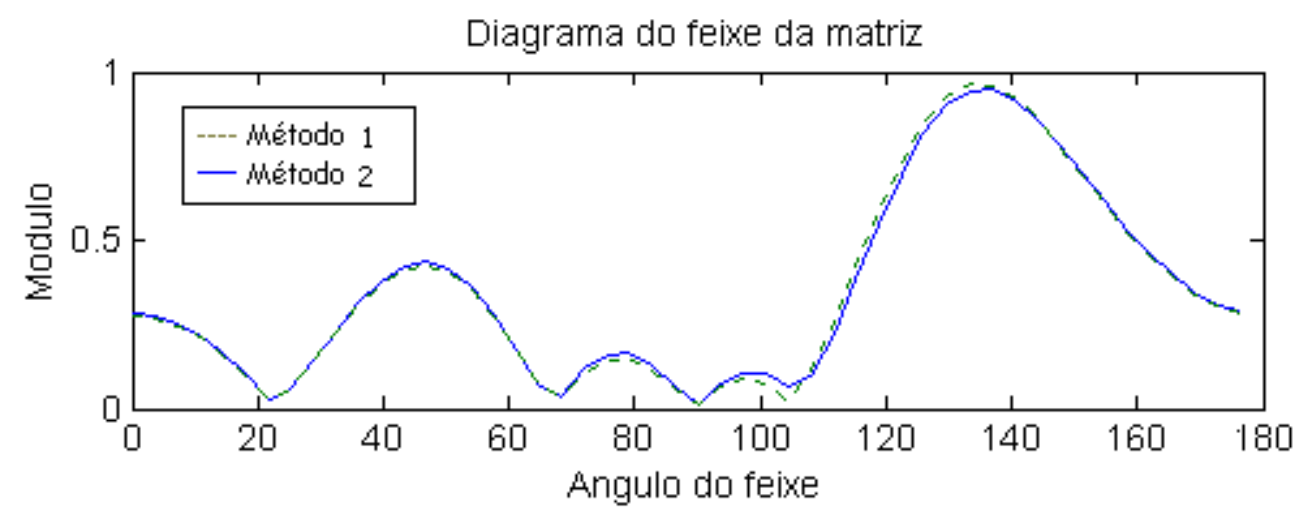

Fig. 5.13 - Diagrama de radiação após 2000 iterações $(S / N=-10 \mathrm{~dB})$

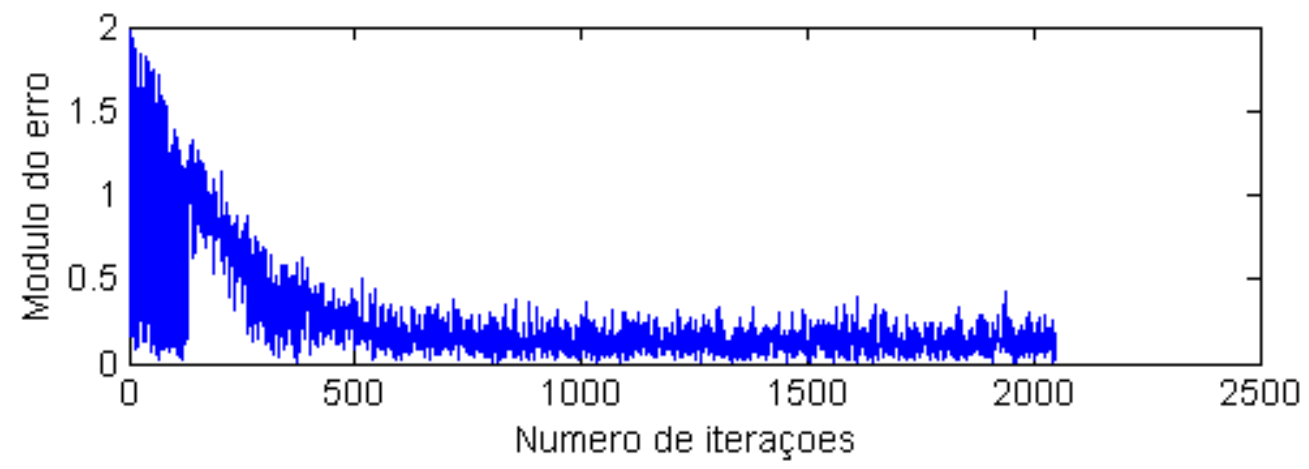

Fig. 5.14 - Gráfico da evolução do valor absoluto do erro após 2000 iterações $(S / N=-10 \mathrm{~dB})$

Outros cenários também foram simulados. Consideramos agora um conjunto de 4 usuários, todos também com a mesma potência no receptor e com os seguintes ângulos de chegada: $90^{\circ}, 22.5^{\circ}, 90^{\circ}, 135^{\circ} \mathrm{e} 67,5^{\circ}$ considerando-se o primeiro ângulo o do sinal desejado. Além disto consideramos uma matriz com 9 elementos. O resultado está mostrado na figura 5.15 onde se observa a menor abertura do feixe. 


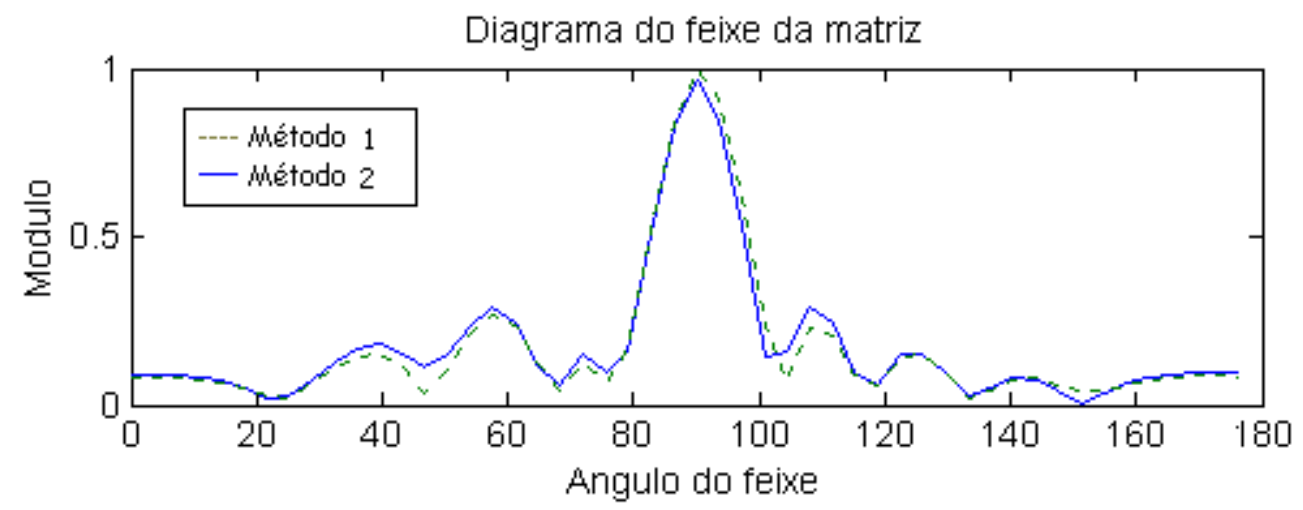

Fig. 5.15 - Diagrama de radiação após 2000 iterações $(S / N=0 \mathrm{~dB})$

Portanto, observamos de forma geral que o método 1 é mais eficiente considerando-se o pequeno número de iterações que o mesmo necessita para convergir. Com relação ao método 2 este mostrou-se mais dependente do número de iterações utilizados apesar de apresentar um diagrama de radiação praticamente igual ao obtido pelo método 1 . 


\section{Desempenho em função do número de usuários}

Nesta seção apresentamos os resultados de avaliação de desempenho dos 2 métodos em presença de grande número de usuários interferentes. Em todos os casos, os códigos dos usuários foram gerados aleatoriamente, o que se aproxima da situação típica do enlace de subida de sistemas como IS-95 onde atrasos relativos de usuários não são sincronizados. Note-se entretanto que nesta simulação os códigos foram sorteados somente na $1^{\mathrm{a}}$ rodada do programa. Para as rodadas subsequentes os códigos são mantidos, isto é, não são sorteados novamente. Todos os sinais foram simulados com mesma potência, em presença de ruído de potência 10 vezes maior.

Consideramos inicialmente dois cenários idealizados, escolhendo os ângulos de chegada de modo a facilitar a interpretação de resultados. No cenário (a) consideramos os usuários interferentes com ângulos igualmente espaçados entre 0 e $\pi$ como ilustrado na figura 5.16

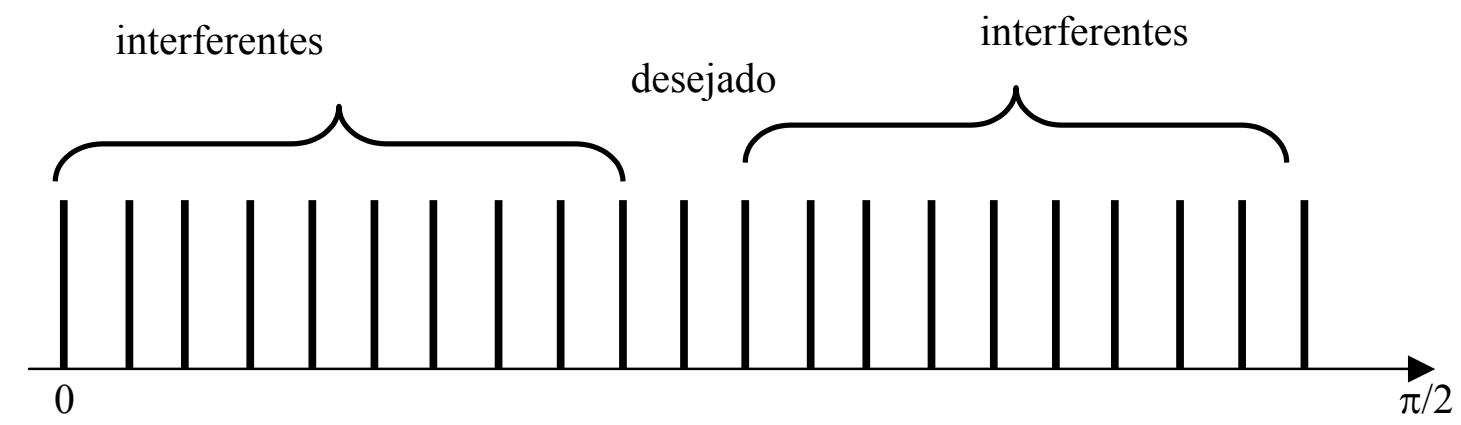

Fig. 5.16 - Distribuição de ângulos de chegada igualmente espaçados entre 0 e $\pi / 2$

Usando uma matriz de antenas com 9 elementos observamos os seguintes resultados apresentados na tabela 5.2 e ilustrados na fig. 5.17. onde podemos verificar graficamente o comportamento da taxa de erro de bit em função do número de usuários presentes no sistema. 


\begin{tabular}{clll}
\hline Usuários & Método 1 & Método 2 & Sem antena adaptativa \\
\hline 80 & 0,0280 & 0.2060 & 0.04 \\
70 & 0.0135 & 0,1305 & 0,0355 \\
60 & 0,008 & 0,036 & 0,0245 \\
50 & 0,0075 & 0,011 & 0,015 \\
\hline
\end{tabular}

Tabela 5.2 - Taxa de erro de bit versus número de usuários

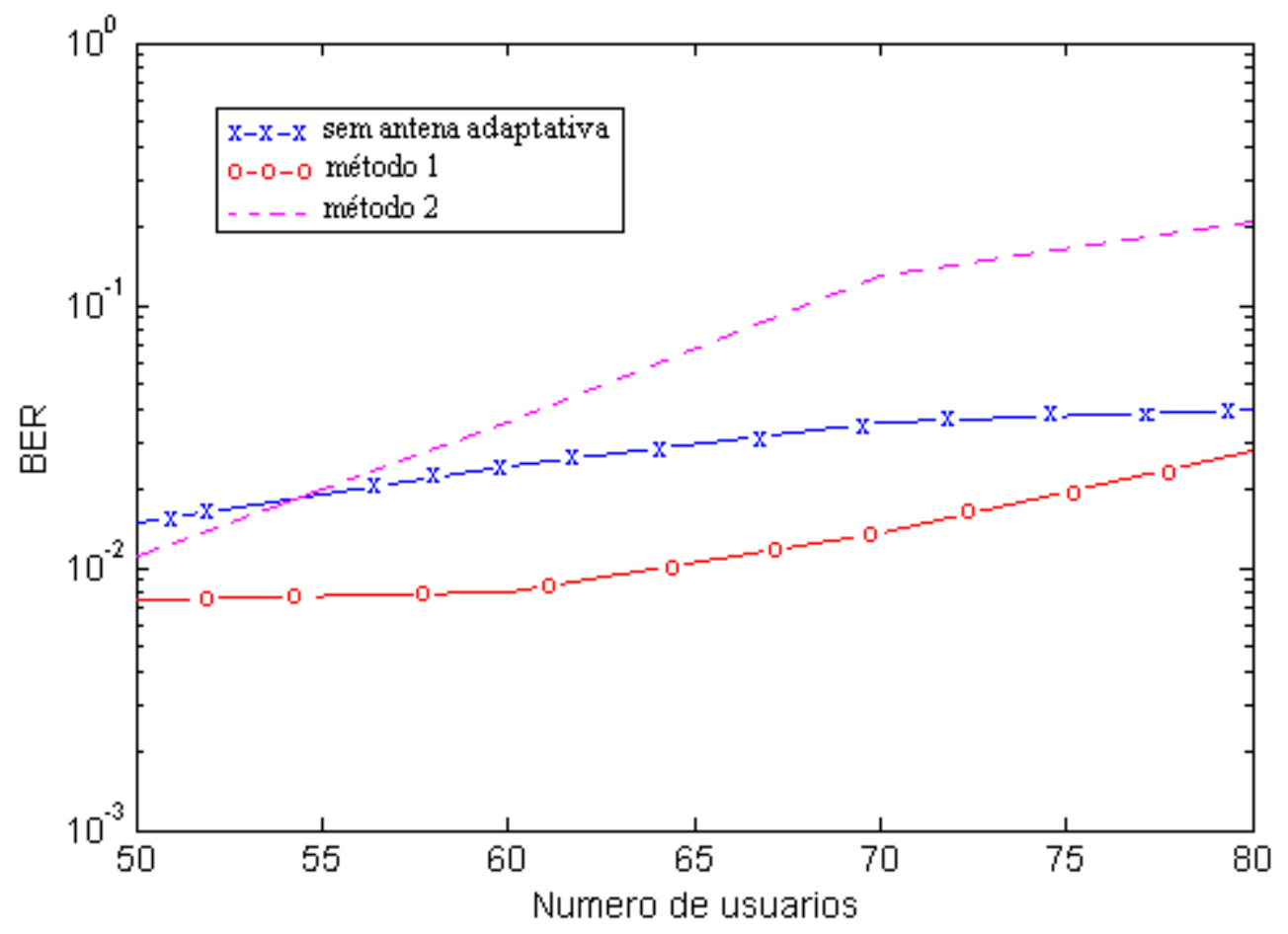

Fig. 5.17 - Taxa de erro de bit versus número de usuários 
Observa-se que o método 1 introduz melhoria na taxa de erro de bit significativa mas o mesmo não acontece com o método 2 que apresenta resultados apenas ligeiramente melhores do que o caso sem antena adaptativa.

O cenário (b) representa um caso extremamente favorável em que os ângulos em que os ângulos de chegada dos sinais interferentes estão fora do feixe principal. Como ilustrado na figura 5.18 foram tomados ângulos igualmente espaçados entre 0 e $\pi / 4$ e entre $3 \pi / 4$ e $\pi$. Foi simulada a transmissão de 1000 bits, o que corresponde a 128000 amostras. Através da figura 5.19 verifica-se o comportamento da taxa de erro de bit em função do número de usuários do sistema.

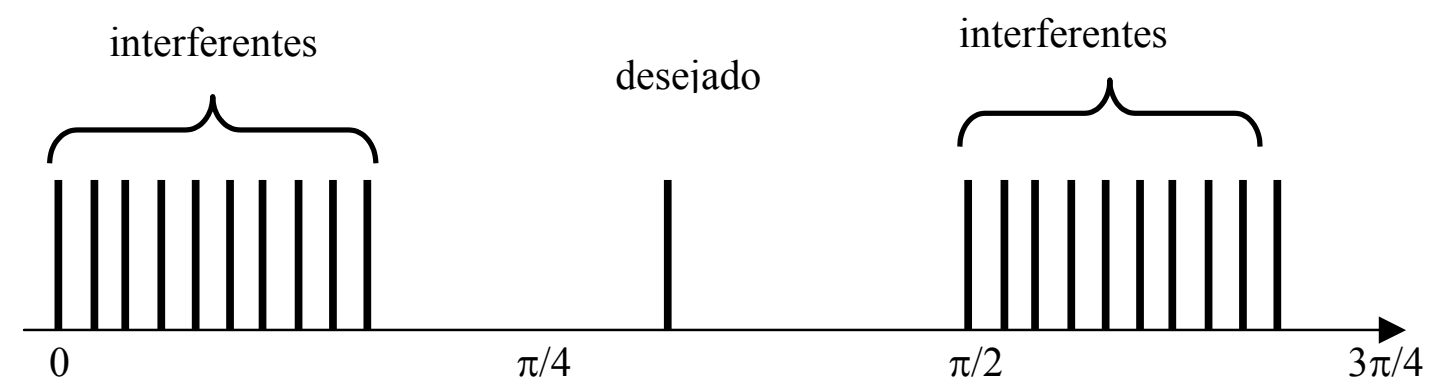

Fig. 5.18 - Distribuição de ângulos de chegada igualmente espaçados entre 0 e $3 \pi / 4$

\begin{tabular}{cccc}
\hline Usuários & Método 1 & Método 2 & Sem antena adaptativa \\
\hline 150 & $2,5 \times 10^{-4}$ & 0,0085 & 0,095 \\
120 & $*$ & $*$ & 0,081 \\
100 & $*$ & $*$ & 0,054 \\
80 & $*$ & $*$ & 0,04 \\
\hline
\end{tabular}

Tabela 5.3 - Taxa de erro de bit versus número de usuários

\footnotetext{
* Com o número de bits considerados não foram observados erros
} 


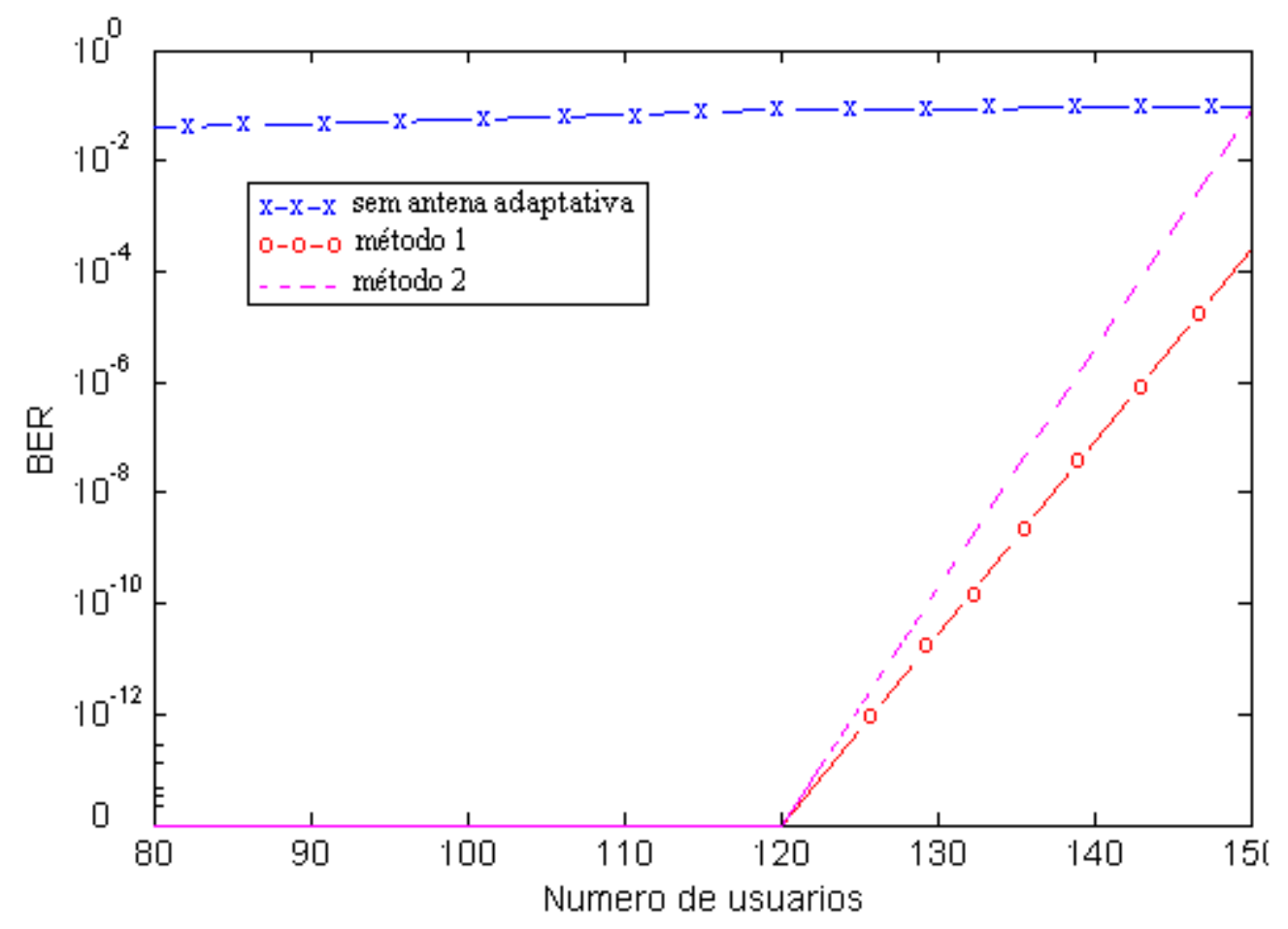

Fig. 5.19 - Taxa de erro de bit versus número de usuários

Como era de se esperar, a eficácia das antenas adaptativas neste caso é muito grande, não se verificando nas simulações a ocorrência de erros com 80, 100 até 120 usuários, e com os métodos se comportando melhor do que no caso sem antenas. Para 150 usuários verificou-se a ocorrência de erros e como no cenário anterior o método 1 é bem melhor que o 2 . 
Consideremos finalmente a atuação mais realista em que os ângulos de chegada são aleatórios e uniformemente distribuídos entre 0 e $\pi$. Neste caso, foram feitas 4 simulações para cada número de usuários. Em cada uma foram sorteados novos ângulos de chegada e novos códigos para os usuários. Na tabela 5.4 mostra-se o valor da taxa de erro de bit correspondente à média entre os diversos resultados obtidos.

\begin{tabular}{llll}
\hline & Método 1 & Método 2 & Sem antena adaptativa \\
\hline 20 usuários & 0,0029 & $*$ & 0,0021 \\
40 usuários & 0,0134 & 0,006 & 0,0101 \\
60 usuários & 0,0147 & 0,0503 & 0,0239 \\
80 usuários & 0,0274 & 0,1576 & 0,0427 \\
100 usuários & 0,0299 & 0,2686 & 0,0607 \\
\hline
\end{tabular}

Tabela 5.4 - Taxa de erro de bits versus número de usuários

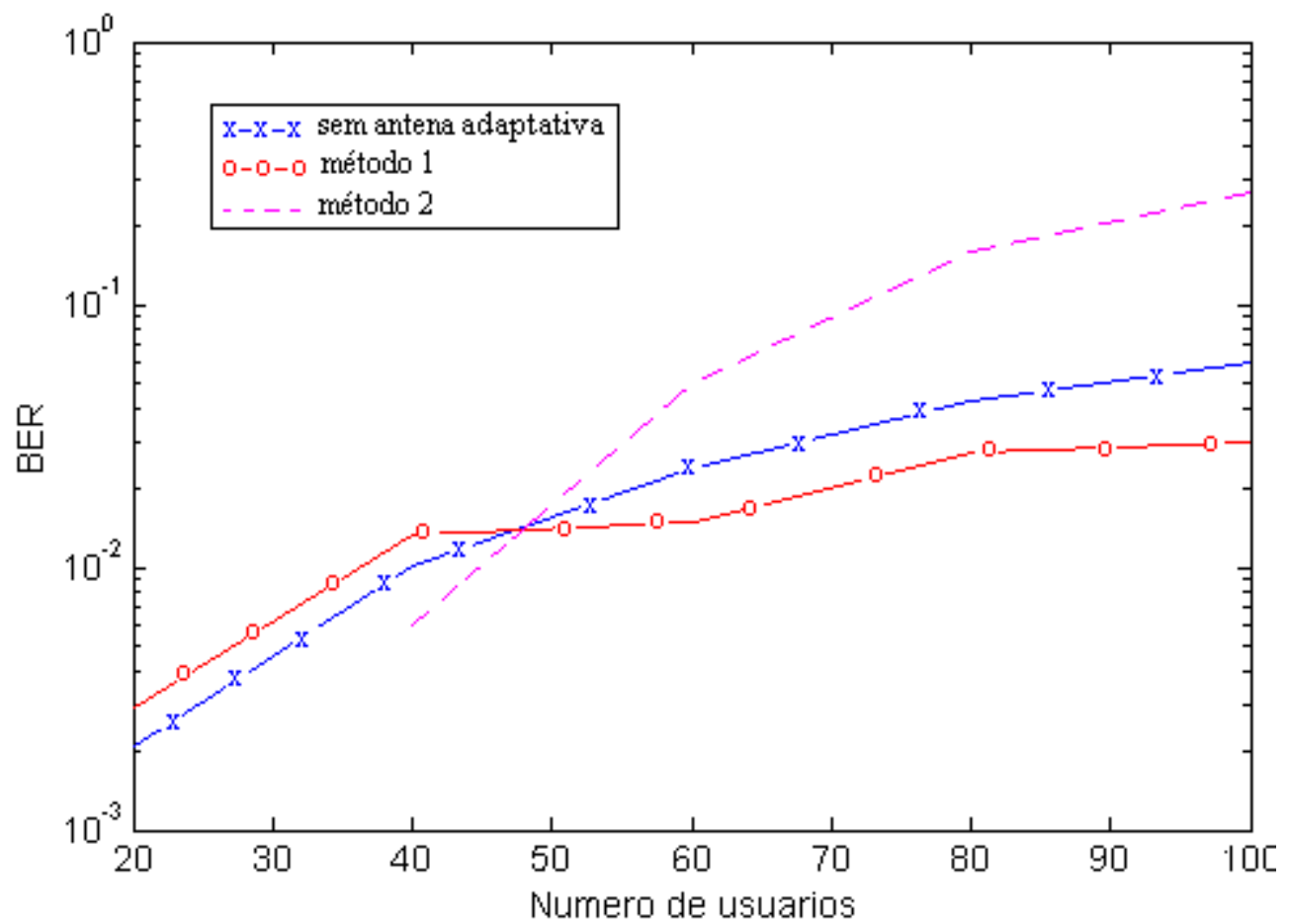

Fig. 5.20 - Taxa de erro de bit versus número de usuários

\footnotetext{
* Com o número de bits considerados não foram observados erros.
} 
As simulações realizadas mostram que as antenas adaptativas efetivamente melhoram o desempenho de sistemas CDMA, reduzindo a interferência que influencia direta e fortemente a capacidade do sistema.

Os resultados obtidos permitem concluir que dependendo do cenário em que as antenas adaptativas vão operar a melhoria pode ser expressiva. Observa-se também que o método 1 é mais eficiente do que o método 2. Na realidade verifica-se que o método 2 deve ser descartado pois seu desempenho não é muito diferente do desempenho sem antena adaptativa. Deve-se observar que aparentemente o método 2 funciona bem para pequeno número de sinais, (como ilustrado nas Figs 5.13 e 5.15 leva ao mesmo diagrama que o método 1) mas no caso de grande número de sinais, pôde-se observar que o diagrama obtido é bastante diferente. 


\section{CONCLUSÃO}

Neste trabalho procuramos investigar a aplicação de antenas adaptativas a sistemas CDMA. Consideramos como ponto de partida uma revisão das arquiteturas e algoritmos de antenas adaptativas encontradas na literatura que serviram como base das aplicações consideradas posteriormente.

Para avaliar as aplicações aos sistemas CDMA, os trabalhos mais relevantes publicados nos últimos anos foram revistos procurando-se definir o potencial de melhoria e as formas de implementação das técnicas consideradas. Para isto procuramos estabelecer um modelo comum onde diferentes técnicas pudessem ser comparadas. Através deste modelo analisamos as arquiteturas propostas incluindo a associação entre receptor Rake com antenas adaptativas.

O levantamento realizado permitiu identificar duas linhas gerais de implementação de antenas adaptativas em sistemas CDMA: uma baseada em estimações a partir da matriz covariância espacial e outra baseada em sinal de referência. Dois algoritmos foram implementados em computador visando uma comparação de desempenho entre as técnicas. De um modo geral verificamos que a utilização de antenas adaptativas pode proporcionar melhorias substanciais, mas isto depende do cenário considerado. E que o método baseado na covariância espacia tem um desempenho bem superior ao método que utiliza sinal de treinamento. Na realidade o método baseado em sinal de treinamento não funciona a contento. Porém deve ser feita a ressalva de que algoritmos mais eficientes do que o utilizado (gradiente estocástico) podem levar a um melhor desempenho. Um desenvolvimento imediato que propomos neste sentido é a utilização do algoritmo de Gauss utilizado em [66].

Mais do que conclusões claras o trabalho aqui apresentado deve ser visto como ponto de partida e motivador para novos desenvolvimentos onde vários aspectos deveriam ser aprofundados. Uma observação importante é que o impacto das melhorias calculadas deve ser cautelosamente avaliado, levandose em conta que não são considerados 
multipercursos nem espalhamento angular. Ou seja, diante de modelos mais realistas, as melhorias proporcionadas tendem a ser bem menores. $\mathrm{Na}$ realidade, existem várias avaliações das melhorias em cenários bastante complexos mas, em geral, nestes casos o efeito das matrizes de antenas é traduzido em um diagrama de radiação idealizado. Um trabalho difícil mas importante é obter melhorias em cenários e implementações realistas.

Por último observamos que as arquiteturas utilizadas apresentam uma grande complexidade e pressupõem a exisência de controle de sincronismo. Uma vez que é possível gerar o sinal reespalhado, de forma sincronizada, podese pensar em associar antenas adaptativas a técnicas de cancelamento de interferência, o que poderia trazer melhorias bem maiores. 


\section{REFERÊNCIAS}

[1] Godard, "Self-recovering equalization and carrier tracking in two-dimensional data communication systems”, IEEE Trans. Commun., vol.COM-28, pp.1867-1875, Nov. 1988

[2] Shynk e R. Gooch, "The Constant Modulus Array for Cochannel Sigral Copy and direction Finding”, IEEE Trans. on Signal Processing, vol. 44, no.3, March 1996

[ 3 ] A.J.van der Veen, A. Paulraj, “An Analytical Constant Modulus Algorithm”, IEEE Trans on Signal Processing, Vol. 44, NO. 5, May 1996, pp 1136-1155

[ 4] S. Haykin, Adaptive Filter Theory Prentice Hall, 2 ed., 1986.

[ 5 ] B.G. Agee, "Blind separation and capture of communication signals using a multitarget constant modulus beamformer,"1989 IEEE Military Communications Conf., Boston, MA, Oct. 1989

[ 6 ] M.Viberg e P. Stoica, 'Editorial Note”, Signal Processing, 50 (1996)

[7] O. Schmidt, "Multiple Emmiter Location and Signal Parameter Estimation", IEEE Trans. on Antennas and Propagation, Vol AP-34, No. 3, March, 1986

[ 8] Roy e T. Kailath, "ESPRIT - Estimation of Signal Parameters via Rotational Invariance Techniques”, IEEE Trans.on Acoust. Speech Signal Process., Vol. 37, July 1989, pp 984-995

[9] W. C. Y. Lee, Mobile Communication Design Fundamentals. New York: Wiley, 1993.

[ 10 ] F.R. Hampel, E. M. Ronchetti, P. J. Rousseeeuv, and W. A. Stahel, Robust Statistics: The Approach Based on Influence Functions. John Wiley \& Sons, New York, 1986.

[11] J. C. Liberti, Änalysis of CDMA Cellular Radio Systems Employing Adaptive Antennas,'Ph.D. Dissertation MPRG-TR-95-17, Mobile \& Portable Radio Research Group, Virginia Tech, Blacksburg, VA, Sept. 1995.

[ 12] J. D. Parsons and J. G. Gardiner, Mobile Communication Systems, Blackie and Son, Limited, Glasgow, Scotland, 1989.

[ 13 ] R Gooch and J. Lundell, "The CM array: An adaptive beamformer for constant modulus signals," in Proc.of ICASSP '86, pp. 2523-2526, April 1986. Tokyo, Japan.

[ 14 ] B.G. Agee, "Blind separation and capture of communication signals using a multitarget constant modulus beamformer," in Proc. MILCOM, pp. 320-346, May 1989.

[ 15 ] B.G. Agee, S.V. Schell, and W.A. Gardner, "Spectral selfcoherence restoral: A new approach to blind adaptive signal extraction," inProc. IEEE, vol. 78, pp. 753-767, April 1990.

[ 16] P.Petrus and J.H. Reed, "AMPS cochannel interference rejection using spectral correlation properties and an adaptive array," inProc. of IEEE Veh. Tech. Conference, vol. 1, pp;. 300-305, July 1995.

[17 ] P.Petrus and J.H. Reed, "Time dependent adaptive arrays," inIEEE Signal Processing Letters, pp. 219-222, Dec. 1995. 
[18] L. Tong, G.Xu e T. Kailath, "Blind Identification and Equalization based on Second Order Statistics: A Time Domain Approach", IEEE Trans. on Information Theory, Vol 40, pp 340-349, Março 1994.

[ 19] E. Moulines et all, "Subspace Methods for the Blind Identification of Multichannel FIR filters", Proc. IEEE ICASSP, 1994, PP IV:573-576.

[ 20 ] W.A. Gardner, Cyclostationarity in communications and signal processing. IEEE Press, 1 ed., 1994.

[21] D. Gerlach, " Base station array receivers in cellular CDMA," in Proc. of IEEE in Asilomar Conf., pp. 646-650, 1992.

[ 22 ] B. H. Khalaj, A . Paulraj, and T. Kailath, "2D Rake receiver for CDMA cellular systems," inProc. of IEEE Globecom Conf., pp. 400-404, 1994.

[ 23 ] B. Suard, " F. Naguib, G. Xu, and A . Paulraj, "Performance of CDMA mobile communication systems using antenna arrays,"Proc. IEEE ICASSP, vol. 4, pp. 153-156, April 1993.

[24] A . F. Naguib, A . Paulraj, and T. Kailath, "Capacity improvement of base-station antenna arrays cellular CDMA,” IEEE Trans. On Vehicular Technology, Vol. 43, No. 3, August 1994, pp. 691 698.

[25] A . F. Naguib and A . Paulraj, "Effects of multipath and basestation antenna arrays on uplink capacity of cellularCDMA," in Proc. of IEEE Globecom Conf., pp. 395-399, 1994.

[ 26] J.Capon, "High Resolution Frequency-Wavenumber Spectral Analysis," Proc .of the IEEE,Vol. 57, No.8, pp. 1408-1418, Aug. 1969.

[27 ] P. Stoica and A.Nehoral, “ MUSIC, Maximun Likelihood, and Cramer-Rao Bound," IEEE Trans. On Acoustics, Speech and Signal Processing, Vol. 37, No. 5, pp. 720-741, May 1989.

[ 28 ] A . J. Weiss and M. Gavish, "Direction finding using ESPRIT with interpolated arrays,"IEEE Trans. Signal Procesing, Vol. 39, pp. 1473-1478, 1991.

[29] G. Xu, S. D. Silverstein, R. H. Roy, and T. Kailath, "Beamspace ESPRIT,"IEEE Trans. Signal Processing, Vol. 42, pp. 349-356, 1994.

[ 30 ] J. A . Gansman, M. D. Zolltowski, and J. V. Krogmeier, "Multidimensional multirate DOA estimation in beamspace,"IEEE Trans. Processing, vol. 44, pp. 2780-2792, 1996.

[ 31 ] R. Hamza and K. Bucley, "Resolution enhanced ESPRIT,"IEEE Trans. Signal Processing, vol. 42, pp. 688-691, 1994.

[ 32 ] A . Pauraj, R. Roy, and T. Kailath, "A subspace rotation approach to signal parameter estimation," Proc. IEEE, vol. 74, pp. 1044-1045, 1986.

[ 33 ] A . L. Swindlehurst, B. Ottersten, R. Roy, and T. Kailath, "Multiple invariance ESPRIT,"IEEE Trans. Signal Processing, vol. 40, pp. 867-881, 1992.

[ 34 ] N. Yuen and B. Friedlander, "Asymptotic performance analysis of ESPRIT, higher order ESPRIT, and virtual ESPRIT algorithms,”IEEE Trans. Signal Processing, vol. 44, pp. 2537-2550, 1996.

[ 35 ] M. D. Zoltowski and D. Stavrinides, "Sensor array signal pocessing via a procrustes rotations based eigenanalysis of the ESPRIT data pencil,"IEEE Trans. Acoust., Spech, Signal Processing, vol. 44, pp. 2537-2550, 1996. 
[ 36 ] S. Haykin, "Radar array processing for angle of arrival estimation," inArray Signal Processing, S. Haykin, Ed. $\quad$ Englewood Cliffs, NJ: PrenticeHall, 1985.

[ 37 ] I. Ziskind and M. Wax, "Maximun likelihood localization of multiple sources by alternating projection," IEEE Trans. Acoust., Speech, Signal Processing, vol. ASSP-36, pp. 1553-1560, 1988.

[ 38 ] H. Lee and R. Stovall, "Maximum likelihood methods for determining the direction of arrival for a single electromagnetic source with unknow polarization,"IEEE Trans. Signal Processing, vol. 42, pp. 474-479, 1994.

[ 39 ] P.C. Stoica and K.C. Sharman, "Maximum Likelihood methods for direction of arrival estimation," IEEE Trans. Signal Processing, vol. 40, pp. 2848-2854, 1992.

[ 40 ] T. Wigren and A .Eriksson, "Accuracy aspects of DOA and angular velocity estimation in sensor array processing," IEEE Signal Processing Lett., vol. 2, pp. 60-62, 1995.

[ 41] A . Zeira and B. Friedlander, "On the performance of direction finding with time varying arrays," Signal Process., vol. 43, pp. 133-147, 1995.

[ 42 ] M. G. Larimore and J. R. Treichle, "CMA-based Techniques for adaptive Interference Rejection," Proc. IEEE Military Communications Conf., Apr. 1986.

[ 43 ] M. G. Larimore and J. R. Treichler, "Convergence Behavior of the Constant Mdulus Algorithm," IEEE Int. Conf. on Acoustics, Speech, and Signal Processing, Boston, MA, 1983.

[ 44 ] Z. Rong, "Simulation of Adaptive Array Algorithms for CDMA Systems,'Master's Thesis MPRG TR-96-31, Mobile \& Portable Radio Research Group, Virginia Tech, Blacksburg, VA, Sept. 1996.

[ 45 ] B. Agee, "Blind Separation and Capture of Communications Signals Using a Multitarget Constant Modulus Beamformer,”'1989 IEEE Military Communications Conf., Boston, MA, Oct. 1989.

[ 46 ] Z. Rong, T.S. Rappaport, "Simulation of MultiTarget Adaptive Algorithms for WirelessCDMA Systems," Proc. IEEE Vehicular Technology Conf., Apr. 1996.

[ 47 ] R.T. Compton, Jr., Adaptive Antennas, Concept and Performance, Prentice Hall, Englewood Cliffs, New Jersey, 1988.

[ 48 ] B. Widrow, P.E. Mantey, L.J. Griffiths, and B.B. Goode. "Adaptive antenna systems," Proc. IEEE, pp. 2143-2159, December 1967.

[ 49] R. Gooch and J. Lundell, "The CM array: An adaptive beamformer for constant modulus signals," Proc. IEEE ICASSP, vol. 4, pp. 2523-2526, April 1986.

[ 50 ] B.G. Agee, "Blind separation and capture of communication signals using a multitarget constant modulus beamformer,"Proc. IEEE Military Communication Conference, pp. 19.2.1-19.2.7, 1989.

[ 51 ] J.J. Shynk and R.P. Gooch, "Convergence properties of the multistage CMA adaptive beamfromer," Proc. $27^{\text {th }}$ Asilomar Conf. on Signals, Systems and Computers, pp. 622-626, 1993.

[ 52 ] J.C. Liberti and T.S. Rappaprt, "A geometrically based model for lineof-sight multipath radio channels,” Proc. IEEE Veh. Technol. Conf., vol. 2, pp. 844-853, 1996.

[ 53 ] T.S. Rappaport, et. Al., "Statistical channel impulse models for factory and open plan building radio communication system design," IEEE Trans. On Communications, vol. COM-39, no. 5, pp. 794806, May 1991

[ 54 ] P.Bello and B. D. Nelin, 'Predetection diversity combining with selectively fading channels,'IRE Trans. Commun. Syst., vol CS-10, p. 32, Mar. 1962. 
[ 55 ] P. G. Proakis, Digital Communications. New York: McGraw-Hill, 1983, p. 175.

[ 56] W. C. Jakes, Jr., et al.,Microwave Mobile Communications. New York: Wiley, 1974.

[ 57 ] J.H. Winters, J.Salz, and R. D. Gitlin, "Adaptive antennas for digital mobile radio,"Proc. IEEE Adaptive Antenna Syst. Symposiun, Melville, NY, Nov. 1992, pp. 81-87.

[ 58 ] R. A . Monzingo and T. W. Miller, Introduction to Adaptive Arrays. New York: Wiley, 1980.

[59] A . Dembo and J. Salz, “ On the least squares tap adjustment algorithm in adaptive digital echo cancellers,” IEEE Trans. Commun.., vol. 38, pp. 622-628, May 1990.

[ 60 ] S. U. Pillai, Array Signal Processing. Springer verlag, New York 1989.

[ 61 ] J. E. Hudson, Adaptive Array Principles. Peter Peregrinus Ltd., Stevennage, UK 1989.

[ 62 ] J. H. Winters, "Signal aquisition and tracking with adaptive arrays in wireless systems," inProc. $43^{\text {rd }}$ Veh. Technol. Conf., Vol. I, pp. 85-88, Nov. 1993.

[ 63 ] D. Gerlach and "Paulraj, "Base-Station transmitting antenna arrays with mobile to base feedback," in Proc. 27 $7^{\text {th }}$ Asilomar Conf. on Signals, Systems and Computers, Pacific Grove, CA, pp. 14321436, Nov. 1993.

[ 64 ] Performance of DS/CDMA with Mary orthogonal modulation cell site antenna arrays, A. Naguib, A. Paulraj, IEEE ICC'95, pp 697-702.

[ 65] A receiver of simple structure for antenna array CDMA systems, J. Choi, IEEE Transactions on Vehicular Technology, Vol 48, No 5, September 1999, pp 13321340

[ 66 ] Joseph. C. Liberti , Theodore S. Rappaport, Snart Antennas for Wireless Communications: IS-95 and Third Generation CDMA Applications, Prentice Hall, 1999.

[ 67 ] W.C.Y. Lee, “Overview of cellular CDMA,” IEEE Trans. Veh. Technol., vol. VT-40, pp. 291-301, May 1991.

[ 68 ] T..S. Rappaport, Paul Petrus "Simulation of Multitarget Adaptive Array Algorithms for Wireless CDMA Systems," IEEE Vehicular Technology Conference, Phoenix, AZ, May 5-7, 1997, pp. 1-5.

[69] A . F. Naguib, Adaptive Antenna for CDMA Wireless NetworkPhD thesis, Stanford University, Stanford, CA., August 1996.

[ 70 ] L.C. Godara "Applications of antenna arrays to mobile communications, part I: Performance improvement, feasibility, and system considerations,"Proc. IEEE, vol. 85, pp. 1031-1060, July, 1997.

[ 71 ] L.C.Godara "Applications of antenna arrays to mobile communications, Part II: Beamforming and direction-of-arrival considerations," Proc.IEEE, vol. 85, pp. 1195-1245, Aug. 1997.

[ 72 ] P. Rooyen, M. Lotter, D. Wyk, "Space-time processing for CDMA mobile communications" Kluwer Academic Publishers, 2000.

[ 73 ] Paul Petrus, Novel Adaptive Array Algorithms and Their Impact on Celullar System Capacity, PhD Thesis, Virginia Polytechnic Institute and State University, Blacksburg, Virginia, March, 1997. 